\title{
Mastering surface reconstruction of metastable spinel oxides for
}

\section{better water oxidation}

Yan Duan, Shengnan Sun, Yuanmiao Sun, Shibo Xi, Xiao Chi, Qinghua Zhang, Xiao Ren, Jingxian Wang, Samuel Jun Hoong Ong, Yonghua Du, Lin Gu, Alexis Grimaud, Zhichuan J. $\mathrm{Xu}^{*}$

Ms. Y. Duan, Dr. S. Sun, Dr. Y. Sun, Dr. X. Ren, Dr. J. Wang, Mr. S. J. H. Ong, Prof. Z. Xu School of Materials Science and Engineering, Nanyang Technological University, Singapore 639798, Singapore

Ms. Y. Duan, Dr. S. Sun, Prof. Z. Xu

Solar Fuels Laboratory, Nanyang Technological University, Singapore 639798, Singapore Ms. Y. Duan, Prof. Z. Xu

Energy Research Institute @NTU, ERI@N, Interdisciplinary Graduate School, Nanyang Technological University, Singapore 639798, Singapore

Dr. S. Xi, Dr. Y. Du

Institute of Chemical and Engineering Sciences A*STAR, 1 Pesek Road, 627833, Singapore

Prof. Q. Zhang, Prof. L. Gu

Institute of Physics, Chinese Academy of Science, P.O.Box 603, Beijing, 100190, China

Mr. S. J. H. Ong, Prof. Z. Xu

Singapore-HUJ Alliance for Research and Enterprise (SHARE), Nanomaterials for Energy and Energy-Water Nexus (NEW), Campus for Research Excellence and Technological Enterprise (CREATE), Singapore 138602

Dr. Alexis Grimaud

Chimie du Solide et de l'Energie, UMR 8260, Collège de France, 75231 Paris Cedex 05, France

Dr. Alexis Grimaud

Réseau sur le Stockage Electrochimique de l'Energie (RS2E), FR CNRS 3459, 80039

Amiens Cedex, France

*E-mail: xuzc@ntu.edu.sg

\section{ABSTRACT}

Developing highly active electrocatalysts for oxygen evolution reaction (OER) is critical for the commercial effectiveness of water splitting to produce hydrogen fuels. Low-cost spinel oxides have attracted increasing interest as alternatives to noble-metal-based OER catalysts. A rational design of spinel catalysts can be guided by studying the structural/elemental properties which determine the reaction mechanism and activity. Here, using density 
functional theory (DFT) calculations, we find that the relative position of $\mathrm{O} p$-band and $\mathrm{M}_{\mathrm{Oh}}$ (Co and $\mathrm{Ni}$ in octahedron) $d$-band centre in $\mathrm{ZnCo}_{2-\mathrm{x}} \mathrm{Ni}_{\mathrm{x}} \mathrm{O}_{4}(\mathrm{x}=0-2)$ correlates with its stability as well as the possibility for lattice oxygen to participate in OER. We therefore testified it by synthesizing $\mathrm{ZnCo}_{2-\mathrm{x}} \mathrm{Ni}_{\mathrm{x}} \mathrm{O}_{4}$ spinel oxides, investigating on their OER performance and surface evolution. Stable $\mathrm{ZnCo}_{2-\mathrm{x}} \mathrm{Ni}_{\mathrm{x}} \mathrm{O}_{4}(\mathrm{x}=0-0.4)$ follows adsorbates evolving mechanism (AEM) under OER conditions. Lattice oxygen participate in the OER of metastable $\mathrm{ZnCo}_{2-}$ ${ }_{x} \mathrm{Ni}_{\mathrm{x}} \mathrm{O}_{4}(\mathrm{x}=0.6,0.8)$ which gives rise to continuously formed oxyhydroxide as surface-active species and consequently enhanced OER activity. $\mathrm{ZnCo}_{1.2} \mathrm{Ni}_{0.8} \mathrm{O}_{4}$ exhibits performance superior to the benchmarked $\mathrm{IrO}_{2}$. Our work illuminates the design of highly active metastable spinel electrocatalysts through the prediction of the reaction mechanism and OER activity by determining the relative positions of the $\mathrm{O} p$-band and $\mathrm{M}_{\mathrm{Oh}} d$-band centre.

The development of efficient electrocatalysts which lower the overpotential of oxygen evolution reaction (OER) is of great importance in improving the overall efficiency of hydrogen fuel production by water electrolysis. [1] Commercially, precious metal oxides catalysts such as $\mathrm{IrO}_{2}$ are used. [2] However, their elemental scarcity and high cost have triggered a search for cost-effective OER electrocatalysts such as $3 d$ transition metal oxides. Among them, families such as the perovskite $\mathrm{ABO}_{3}$ and the spinel $\mathrm{AB}_{2} \mathrm{O}_{4}$ ones have attracted great attention due to their tuneable structural/elemental properties allowed by A and B sites cation substitution. [3, 4] Perovskite $\mathrm{ABO}_{3}$ oxides have a simple structure with rare-earth or alkaline earth element occupying cuboctahedral A-site while the B-site transition metal (TM) sites in an octahedral environment. [3] Spinel oxides, however, can be either normal or 
inverse structure depending on the relative occupancy of divalent and trivalent cations in the octahedral and tetrahedral sites. [4] Owing to this inherent complexity related to cation mixing, very few studies have been systematically studying the spinel family as OER catalysts $[4 \mathrm{~b}, \mathrm{c}, \mathrm{e}]$ when compared to the perovskites, and were focusing on the effect of cation substitution on the OER activity. Hence, to correlate the OER performance with their structural/elemental properties and guide the design of highly active catalysts, descriptors for the OER activity were searched for spinel oxides. [4c] For instance, $e_{g}$ occupancy of active TM in octahedral sites was proposed as an activity descriptor for spinel oxides such as $\mathrm{Mn}_{\mathrm{x}} \mathrm{Co}_{3-\mathrm{x}} \mathrm{O}_{4}(\mathrm{x}=2,2.5,3), \mathrm{Li}_{\mathrm{x}} \mathrm{Mn}_{2} \mathrm{O}_{4}(\mathrm{x}=0.7,1), \mathrm{XCo}_{2} \mathrm{O}_{4}(\mathrm{X}=\mathrm{Co}, \mathrm{Zn}), \mathrm{XFe}_{2} \mathrm{O}_{4}(\mathrm{X}=\mathrm{Mn}$, $\mathrm{Co}, \mathrm{Ni})$ [4c] and $\mathrm{ZnCo}_{2-\mathrm{x}} \mathrm{Fe}_{\mathrm{x}} \mathrm{O}_{4}(\mathrm{x}=0.0-2.0)$ [4e]. However, several unstable spinel oxides which undergo surface amorphization after OER cycles were recently found [5]. Hence, owing to the evolving spinel surface during OER, it is tough to predict the OER activity of these materials as a function of $\mathrm{M}-\mathrm{O}$ binding energy based on the ideal pristine surfaces. Such unstable catalysts have been observed in the perovskite family as well, [6] and lattice oxygen participation to the overall OER mechanism (LOM) has been proposed to be at the origin of their instability. [7] In contrast, it is still not yet fully understood which spinel oxides would also undergo LOM, motivating the search for metastable spinel oxides. In this work, we have found a simple method to predict the stability of spinel oxide by calculating the density of states (DOS) of substituted spinel oxides and observing the relative position of the $\mathrm{O} p$-band versus the $\mathrm{M}_{\mathrm{Oh}} d$-band. For that, we have studied the $\mathrm{ZnCo}_{2-\mathrm{x}} \mathrm{Ni}_{\mathrm{x}} \mathrm{O}_{4}(\mathrm{x}=0-2)$ series.

$\mathrm{ZnCo}_{2} \mathrm{O}_{4}$ is a representative spinel oxide with $\mathrm{Zn}^{2+}$ occupying tetrahedral (Td) site and $\mathrm{Co}^{3+}$ staying in octahedral $(\mathrm{Oh})$ site [8]. With more electronegative Ni metal cations partially substituting $\mathrm{Co}^{3+}$, electrons would be drawn away from the remaining $\mathrm{Co}^{3+}$ and the energy of antibonding states would be lowered down, [9] initiating a redistribution of electronic density 
between metal cations and oxygen [10] and thus altering the electrocatalytic performances. To figure out the interaction between metal $d$-band and oxygen $p$-band orbitals, we have carried out first-principles DFT+U calculations on the transition metal $d$ states and oxygen $p$ states for $\mathrm{ZnCo}_{2-\mathrm{x}} \mathrm{Ni}_{\mathrm{x}} \mathrm{O}_{4}$. Detailed calculation methods are shown in the supporting information. $\mathrm{M}_{\mathrm{Oh}} d$-band centre (relative to $\mathrm{E}_{\mathrm{F}}$ ) is initially $0.705 \mathrm{eV}$ higher than $\mathrm{O} p$-band centre (relative to $\mathrm{E}_{\mathrm{F}}$ ) in $\mathrm{ZnCo}_{2} \mathrm{O}_{4}$ and decreases to $0.455 \mathrm{eV}$ for $\mathrm{ZnCo}_{1.8} \mathrm{Ni}_{0.2} \mathrm{O}_{4}$ (Supplementary Figure 1). When $\mathrm{x} \geq 0.4, \mathrm{O} p$-band centre becomes higher than $\mathrm{M}_{\mathrm{Oh}} d$-band centre and the energy difference between them grows larger with further increased $\mathrm{Ni}$ substitution ratios. The relative position of $\mathrm{O} p$-band and $\mathrm{M}_{\mathrm{Oh}} d$-band should, to some extent, explain and predict the structural stability of spinel $\mathrm{ZnCo}_{2-\mathrm{x}} \mathrm{Ni}_{\mathrm{x}} \mathrm{O}_{4}$. In spinel with the ratio $\mathrm{x}=0$ and 0.2 , the energy of $\mathrm{O}$ states is lower than that of $\mathrm{M}_{\mathrm{Oh}}$, suggesting that lattice oxygen is redox inactive under oxidative conditions and that oxygen would binds strongly to the cations. When $\mathrm{x}$ is continuously increased to 0.4 , the energy of $\mathrm{O}$ states becomes higher than that of $\mathrm{M}_{\mathrm{Oh}}$ and thus oxygen ions become redox active. Nevertheless, since their energy are still relatively close, the whole lattice structure is still stable. However, when $\mathrm{x}$ is further increased to 0.6 and above, the energy of $\mathrm{O}$ states becomes greater than the energy of $\mathrm{M}_{\mathrm{Oh}}$ states. According to previous work on perovskites, this finding suggets higher activity for lattice oxygen in the materials and thus the destabilization of the oxide. [7d] To verify whether $\mathrm{ZnCo}_{2-\mathrm{x}} \mathrm{Ni}_{\mathrm{x}} \mathrm{O}_{4}(\mathrm{x}=0-2)$ oxides are thermodynamically stable in these spinel phases, we have calculated their formation energies (Figure 1a). The formation enthalpy of $\mathrm{ZnCo}_{2} \mathrm{O}_{4}$ is weaker than that of $\mathrm{ZnCo}_{2-\mathrm{x}} \mathrm{Ni}_{\mathrm{x}} \mathrm{O}_{4}$. Hence, with increasing $\mathrm{Ni}$ substitution into $\mathrm{ZnCo}_{2} \mathrm{O}_{4}$, the structure becomes more unstable. In order to assess the effect of the continuous shift of the spinel electronic structure, pure $\mathrm{ZnCo}_{2-\mathrm{x}} \mathrm{Ni}_{\mathrm{x}} \mathrm{O}_{4}(\mathrm{x}=0.0,0.2,0.4,0.6,0.8)$ phases were synthetized by thermal decomposition methods. Figure 2a exhibits the XRD patterns of the as-synthesized $\mathrm{ZnCo}_{2-\mathrm{x}} \mathrm{Ni}_{\mathrm{x}} \mathrm{O}_{4}(\mathrm{x}=0.0,0.2,0.4,0.6,0.8)$ oxides. With the increased amount 
of Ni replacing Co, a continous peak shift towards smaller angle is observed, consistent with the increased lattice parameter for $\mathrm{ZnCo}_{2-\mathrm{x}} \mathrm{Ni}_{\mathrm{x}} \mathrm{O}_{4}(\mathrm{x}=0.0,0.2,0.4,0.6,0.8)$ from 8.124(7) $\AA$ to 8.180(7) $\AA$ (Figure S2-S6, Table S1). This increase in lattice parameter corresponds to the simultaneous increase of Ni-O (Table S2), Co-O (Table S3) and Zn-O bond lengths (Table S5), and an expanded unit cell as well as a decreased thermodynamic stability. $\mathrm{ZnCo}_{2} \mathrm{O}_{4}$ has the largest BET surface area of $57 \mathrm{~m}^{2} \mathrm{~g}^{-1}$ out of the samples synthesized. With the incorporation of $\mathrm{Ni}$ (from $\mathrm{x}=0.2$ to $\mathrm{x}=0.8$ ), the surface areas of the samples decrease from 56 to $38 \mathrm{~m}^{2} \mathrm{~g}^{-1}$ (inset of Figure 2a). The valency and site occupation of $\mathrm{Zn}$, Co and $\mathrm{Ni}$ in $\mathrm{ZnCo}_{2}$ ${ }_{x} \mathrm{Ni}_{\mathrm{x}} \mathrm{O}_{4}(\mathrm{x}=0.0,0.2,0.4,0.6,0.8)$ oxides have been determined by XANES spectroscopies (see Figure 2b and S7) and X-ray absorption fine structure (EXAFS) (Figure 2c and Figure S7). They confirm $\mathrm{ZnCo}_{2-\mathrm{x}} \mathrm{Ni}_{\mathrm{x}} \mathrm{O}_{4}(\mathrm{x}=0.0,0.2,0.4,0.6,0.8)$ to have a normal spinel structure with $\mathrm{Zn}^{2+}$ accommodating the center of tetrahedrons, $\mathrm{Co}^{3+}$ and $\mathrm{Ni}^{3+}$ staying in octahedral sites. However, when Ni substitution ratio is too high, to the extent where the $\mathrm{O} p$-band centre is much higher in energy relative compared to $\mathrm{M}_{\mathrm{Oh}} d$-band centre, the structure becomes unstable and phase separation into rock-salt structure and wurtzite structure is observed by $\mathrm{XRD}$ where $\mathrm{NiO}$ and $\mathrm{ZnO}$ secondary phases coexist for $\mathrm{ZnCo}_{0.8} \mathrm{Ni}_{1.2} \mathrm{O}_{4}$ and $\mathrm{ZnNi}_{2} \mathrm{O}_{4}$ (Figure S8). This is further confirmed by the X-ray absorption near edge structure (XANES) data for $\mathrm{ZnCo}_{2-\mathrm{x}} \mathrm{Ni}_{\mathrm{x}} \mathrm{O}_{4}(\mathrm{x}=1.2,1.6,2.0)$ (left panel of Figure S9), where the increase of F1 feature and the decrease of $\mathrm{F} 2$ in the white line of $\mathrm{Zn} \mathrm{K}$-edge in $\mathrm{ZnCo}_{2-\mathrm{x}} \mathrm{Ni}_{\mathrm{x}} \mathrm{O}_{4}(\mathrm{x}=1.2,1.6,2.0)$ indicate the appearance of $\mathrm{ZnO}$ wurtzite phase [11a]. The position of $\mathrm{Ni} \mathrm{K}$-edge in $\mathrm{ZnCo}_{2-\mathrm{x}} \mathrm{Ni}_{\mathrm{x}} \mathrm{O}_{4}$ $(\mathrm{x}=1.2,1.6,2.0)$ (right panel of Figure S9) progressively shifts towards lower energies, closer to that of $\mathrm{NiO}$, indicating the dropped valence state of $\mathrm{Ni}$ cations and supporting the existence of $\mathrm{NiO}$ in $\mathrm{ZnCo}_{2-\mathrm{x}} \mathrm{Ni}_{\mathrm{x}} \mathrm{O}_{4}(\mathrm{x}=1.2,1.6,2.0)$.

The PDOS for pure-phase $\mathrm{ZnCo}_{2} \mathrm{O}_{4}, \mathrm{ZnCo}_{1.6} \mathrm{Ni}_{0.4} \mathrm{O}_{4}$ and $\mathrm{ZnCo}_{1.2} \mathrm{Ni}_{0.8} \mathrm{O}_{4}$ spinel oxides are shown in Figure S10. Non-bonded oxygen $p$ states can be observed for $\mathrm{ZnCo}_{1.2} \mathrm{Ni}_{0.8} \mathrm{O}_{4}$, but 
not for $\mathrm{ZnCo}_{2} \mathrm{O}_{4}$ and $\mathrm{ZnCo}_{1.6} \mathrm{Ni}_{0.4} \mathrm{O}_{4}$, which can be oxidized and form electrophilic oxygen species as active sites [11b]. With increased substitution level, oxygen becomes much more electropositive than the metal cations in octahedron especially when $\mathrm{x}$ is larger than 0.4 . Electrons from the $\mathrm{O} p$-band are poured into the $d$-band for $\mathrm{ZnCo}_{2-\mathrm{x}} \mathrm{Ni}_{\mathrm{x}} \mathrm{O}_{4}(\mathrm{x}=0.6,0.8)$, which initiates the dropped in formation energy of oxygen vacancies [12] and structural relaxations. Overall, those two findings (presence of non-bonding oxygen states and oxygen states at the Fermi level) suggets that lattice oxygen are more prone to participate to the OER reaction on the surface of $\mathrm{ZnCo}_{2-\mathrm{x}} \mathrm{Ni}_{\mathrm{x}} \mathrm{O}_{4}(\mathrm{x}=0.6,0.8)$.

Electrochemical measurements were then performed on pure $\mathrm{ZnCo}_{2-\mathrm{x}} \mathrm{Ni}_{\mathrm{x}} \mathrm{O}_{4}(\mathrm{x}=0.0,0.2,0.4$, 0.6, 0.8) spinel phases. Cyclic voltammetry $(\mathrm{CV})$ curves for $\mathrm{ZnCo}_{2-\mathrm{x}} \mathrm{Ni}_{\mathrm{x}} \mathrm{O}_{4}$ at the $2^{\text {nd }}$ and $1000^{\text {th }}$ cycle are shown in Figure 3a. $\mathrm{ZnCo}_{2-\mathrm{x}} \mathrm{Ni}_{\mathrm{x}} \mathrm{O}_{4}$ oxides exhibit for every Ni substitution level comparable activities at the $2^{\text {nd }}$ cycle when normalized by BET surface area. After one thousand scans, the current density triples for $\mathrm{ZnCo}_{1.4} \mathrm{Ni}_{0.6} \mathrm{O}_{4}$ and that of $\mathrm{ZnCo}_{1.2} \mathrm{Ni}_{0.8} \mathrm{O}_{4}$ septuples to become superior to that of the state-of-the-art $\mathrm{Co}^{3+}$-based perovskite $\mathrm{LaCoO}_{3}[3 \mathrm{f}]$, $\mathrm{Ni}^{3+}$-based perovskite $\mathrm{LaNiO}_{3}[3 \mathrm{f}]$, as well as to the benchmarked $\mathrm{IrO}_{2}$ [13] and comparable to that of the best-ever reported $\mathrm{IrO}_{2}$ nanaoparticles [14] (inset of Figure 3a). The overpotential measured for $\mathrm{ZnCo}_{1.4} \mathrm{Ni}_{0.6} \mathrm{O}_{4}$ and $\mathrm{ZnCo}_{1.2} \mathrm{Ni}_{0.8} \mathrm{O}_{4}$ at $25 \mu \mathrm{A} \mathrm{cm}{ }_{\text {oxide }}$ are found decreased from 0.389 and 0.391 to $0.336 \mathrm{~V}$ and $0.311 \mathrm{~V}$, respectively, after one thousand cycles (Figure 3b). These observations contrast with those for $\mathrm{ZnCo}_{2} \mathrm{O}_{4}, \mathrm{ZnCo}_{1.8} \mathrm{Ni}_{0.2} \mathrm{O}_{4}$ and $\mathrm{ZnCo}_{1.6} \mathrm{Ni}_{0.4} \mathrm{O}_{4}$, for which the OER activity remains stable during repeated scans. This finding is also confirmed by chronoamperometry (CA) studies after cycling (Figure S11). When looking into the subsequent $\mathrm{CV}$ curves for the stable $\mathrm{ZnCo}_{2} \mathrm{O}_{4}$ (Figure S13a) and the metastable $\mathrm{ZnCo}_{1.2} \mathrm{Ni}_{0.8} \mathrm{O}_{4}$ (Figure 3c), $\mathrm{ZnCo}_{1.2} \mathrm{Ni}_{0.8} \mathrm{O}_{4}$ yields continuously increased OER current along with cycles (decrease of the potential at $25 \mu \mathrm{A} \mathrm{cm}{ }^{-2}$ oxide from $1.621 \mathrm{~V}$ to 1.543 V). In contrast, $\mathrm{ZnCo}_{2} \mathrm{O}_{4}$ presents negligible change in activity during cycling. This result 
confirms the role of $\mathrm{Ni}$ substitution in controlling both stability and activity for $\mathrm{ZnCo}_{2} \mathrm{O}_{4}$. To further understand the different activity/stability behaviour of $\mathrm{ZnCo}_{2} \mathrm{O}_{4}$ and $\mathrm{ZnCo}_{1.2} \mathrm{Ni}_{0.8} \mathrm{O}_{4}$, the evolution of the pseudocapacitive charge was tracked over thousands of cycles (Figure S13b and 3d). Neither significant change in capacitive current nor evolution of pseudocapacitive curve along with OER activity is observed for $\mathrm{ZnCo}_{2} \mathrm{O}_{4}$. In contrast, the pseudocapacitive charge is correlated with the OER activity for $\mathrm{ZnCo}_{1.2} \mathrm{Ni}_{0.8} \mathrm{O}_{4}$ (Figure 3c inset and 3d), which indicates that the major increase in the OER activity for $\mathrm{ZnCo}_{1.2} \mathrm{Ni}_{0.8} \mathrm{O}_{4}$ is well-explained by the reconstruction of a new surface. The Tafel slope for $\mathrm{ZnCo}_{1.2} \mathrm{Ni}_{0.8} \mathrm{O}_{4}$ increases to $\sim 60 \mathrm{mV} \mathrm{dec}^{-1}$ after cycling (inset of Figure 3a), similar to what is found for pure $\mathrm{NiOOH}$, hence suggesting the formation of $\mathrm{NiOOH}$ on the surface of $\mathrm{ZnCo}_{1.2} \mathrm{Ni}_{0.8} \mathrm{O}_{4}$ [15]. This is different from earlier studies in which mixed nickel/cobalt oxyhydroxide formed on the surface of Co-Ni oxides [16] was found to exhibit a Tafel slope of $\sim 40-60 \mathrm{mV} \mathrm{dec}^{-1}$. Therefore, this calls for a careful study of the chemical and structural properties of the reconstructed surface of these spinel materials.

A new phase is observed by high-resolution transmission electron microscopy (HRTEM) on the surface of $\mathrm{ZnCo}_{1.2} \mathrm{Ni}_{0.8} \mathrm{O}_{4}$ after cycling (Figure 3e and Figure S19). To reveal the elemental composition of the new surface phase, scanning transmission electron microscopyenergy-dispersive X-ray spectroscopy (STEM-EDS) and line-scan were conducted. The surface is found rich in Ni, while deficient in $\mathrm{Zn}$ and Co (Figure 3f, 3g; Figure S19,21), suggesting that surface $\mathrm{Zn}$ and $\mathrm{Co}$ atoms are leached out during the OER process, while Ni segregates on the surface to reconstruct into a layer-type NiOOH. As observed by Electron energy loss spectroscopy (EELS), the disappearance of the feature B (Figure S22a) at 532 $\mathrm{eV}$ in the $\mathrm{O} \mathrm{K}$-edge indicates the decreased hybridization between oxygen and the antibonding minority spin M $3 d$ states after cycling, suggesting an increase in oxygen vacancies and structural relaxation [17] due to structural oscillations [18]. From the ratios of 
L3/L2 (Figure S22b and S22c) calculated by Hartree-Slater cross section method [19], surface Ni cations possess higher valence state after cycling, which is confirmed by XPS spectra. Indeed, peaks referring to $\mathrm{Ni}^{2+}$ at about $873 \mathrm{eV}$ and $854 \mathrm{eV}$ [20a] disappear, while remaining peaks at $971 \mathrm{eV}$ and $855.5 \mathrm{eV}$ [20b] can be ascribed to $\mathrm{Ni}^{3+}$ after OER (Figure S23). This is consistent with the presence of $\mathrm{Ni}^{\mathrm{III}}$ (oxy) hydroxide on the surface of this catalyst. Finally, a remarkable increase in the satellite structure of $\mathrm{Ni}$ edges at $861 \mathrm{eV}$ and $881 \mathrm{eV}$ is observed after OER cycling (Figure S24).

Soft XAS and X-ray magnetic circular dichroism (XMCD) have then been employed to unveil the change in surface electronic structure of $\mathrm{ZnCo}_{1.2} \mathrm{Ni}_{0.8} \mathrm{O}_{4}$ before and after OER cycling. The average $\mathrm{L}_{2,3}$ absorption centroids for the Ni XAS of $\mathrm{ZnCo}_{1.2} \mathrm{Ni}_{0.8} \mathrm{O}_{4}$ is shifted to higher energy, which agrees well with the increased Ni valence state [21] after OER as detected by XPS. The Ni $\mathrm{L}_{2,3}$ edge spectrum of cycled $\mathrm{ZnCo}_{1.2} \mathrm{Ni}_{0.8} \mathrm{O}_{4}$ after subtraction of the non-cycled one is illustrated by a pink line in Figure S25, which coincid with that of $\mathrm{NiOOH}$ [22]. From the XMCD spectra (Figure S26), the net magnetic moment of surface Ni for $\mathrm{ZnCo}_{1.2} \mathrm{Ni}_{0.8} \mathrm{O}_{4}$ disappears after OER cycling. The disappeared magnetic moment arises from the newly formed $\mathrm{NiOOH}$ on the surface of $\mathrm{ZnCo}_{1.2} \mathrm{Ni}_{0.8} \mathrm{O}_{4}$ owing to the fact that $\mathrm{NiOOH}$ has no magnetic moment [23]. From the surface characterizations conducted before and after OER, we confirm that the leaching of $\mathrm{Zn}$ gives rise to surface reconstruction and a larger concentration of near-surface $\mathrm{Ni}^{3+}$ active species. The $\mathrm{Ni}^{3+}$ rich surface induces a strong surface hydroxylation of $\mathrm{ZnCo}_{1.2} \mathrm{Ni}_{0.8} \mathrm{O}_{4}$ and leads in alkaline conditions to the formation of $\mathrm{NiOOH}$, which is the main active phase for OER and leads to the promotion of the OER performances. However, at that stage of our study, understanding the exact reconstruction mechanism from spinel $\mathrm{ZnCo}_{2-\mathrm{x}} \mathrm{Ni}_{\mathrm{x}} \mathrm{O}_{4}$ to oxyhydroxide and how the stability correlates with the reconstruction mechanism requires further elaboration. 
To aid the understanding of the OER reaction mechanism for $\mathrm{ZnCo}_{2-\mathrm{x}} \mathrm{Ni}_{\mathrm{x}} \mathrm{O}_{4}, \mathrm{pH}$ dependent experiments were conducted on both pristine and cycled $\mathrm{ZnCo}_{2-\mathrm{x}} \mathrm{Ni}_{\mathrm{x}} \mathrm{O}_{4}$ (see SI for details). An increase in current density along with $\mathrm{pH}$ is observed for the whole series of $\mathrm{ZnCo}_{2}$ ${ }_{x} \mathrm{Ni}_{\mathrm{x}} \mathrm{O}_{4}$ at the second cycle (Figure $\mathbf{S 2 8}$ ). A decreased Tafel slope along with increased $\mathrm{pH}$ is also observed, suggesting a change in rate limiting step or reaction pathways when increasing the $\mathrm{KOH}$ concentration. [24] To further understand this observation, the Nernstian/nonNernstian potential shift was studied (Figure S29). The Pourbaix slopes $\left(\Delta \mathrm{E}_{\text {peak,SHE}} / \Delta \mathrm{pH}\right)$ reach values lower than $-120 \mathrm{mV} / \mathrm{pH}$ for both $\mathrm{ZnCo}_{2} \mathrm{O}_{4}(-146.34 \mathrm{mV} / \mathrm{pH})$ and $\mathrm{ZnCo}_{1.2} \mathrm{Ni}_{0.8} \mathrm{O}_{4}$ $(-129.27 \mathrm{mV} / \mathrm{pH})$, indicative of a super-Nernstian effect with two protons exchanging for a single electron [25]. The decomposition of spinel oxides $\mathrm{ZnCo}_{2-\mathrm{x}} \mathrm{Ni}_{\mathrm{x}} \mathrm{O}_{4}$ to $\mathrm{CoOOH}(\mathrm{x}=0)$ or $\mathrm{NiOOH}(\mathrm{x}=0.8)$ were further studied by sweeping one electrode in each $\mathrm{KOH}$ electrolyte from low to high concentration (Figure S30, 31) and the other electrode from high to low concentration (Figure S31-34). The activity of $\mathrm{ZnCo}_{2} \mathrm{O}_{4}$ in $\mathrm{pH}=13$ does not return to its initial value after three cycles at $\mathrm{pH}=14$ and $\mathrm{pH}=13.5$ (Figure S31a), and a similar observation is made for $\mathrm{pH}=13.5$ (Figure S31b). At high $\mathrm{pH}$ of 14, stable performances are obtained independently of the $\mathrm{pH}$ used for the activation process (Figure S31c). These results suggest that the kinetics of decomposition from pristine $\mathrm{ZnCo}_{2} \mathrm{O}_{4}$ to $\mathrm{CoOOH}$ is more significant at higher $\mathrm{pH}$. When sweeping from high to low $\mathrm{pH}$, the activity does not change, (Figure S33a) indicating that a stable $\mathrm{CoOOH}$ layer quickly forms and its OER is not $\mathrm{pH}$ dependent. Similarly, the kinetics for the transition from $\mathrm{ZnCo}_{1.2} \mathrm{Ni}_{0.8} \mathrm{O}_{4}$ to $\mathrm{NiOOH}$ layer are faster at higher $\mathrm{pH}$ values (Figure $\mathbf{S 3 1 m}$ to o). However, unlike that of $\mathrm{ZnCo}_{2} \mathrm{O}_{4}($ Figure S33a), when sweeping from high to low $\mathrm{pH}$, activity of $\mathrm{ZnCo}_{1.2} \mathrm{Ni}_{0.8} \mathrm{O}_{4}$ at $\mathrm{pH} 13.5$ is greater than at $\mathrm{pH} 14$ (Figure S33b). This is attributed to the unstable nature of $\mathrm{ZnCo}_{1.2} \mathrm{Ni}_{0.8} \mathrm{O}_{4}$ for which more cycles are needed to reach a stable surface. In other words, $\mathrm{ZnCo}_{1.2} \mathrm{Ni}_{0.8} \mathrm{O}_{4}$ easily decomposes to form a thicker $\mathrm{NiOOH}$ layer at high $\mathrm{pH}$ value. $\mathrm{pH}$ dependent experiments for 
cycled $\mathrm{ZnCo}_{2-\mathrm{x}} \mathrm{Ni}_{\mathrm{x}} \mathrm{O}_{4}$ were then conducted. The cycled $\mathrm{ZnCo}_{2} \mathrm{O}_{4}$ shows no $\mathrm{pH}$ dependence after the $1000^{\text {th }}$ OER cycles (Figure S35, 36), indicating that the CoOOH layer formed on the surface is highly stable and undergoes a classical concerted proton electron transfer. For cycled $\mathrm{ZnCo}_{1.2} \mathrm{Ni}_{0.8} \mathrm{O}_{4}$, whether sweeping from low to high or high to low $\mathrm{pH}$, identical performances are obtained for a given $\mathrm{pH}$ value (Figure S37), indicating the formation of a stable $\mathrm{NiOOH}$ layer after the $1000^{\text {th }}$ cycle. However, unlike for cycled $\mathrm{ZnCo}_{2} \mathrm{O}_{4}$, the OER performance of $\mathrm{ZnCo}_{1.2} \mathrm{Ni}_{0.8} \mathrm{O}_{4}$ is found $\mathrm{pH}$ dependent (Figure 4a), which can tentively be explained by the different stability for both phases. Stable materials such as $\mathrm{ZnCo}_{2} \mathrm{O}_{4}$, $\mathrm{ZnCo}_{1.8} \mathrm{Ni}_{0.2} \mathrm{O}_{4}$ and $\mathrm{ZnCo}_{1.6} \mathrm{Ni}_{0.4} \mathrm{O}_{4}$ quickly form a thin layer of $\mathrm{CoOOH}$ (formed by $\mathrm{ZnCo}_{2} \mathrm{O}_{4}$ ) or $\mathrm{NiOOH}$ (formed by $\mathrm{ZnCo}_{1.8} \mathrm{Ni}_{0.2} \mathrm{O}_{4}$ and $\mathrm{ZnCo}_{1.6} \mathrm{Ni}_{0.4} \mathrm{O}_{4}$ ) on the surface. $\mathrm{ZnCo}_{1.4} \mathrm{Ni}_{0.6} \mathrm{O}_{4}$ and $\mathrm{ZnCo}_{1.2} \mathrm{Ni}_{0.8} \mathrm{O}_{4}$, however, are unstable under OER conditions, and so their surface continuously reconstruct and $\mathrm{NiOOH}$ is formed, which results in more durable improved activity upon cycling (Figure 4b). Because this thicker amorphous layer participates in the OER, it might selectively impede the proton or electron transport within the whole thickness (Figure 4c), which is not the case for thin surface made of $\mathrm{CoOOH}$. Hence, the stability of oxides is critical in determining the depth of $\mathrm{CoOOH}$ or $\mathrm{NiOOH}$ formation from the surface and thus the OER mechanism, which affects the activity of surface active species.

A representative unit for spinel oxide has been selected to study the ability of lattice oxygen to participate in the OER. In this cluster, one tetrahedron and three octahedrons are connected by an oxygen atom (Figure S38). Zn occupies the tetrahedral site, while Co and $\mathrm{Ni}$ are accomodated in octahedral sites. The lowest unoccupied molecular orbital (LUMO) of the cluster has been calculated while varying the number of $\mathrm{Ni}$ in octahedral sites from 0 to 2 . The LUMO, which controls the energy required to remove an electron from the cluster and which is found to be of oxgen character mostly (inset in Figure 4d), dictates for these clusters the potential at which lattice oxygen becomes redox active. Thus, the lower the 
LUMO for the material, the easier the lattice oxygen evolution reaction. In Figure 4d, when the number of $\mathrm{Ni}$ in octahedral sites is increased from 0 to 2, LUMO first decreases before to increase. It indicates the increased ability for the material with a Ni substitution around 33\% to undergo lattice oxidation under OER conditions. From the charge density of the materials, decreased oxygen bonding is observed for the $33 \% \mathrm{Ni}$ substituted model, indicating that the lattice oxygen can be easily activated in this case. Hence, activating the redox for lattice oxygen in $\mathrm{ZnCo}_{1.4} \mathrm{Ni}_{0.6} \mathrm{O}_{4}$ and $\mathrm{ZnCo}_{1.2} \mathrm{Ni}_{0.8} \mathrm{O}_{4}$ would increase the participation of lattice oxygen in the OER, creating oxygen vacancies on the surface and continuously destabilizing the structure of the spinel, as we observed upon cycling. This results in the formation of a thick Ni oxyhydroxide surface layer and the continuous improvement of the OER activity.

In summary, by combining theoretical calculations with experimental characterizations, we demonstrate that Ni substitution in Co-based spinel oxide triggers the phase instability, by activating lattice oxygen which leads to surface reconstruction. The Ni substitution manipulates the key intrinsic property of relative position between $\mathrm{O} p$-band center (relative to $\mathrm{E}_{\mathrm{F}}$ ) and $\mathrm{M}_{\mathrm{Oh}} d$-band center (relative to $\mathrm{E}_{\mathrm{F}}$ ) in $\mathrm{ZnCo}_{2} \mathrm{O}_{4}$, and hence alters its reaction mechanism, which results in enhanced OER activity. Electrochemical studies show $\mathrm{ZnCo}_{2} \mathrm{O}_{4}$, $\mathrm{ZnCo}_{1.8} \mathrm{Ni}_{0.2} \mathrm{O}_{4}$ and $\mathrm{ZnCo}_{1.6} \mathrm{Ni}_{0.4} \mathrm{O}_{4}$ to be stable under OER conditions, whereas metastable $\mathrm{ZnCo}_{1.4} \mathrm{Ni}_{0.6} \mathrm{O}_{4}$ and $\mathrm{ZnCo}_{1.2} \mathrm{Ni}_{0.8} \mathrm{O}_{4}$ undergo strong surface reconstruction and exhibit threefold and sevenfold higher catalytic specific activities after OER cycling, respectively. The findings here open a new perspective in the fundamental understanding of surface evolution for spinel electrocatalysts where tailoring the OER mechanism by metal cation substitution can be critical in achieving highly active metastable OER catalysts. 


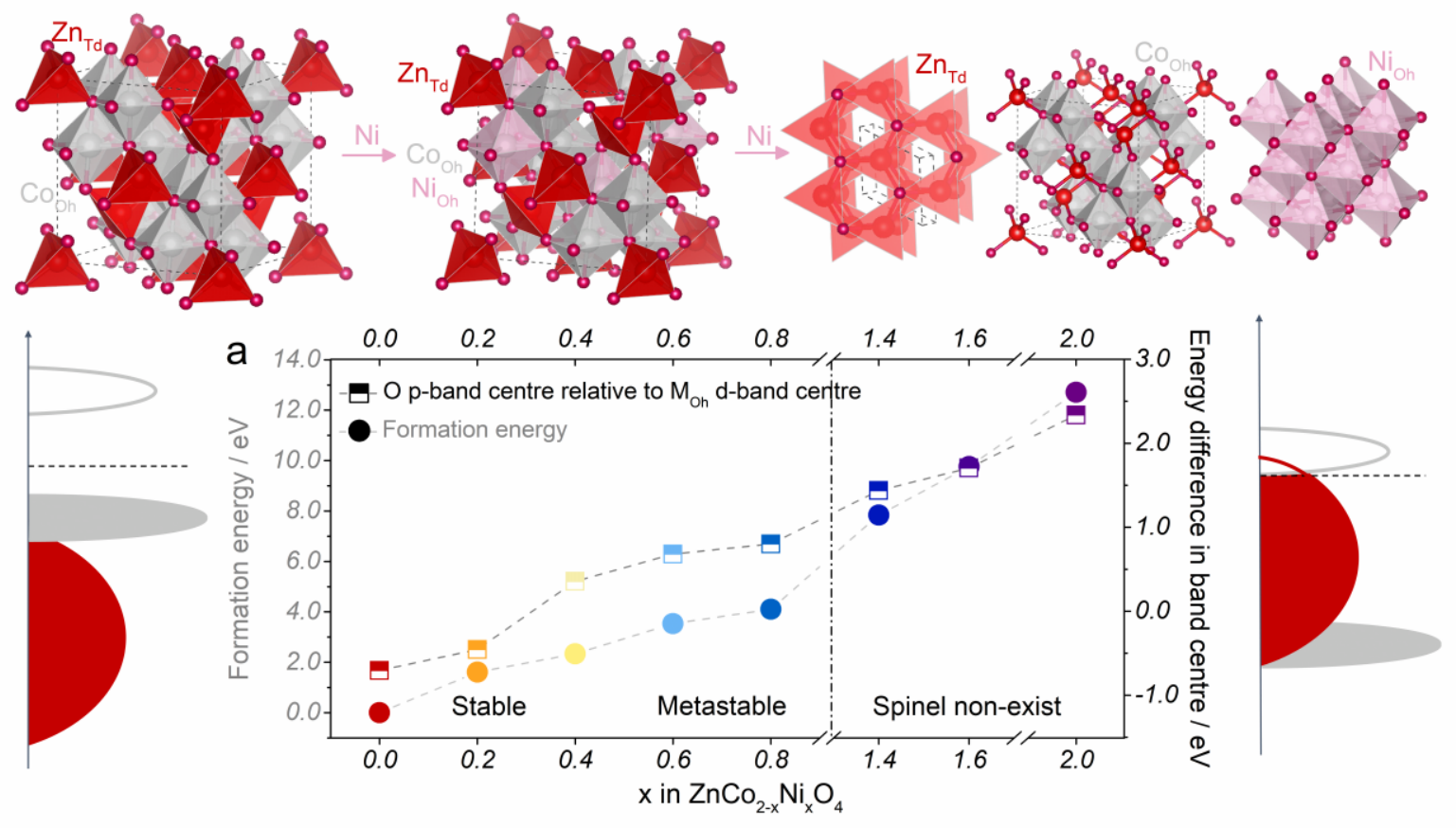

Figure 1. Top panel shows the crystal structures of $\mathrm{Ni}$ substituted $\mathrm{ZnCo}_{2} \mathrm{O}_{4} \cdot \mathrm{ZnCo}_{2-\mathrm{x}} \mathrm{Ni}_{\mathrm{x}} \mathrm{O}_{4}$ $(\mathrm{x} \leq 0.8)$ possesses a spinel structure with $\mathrm{Zn}$ accommodating tetrahedron (red), Co (grey) and $\mathrm{Ni}$ (pink) occupying and octahedron. $\mathrm{ZnCo}_{2-\mathrm{x}} \mathrm{Ni}_{\mathrm{x}} \mathrm{O}_{4}(\mathrm{x}>0.8)$ has phase separation into wurtzite, spinel and rock-salt structures. Bottom left panel shows the schematic representation of $\mathrm{M}_{\mathrm{Oh}} d$-band and $\mathrm{O} p$-band for $\mathrm{ZnCo}_{2-\mathrm{x}} \mathrm{Ni}_{\mathrm{x}} \mathrm{O}_{4}(\mathrm{x}=0,0.2)$ with $\mathrm{M}_{\mathrm{Oh}} d$-band centre higher than $\mathrm{O} p$-band centre. Bottom right panel is the schematic representation of $\mathrm{M}_{\mathrm{Oh}}$ $d$-band and $\mathrm{O} p$-band for $\mathrm{ZnCo}_{2-\mathrm{x}} \mathrm{Ni}_{\mathrm{x}} \mathrm{O}_{4}(\mathrm{x}=0.4,0.6,0.8)$ with $\mathrm{O} p$-band centre higher than $\mathrm{M}_{\mathrm{Oh}} d$-band centre. (a) Formation energy of $\mathrm{ZnCo}_{2-\mathrm{x}} \mathrm{Ni}_{\mathrm{x}} \mathrm{O}_{4}(\mathrm{x}=0,0.2,0.4,0.6,0.8,1.4,1.6$, 2.0) relative to $\mathrm{ZnCo}_{2} \mathrm{O}_{4}$ and $\mathrm{O} p$-band centre relative to $\mathrm{M}_{\mathrm{Oh}} d$-band centre of $\mathrm{ZnCo}_{2-\mathrm{x}} \mathrm{Ni}_{\mathrm{x}} \mathrm{O}_{4}$ $(\mathrm{x}=0,0.2,0.4,0.6,0.8,1.4,1.6,2.0)$. Three regions are distinguished with the increased amount of $\mathrm{x}$ ratio: stable region for $\mathrm{ZnCo}_{2-\mathrm{x}} \mathrm{Ni}_{\mathrm{x}} \mathrm{O}_{4}(\mathrm{x}=0,0.2$ and 0.4$)$; unstable region for $\mathrm{ZnCo}_{2-\mathrm{x}} \mathrm{Ni}_{\mathrm{x}} \mathrm{O}_{4}(\mathrm{x}=0.6$ and 0.8$)$ which undergoes significant surface reconstruction during OER cycles; for $\mathrm{ZnCo}_{2-\mathrm{x}} \mathrm{Ni}_{\mathrm{x}} \mathrm{O}_{4}$ with $\mathrm{x}>0.8$, too high the formation energy or $\mathrm{O} p$-band centre relative to $\mathrm{M}_{\mathrm{Oh}} d$-band centre results in very unstable phase and non-existent spinel structure. 

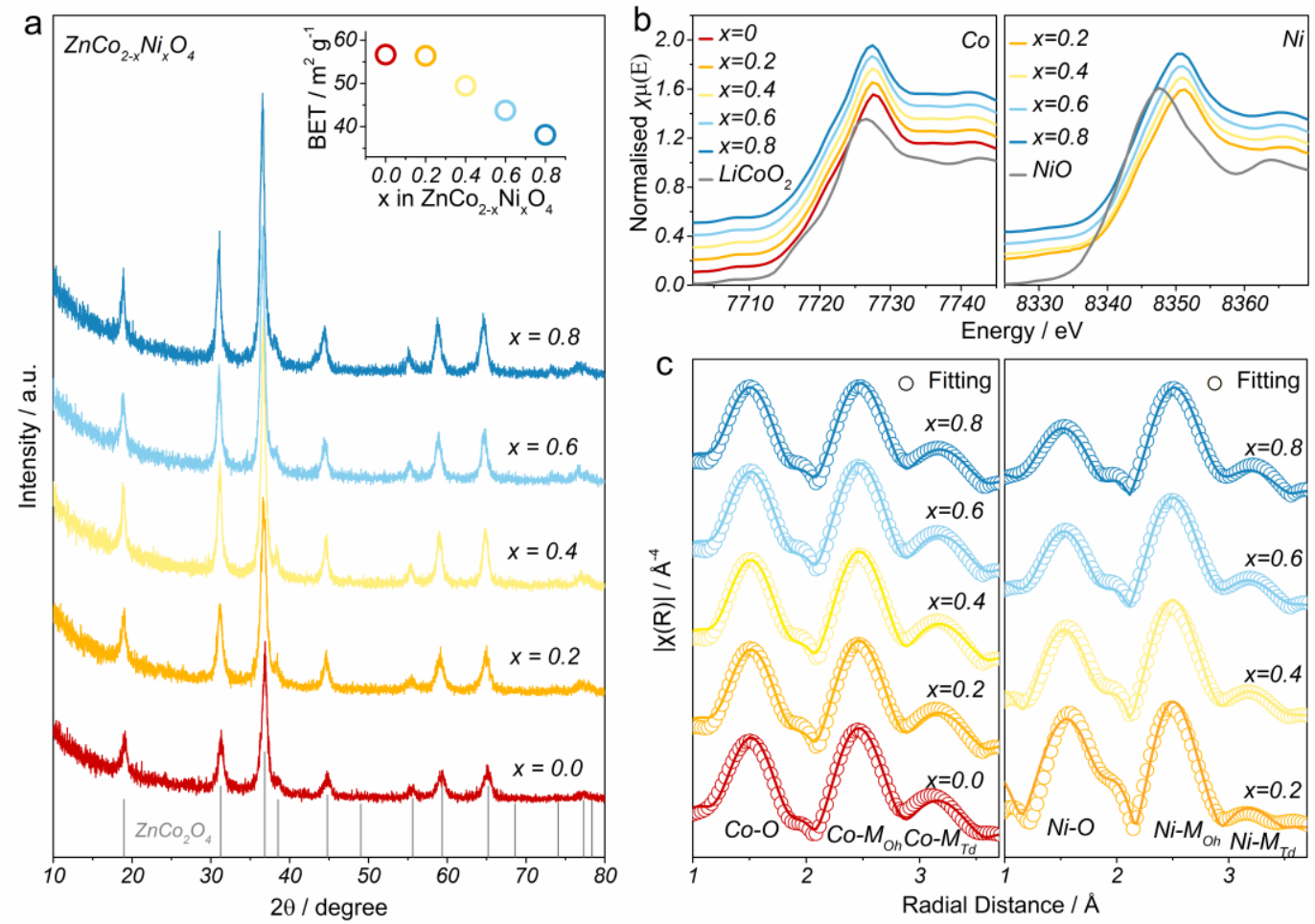

Figure 2. (a) XRD patterns of $\mathrm{ZnCo}_{2-\mathrm{x}} \mathrm{Ni}_{\mathrm{x}} \mathrm{O}_{4}(\mathrm{x}=0.0,0.2,0.4,0.6,0.8)$; BET surface area of $\mathrm{ZnCo}_{2-\mathrm{x}} \mathrm{Ni}_{\mathrm{x}} \mathrm{O}_{4}$ (inset). (b) Electronic structural characterization of $\mathrm{ZnCo}_{2-\mathrm{x}} \mathrm{Ni}_{\mathrm{x}} \mathrm{O}_{4}(\mathrm{x}=0.0,0.2$, $0.4,0.6,0.8)$ by XANES. Normalized Co K-edge XANES spectra (left panel) and Normalized $\mathrm{Ni}$ K-edge XANES spectra (right panel). (c) Geometric information characterization by Fourier transform of the EXAFS (FT-EXAFS). FT-EXAFS spectra and fitting for Co K-edge (left panel) and Ni K-edge (right panel). 

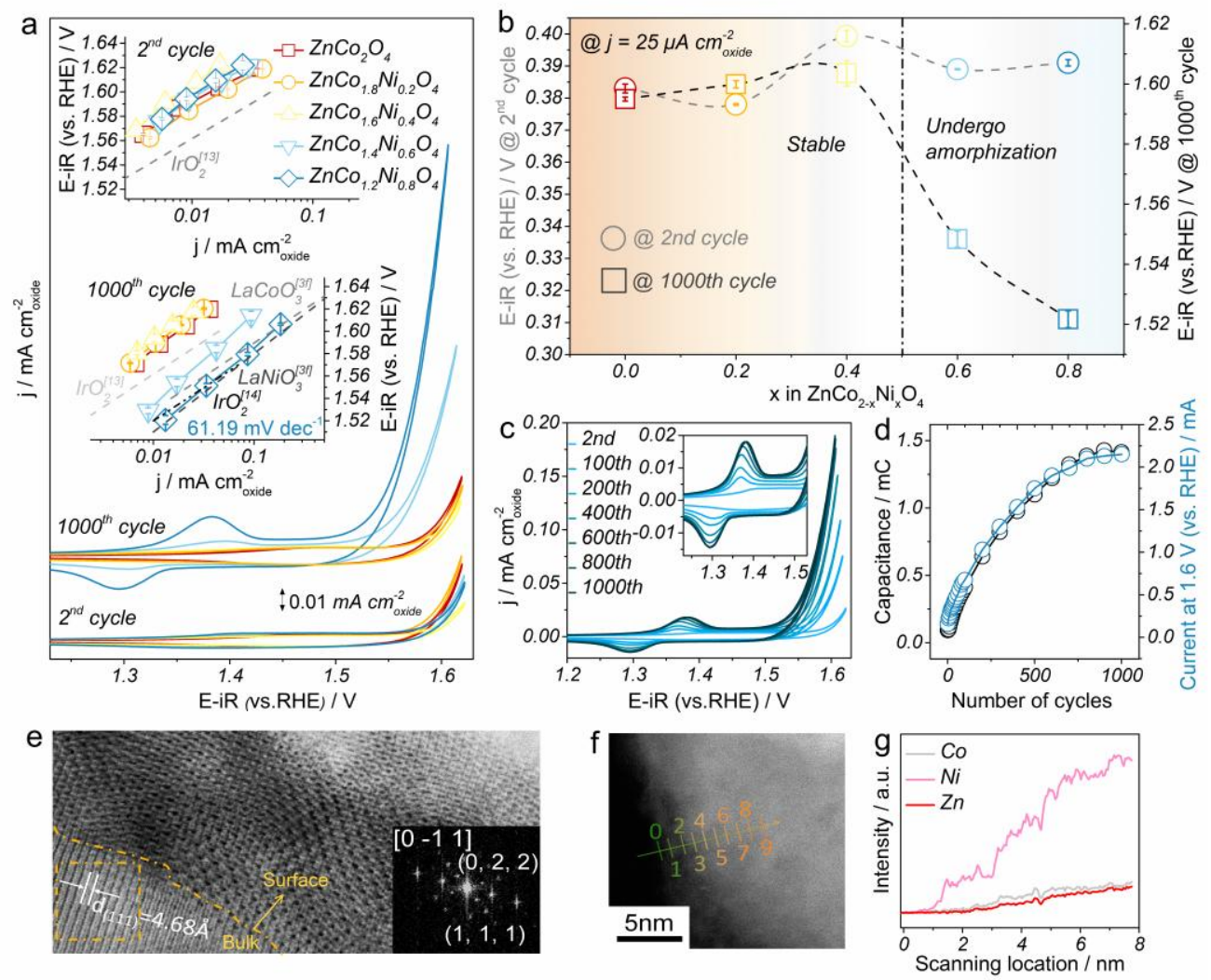

Figure 3. Electrochemical characterization on OER performance of $\mathrm{ZnCo}_{2-\mathrm{x}} \mathrm{Ni}_{\mathrm{x}} \mathrm{O}_{4}(\mathrm{x}=0.0,0.2$, $0.4,0.6,0.8)$. All data points and error bars were obtained by averaging the results of at least three independent measurements. (a) $\mathrm{CV}$ curves of the $1000^{\text {th }}$ cycle comparing to the $2^{\text {nd }}$ cycle of $\mathrm{ZnCo}_{2-\mathrm{x}} \mathrm{Ni}_{\mathrm{x}} \mathrm{O}_{4}(\mathrm{x}=0.0,0.2,0.4,0.6,0.8)$. The insets present the Tafel plot for surfacearea-normalized $\mathrm{ZnCo}_{2-\mathrm{x}} \mathrm{Ni}_{\mathrm{x}} \mathrm{O}_{4}(\mathrm{x}=0.0,0.2,0.4,0.6,0.8)$ at the $2^{\text {nd }}$ cycle (top) and $1000^{\text {th }}$ cycle (bottom) compared with $\mathrm{LaCoO}_{3}{ }^{[3 \mathrm{f}]}, \mathrm{LaNiO}_{3}{ }^{[3 \mathrm{f}]}, \mathrm{IrO}_{2}(100)$ extracted from $\mathrm{IrO}_{2}{ }^{[13]}$ and $\mathrm{IrO}_{2}{ }^{[14]}$. (b) $\mathrm{iR}$ corrected potential (in RHE scale) of the $1000^{\text {th }}$ cycle comparing to the $2^{\text {nd }}$ cycle of $\mathrm{ZnCo}_{2-\mathrm{x}} \mathrm{Ni}_{\mathrm{x}} \mathrm{O}_{4}(\mathrm{x}=0.0,0.2,0.4,0.6,0.8)$ at $25 \mu \mathrm{A} \mathrm{cm}{ }_{\text {oxide. }}^{-2}$ (c) Evolutive $\mathrm{CV}$ curves for representative $\mathrm{ZnCo}_{1.2} \mathrm{Ni}_{0.8} \mathrm{O}_{4}$ from $2^{\text {nd }}$ to $1000^{\text {th }}$ cycle in $1 \mathrm{M} \mathrm{KOH}$ at $10 \mathrm{mV} \mathrm{s}^{-1}$ in between 0.904 and $1.624 \mathrm{~V}$ (vs. RHE). The insets show the redox peaks from $1.23 \mathrm{~V}$ to $1.5 \mathrm{~V}$. (d) Evolution of the pseudocapacitive charge during cycling (0.904-1.624 V versus RHE) in $1 \mathrm{M} \mathrm{KOH}$ (left axis) and the OER activity at $1.6 \mathrm{~V}$ versus $\mathrm{RHE}$ (right axis) for $\mathrm{ZnCo}_{1.2} \mathrm{Ni}_{0.8} \mathrm{O}_{4}$. Structural and compositional characterization of $\mathrm{ZnCo}_{1.2} \mathrm{Ni}_{0.8} \mathrm{O}_{4}$ before and after OER cycling. 
(e) $\mathrm{ABF}$ image of $\mathrm{ZnCo}_{1.2} \mathrm{Ni}_{0.8} \mathrm{O}_{4}$ after thousand cycles of OER in $1 \mathrm{M} \mathrm{KOH}$ at $10 \mathrm{mV} / \mathrm{s}$ between 0.904 and $1.624 \mathrm{~V}$ (vs. RHE). The inset at the bottom right is the FFT pattern for the bulk which can be referred to Fd3m space group. (f, g) STEM-EDS image and analysis of cycled $\mathrm{ZnCo}_{1.2} \mathrm{Ni}_{0.8} \mathrm{O}_{4}$.

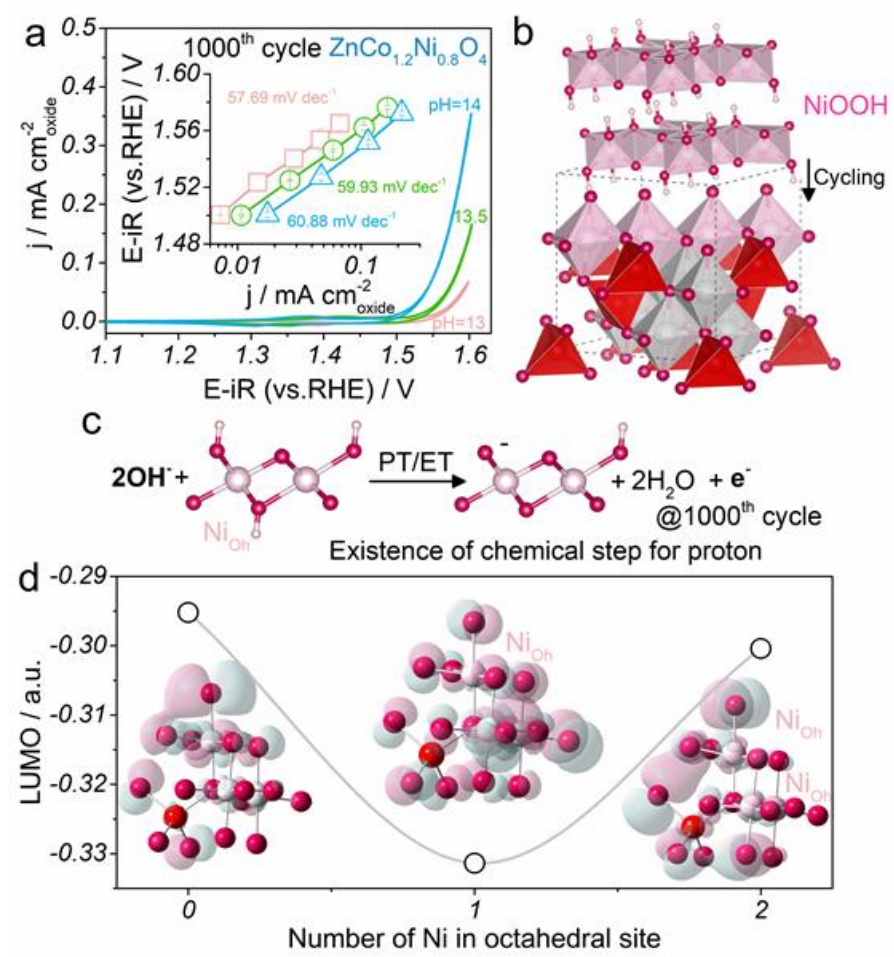

Figure 4. (a) $\mathrm{pH}$-dependent OER activity for cycled $\mathrm{ZnCo}_{1.2} \mathrm{Ni}_{0.8} \mathrm{O}_{4}$. (b) The schematic for the transition from pristine $\mathrm{ZnCo}_{2} \mathrm{O}_{4} / \mathrm{ZnCo}_{1.2} \mathrm{Ni}_{0.8} \mathrm{O}_{4}$ to $\mathrm{CoOOH} / \mathrm{NiOOH}$. (c) The schematic for nonconcerted proton-electron transfer $\left(2 \mathrm{H}^{+}: 1 \mathrm{e}^{-}\right.$ratio is shown as an example) of surface deprotonation of cycled $\mathrm{ZnCo}_{1.2} \mathrm{Ni}_{0.8} \mathrm{O}_{4}$.(d) Energy of lowest unoccupied molecular orbital (LUMO) versus number of $\mathrm{Ni}$ in octahedral site. Insets are the schematic plots of models with one $\mathrm{Zn}$ atom in tetrahedral site, three $\mathrm{Co}$ or $\mathrm{Ni}$ atoms in octahedral site.

\section{REFERENCE}


[1] a) N. S. Lewis, Science. 2007, 315, 798; b) C. C. McCrory, S. Jung, J. C. Peters, T. F. Jaramillo, J. Am. Chem. Soc. 2013, 135, 16977.

[2] a) S. Song, H. Zhang, X. Ma, Z. Shao, R. T. Baker, B. Yi, Int. J. Hydrog. Energy. 2008, 33, 4955. b) S. Trasatti, J Electroanal. Chem. 1980, 111, 125.

[3] a) W. T. Hong, R. E. Welsch, Y. Shao-Horn, J. Phys. Chem. C. 2015, 120, 78 ; (b) J. O. M. Bockris, J. Electrochem. Soc. 1984, 131, 290; (c) J. Suntivich, W. T. Hong, Y. L. Lee, J. M. Rondinelli, W. Yang, J. B. Goodenough, B. Dabrowski, J. W. Freeland, Y. Shao-Horn, J. Phys. Chem. C. 2014, 118, 1856; (d) W. Zhou, J. Sunarso, J. Phys. Chem. Lett. 2013, 4, 2982; (e) M. Ezbiri, K. M. Allen, M. E. Galvez, R. Michalsky, A. Steinfeld, ChemSusChem. 2015, 8, 1966; (f) J. Suntivich, K. J. May, H. A. Gasteiger, J. B. Goodenough, Y. Shao-Horn, Science. 2011, 334, 1383; g) A. Vojvodic, J. K. Nørskov, Science. 2011, 334, 1355.

[4] a) Q. Zhao, Z. Yan, C. Chen, J. Chen, Chem. Rev. 2017, 117, 10121; b) J. S. Kim, B. Kim, H. Kim, K. Kang, Adv. Energy Mater. 2018, 8, 1702774; c) C. Wei, Z. Feng, G. G. Scherer, J. Barber, Y. Shao- Horn, Z. J. Xu, Adv. Mater. 2017, 29, 1606800; d) Y. Zhou, S. Sun, S. Xi, Y. Duan, T. Sritharan, Y. Du, Z. J. Xu, Adv. Mater. 2018, 30, 1705407. e) Y. Zhou, S. Sun, J. Song, S. Xi, B. Chen, Y. Du, Z. J. Xu, Adv. Mater. 2018, 30, 1802912.

[5] a) I. Abidat, C. Morais, C. Comminges, C. Canaff, J. Rousseau, N. Guignard, T. W. Napporn, A. Habrioux K. B. Kokoh, J. Mater. Chem. A. 2017, 5, 7173; b) I. Abidat, N. Bouchenafa-Saib, A. Habrioux, C. Comminges, C. Canaff, J. Rousseau, T. W. Napporn, D. Dambournet, O. Borkiewicze, K. B. Kokoh, J. Mater. Chem. A. 2015, 3, 17433 .

[6] a) C. Tang, N. Cheng, Z. Pu, W. Xing, X. Sun, Angew. Chem. Int. Ed. Engl. 2015, 54, 9351; b) A. Grimaud, K. J. May, C. E. Carlton, Y. L. Lee, M. Risch, W. T. Hong, J. G. Zhou, 
Y. Shao-Horn, Nat. Commun. 2013, 4, 2439; c) S. H. Chang, N. Danilovic, K. C. Chang, R. Subbaraman, A. P. Paulikas, D. D. Fong, M. J. Highland, P. M. Baldo, V. R. Stamenkovic, J. W. Freeland, J. A. Eastman, N. M. Markovic, Nat. Commun. 2014, 5, 4191; d) O. DiazMorales, D. Ferrus-Suspedra, M. T. Koper, Chem. Sci. 2016, 7, 2639; e) N. Danilovic, R. Subbaraman, K. C. Chang, S. H. Chang, Y. J. Kang, J. Snyder, A. P. Paulikas, D. Strmcnik, Y. T. Kim, D. Myers, V. R. Stamenkovic, N. M. Markovic, J. Phys. Chem. Lett. 2014, 5, 2474.

[7] a) M. G. Mavros, T. Tsuchimochi, T. Kowalczyk, A. McIsaac, L. P. Wang, T. V. Voorhis, Inorg. Chem. 2014, 53, 6386; b) L. P. Wang, T. Van Voorhis, J. Phys. Chem. Lett. 2011, 2, 2200; c) T. A. Betley, Q. Wu, T. Van Voorhis, D. G. Nocera, Inorg. Chem. 2008, 47, 1849; d) A. Grimaud, O. Diaz-Morales, B. H. Han, W. T. Hong, Y. L. Lee, L. Giordano, K. A. Stoerzinger, M. T. M. Koper, Y. Shao-Horn, Nat. Chem. 2017, 9, 457; e) X. Rong, , P. Jules, M. K. Alexie, ACS Catal. 2016, 6, 1153; f) J. S. Yoo, X. Rong, Y. Liu, A. M. Kolpak, ACS Catal. 2018, 8, 4628.

[8] P. Parida, R. Kashikar, A. Jena, B. R. K. Nanda, J. Phys. Chem. Solids. 2018, 123, 133.

[9] D. A. Kuznetsov, B. Han, Y. Yu, R. R. Rao, J. Hwang, Y. Román-Leshkov, Y. ShaoHorn, Joule. 2017, 2, 225.

[10] V. Krewald, F. Neese, D.A. Pantazis, Phys. Chem. Chem. Phys. 2016, 18, 10739.

[11] a) B. Henne, V. Ney, K. Ollefs, F. Wilhelm, A. Rogalev, A. Ney, Sci. Rep. 2015, 5, 16863; b) A. Grimaud, A. Demortière, M. Saubanere, W. Dachraoui, M. Duchamp, M. L. Doublet, J. M. Tarascon, Nat. Energy. 2017, 2, 16189.

[12] A. Grimaud, W. T. Hong, Y. Shao-Horn, J. M. Tarascon, Nat. Mater. 2016, 15, 121.

[13] T. D. Nguyen, , G. G. Scherer, Z. J. Xu, Electrocatalysis. 2016, 7, 420. 
[14] Y. Lee, J. Suntivich, K. J. May, E. E. Perry, Y. Shao-Horn, J. Phys. Chem. Lett. 2012, 3, 399.

[15] C. Yang, O. Fontaine, J. M. Tarascon, A. Grimaud, Angew. Chem. 2017, 129, 8778.

[16] a) I. Abidat, C. Morais, C. Comminges, C. Canaff, J. Rousseau, N. Guignard, T. W. Napporn, A. Habrioux, K. B. Kokoh, J. Mater. Chem. A. 2017, 5, 7173; b) L. Trotochaud, J. K. Ranney, K. N. Williams, S. W. Boettcher, J. Am. Chem. Soc. 2012, 134, 17253.

[17] a) S. Mildner, M. Beleggia, D. Mierwaldt, T. W. Hansen, J. B. Wagner, S. Yazdi, T. Kasama, J. Ciston, Y. M. Zhu, C. Jooss, J. Phys. Chem. C. 2015, 119, 5301; b) D. A. Muller, N. Nakagawa, A. Ohtomo, J. L. Grazul, H. Y. Hwang, Nature. 2004, 430, 657; c) G. Atiya, V. Mikhelashvili, G. Eisenstein, W. D. Kaplan, J. Mater. Sci. 2014, 49, 3863.

[18] B. Han, K. A. Stoerzinger, V. Tileli, A. D. Gamalski, E. A. Stach, Y. Shao-Horn, Nat Mater. 2017, 16, 121.

[19] a) Z. L. Wang, J. S. Yin, Y. D. Jiang, Micron. 2000, 31, 571; b) H. Tan, J. Verbeeck, A. Abakumov, G. Van Tendeloo, Ultramicroscopy. 2012, 116, 24; c) J. Graetz, C. C. Ahn, H. Ouyang, P. Rez, B. Fultz, Phys. Rev. B. 2004, 69, 235103.

[20] a) Z. X. Shen, C. K. Shih, O. Jepsen, W. E. Spicer, I. Lindau, J. W. Allen, Phys. Rev. Lett. 1990, 64, 2442; b) K. T. Ng, D. M. Hercules, J. Phys. Chem. 1976, 80, 2094.

[32] A. Fujimori, F. Minami, Phys. Rev. B. 1984, 30, 957.

[33] a) B. W. Veal, A. P. Paulikas, Phys. Rev. B. 1985, 31, 5399; b) J. Ghijsen, L. H. Tjeng, J. van Elp, H. Eskes, J. Westerink, G. A. Sawatzky, M. T. Czyzyk Phys. Rev. B. 1988, 38, 11322; c) C. A. F. Vaz, D. Prabhakaran, E. I. Altman, V. E. Henrich, Phys. Rev. B. 2009, 80, 155457.

[21] H. Wang, C. Y. Ralston, D. S. Patil, R. M. Jones, W. Gu, M. Verhagen, M. Adams, P. Ge, C. Riordan, C. A. Marganian, P. Mascharak, J. Kovacs, C. G. Miller, T. J. Collins, S. 
Brooker, P. D. Croucher, K. Wang, E. I. Stiefel, S. P. Cramer, J. Am. Chem. Soc. 2000, 122, 10544.

[22] J. Deng, , X. Lv, H. Zhang, B. Zhao, X. Sun, J. Zhong, Phys. Chem. Chem. Phys, 2016, $18,10453$.

[23] a) P. Zou, Magnetic Field Effects on Nickel Electrodes for Nickel Metal Hydride Batteries (Doctoral dissertation, University of Iowa), 2003 ; b) A. J. Tkalych, K. Yu, E. A. Carter, J. Phys. Chem. C, 2015, 119, 24315.

[24] W. T. Hong, K. A. Stoerzinger, Y. L. Lee, L. Giordano, A. Grimaud, A. M. Johnson, J. Hwang, E. J. Crumlin, W. Yange, Y. Shao-Horn, Energy Environ. Sci. 2017, 10, 2190.

[25] a) D. Y. Kuo, J. K. Kawasaki, J. N. Nelson, J. Kloppenburg, G. Hautier, K. M. Shen, D. G. Schlom, J. Suntivich, J. Am. Chem. Soc. 2017, 139, 3473; b) M. Görlin, J. Ferreira de Araújo, H. Schmies, D. Bernsmeier, S. Dresp, M. Gliech, Z. Jusys, P. Chernev, R. Kraehnert, H. Dau, P. Strasser, J. Am. Chem. Soc. 2017, 139, 2070.

\section{Supporting information}

Supporting Information is available from the Wiley Online Library or from the author.

\section{Acknowledgements}

Y.D., S.S. contributed equally to this work. This work was supported by the Singapore Ministry of Education Tier 2 Grant (MOE2017-T2-1-009) and the Singapore National Research Foundation under its Campus for Research Excellence and Technological Enterprise (CREATE) programme. Authors thank the Facility for Analysis, Characterisation, Testing and Simulation (FACTS) in Nanyang Technological University for materials 
characterizations. Authors thank Martial Duchamp and Tiukalova Elizaveta for fruitful discussion on TEM characterizations.

\section{Conflict of interest}

The authors declare no conflict of interest.

Metastable spinel oxides for efficient water oxidation can be designed by a graduate substitution strategy. A systematic study on $\mathrm{Ni}$ substituted spinel $\mathrm{ZnCo}_{2} \mathrm{O}_{4}$ indicates the relative position of $\mathrm{M} 3 \mathrm{~d}$ and $\mathrm{O} 2 \mathrm{p}$ an indicator of lattice oxygen stability. With $\mathrm{Ni}$ substitution, the surface reconstruction is activated towards a spinel with lattice oxygen mechanism for water oxidation.

Keyword: oxygen evolution reaction; spinel oxides; surface reconstruction; $\mathrm{M}$ d-band centre and $\mathrm{O}$ p-band centre; lattice oxygen evolution

Yan Duan, Shengnan Sun, Yuanmiao Sun, Shibo Xi, Xiao Chi, Qinghua Zhang, Xiao Ren, Jingxian Wang, Samuel Jun Hoong Ong, Yonghua Du, Lin Gu, Alexis Grimaud, Zhichuan J. $\mathrm{Xu}^{*}$

Mastering surface reconstruction of metastable spinel oxides for better water oxidation
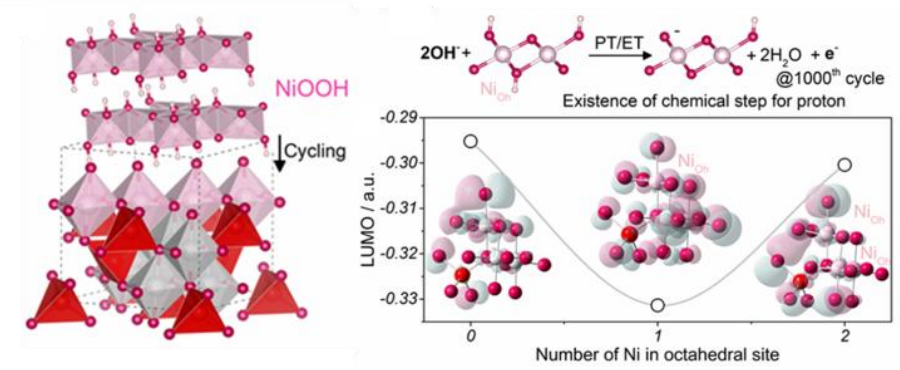


\section{Supporting Information}

\section{Mastering surface reconstruction of metastable spinel oxides for}

\section{better water oxidation}

Yan Duan, ${ }^{\Delta 1,2,3}$ Shengnan Sun, ${ }^{\Delta 1,2}$ Yuanmiao Sun, ${ }^{1}$ Shibo $\mathrm{Xi},{ }^{4}$ Xiao Chi, ${ }^{4}$ Qinghua Zhang, ${ }^{5}$ Xiao Ren, ${ }^{1}$ Jingxian Wang, ${ }^{1}$ Samuel Jun Hoong Ong, ${ }^{1,6}$ Yonghua Du, ${ }^{4}$ Lin Gu, ${ }^{5}$ Alexis Grimaud $^{7,8}$ and Zhichuan J. Xu*1,2,3,6

${ }^{1}$ School of Materials Science and Engineering, Nanyang Technological University, Singapore 639798, Singapore;

${ }^{2}$ Solar Fuels Laboratory, Nanyang Technological University, Singapore 639798, Singapore;

${ }^{3}$ Energy Research Institute @NTU, ERI@N, Interdisciplinary Graduate School, Nanyang Technological University, Singapore 639798, Singapore;

${ }^{4}$ Institute of Chemical and Engineering Sciences A*STAR, 1 Pesek Road, 627833, Singapore; ${ }^{5}$ Institute of Physics, Chinese Academy of Science, P.O. Box 603, Beijing, 100190, China;

${ }^{6}$ Singapore-HUJ Alliance for Research and Enterprise (SHARE), Nanomaterials for Energy and Energy-Water Nexus (NEW), Campus for Research Excellence and Technological Enterprise (CREATE), Singapore 138602; 
${ }^{47}$ Chimie du Solide et de l'Energie, UMR 8260, Collège de France, 75231 Paris Cedex 05, France;

${ }^{8}$ Réseau sur le Stockage Electrochimique de l'Energie (RS2E), FR CNRS 3459, 80039 Amiens Cedex, France.

${ }^{\Delta}$ These authors contributed equally

\section{DFT Calculations:}

Researchers initially use metal $d$-band orbitals to describe the trend discovered in the adsorption energy of molecules on transition metals and metal alloys. They successfully correlated the $d$-band centre with electrocatalytic performance [1-3]. Motivated by this, researchers established the occupancy of $\mathrm{e}_{\mathrm{g}}$ electron for transition metal oxides as an activity descriptor, which correlates the surface adsorbate binding with the catalytic activity for transition metal oxides. [4] Later, an iono-covalent metal-oxygen bond is found to describe electronic structures of metal oxides more accurately [5], especially when oxygen redox reaction is considered in the electrochemical process [6]. To figure out the interaction between metal $d$-band and oxygen $p$-band orbitals for a better understanding of the electronic properties and electrocatalytic performances of substituted spinel oxides, we have carried out first-principles DFT+U calculations on the transition metal $d$ states and oxygen $p$ states for $\mathrm{ZnCo}_{2-\mathrm{x}} \mathrm{Ni}_{\mathrm{x}} \mathrm{O}_{4}$. The DFT calculations have been done based on the assumption that $\mathrm{ZnCo}_{2} \mathrm{O}_{4}$ is a representative spinel oxide with $\mathrm{Zn}^{2+}$ occupying tetrahedral $(\mathrm{Td})$ site and $\mathrm{Co}^{3+}$ staying in octahedral (Oh) site [5]. When $\mathrm{Ni}$ is substituted into $\mathrm{ZnCo}_{2} \mathrm{O}_{4}$, $\mathrm{Ni}$ atoms would take the place of Co atoms in octahedron. This is due to the preferential $\mathrm{Td}$ site occupancy of divalent $\mathrm{Zn}$ in spinel [7] and the large formation energy for antisite defects, $\mathrm{E}_{\mathrm{Zn}-\mathrm{M}}(\mathrm{M}$ denotes metal cations in octahedral sites) [8]. Besides, $\mathrm{Ni}$ and Co cations with a $3 \mathrm{~d}^{6 \sim 8}$ electron configuration favor octahedral coordination (according to the crystal field stability energy). [9] This has been verified by XAFS characterizations. 
All density functional theory (DFT) calculations were carried out by the Vienna Ab-initio Simulation Package (VASP) [10], employing the projected augmented wave (PAW) model. The Perdew-Burke-Ernzerhof (PBE) functional, within the generalized gradient approximation (GGA) approach, was used to describe the exchange and correlation effect. [11] The GGA+U calculations were performed using the model proposed by Dudarev et al., [12] with the $\mathrm{U}_{\text {eff }}\left(\mathrm{U}_{\text {eff }}=\right.$ Coulomb $\mathrm{U}$ - exchange $\left.\mathrm{J}\right)$ values of $4.7 \mathrm{eV}, 3.3 \mathrm{eV}$, and $6.4 \mathrm{eV}$ for $\mathrm{Zn}, \mathrm{Co}$, and $\mathrm{Ni}$, respectively. In all the cases, the cutoff energy was set to be $450 \mathrm{eV}$. The Monkhorst-Pack [13] k-point mesh was set to be $6 \times 6 \times 6$ and $9 \times 9 \times 9$ for bulk optimazation and electronic structure calculations, respectively. Of all the calculations, the Brillouin zone was integrated using tetrahedron method with Blöch corrections. The force and energy convergence tolerance were set to be $0.05 \mathrm{eV}^{-1}$ and $10^{-5} \mathrm{eV}$, respectively.

The normal $\mathrm{ZnCo}_{2-\mathrm{x}} \mathrm{Ni}_{\mathrm{x}} \mathrm{O}_{4}$ spinels were constructed with $\mathrm{Zn}^{2+}$ located at the tetrahedral sites and $\mathrm{Co}^{3+}$ and $\mathrm{Ni}^{3+}$ at the octahedral sites. The value of $\mathrm{x}$ was controlled by substituting $\mathrm{Co}$ atoms by $\mathrm{Ni}$ in spinel $\mathrm{ZnCo}_{2} \mathrm{O}_{4}$. Both the $\mathrm{O} p$-band centre and $\mathrm{M}_{\mathrm{Oh}} d$-band centre were computed by taking the weighted mean energy of the projected density of states of $\mathrm{O}-p$ and $\mathrm{M}_{\mathrm{Oh}} d$-states (both occupied and unoccupied states) relative to the Fermi level.

To verify whether $\mathrm{ZnCo}_{2-\mathrm{x}} \mathrm{Ni}_{\mathrm{x}} \mathrm{O}_{4}(\mathrm{x}=0-2)$ oxides are thermodynamically stable in spinel phase, we have calculated their formation energies. The value of formation energy due to cation substitution is influenced by two physical effects: (1) the difference in atomic radius between the two cations; (2) the bonding strengths resulted from the hybridization between metal $d$ states and oxygen $2 p$ states. [14] Here, as the $\mathrm{Co}^{3+}$ and $\mathrm{Ni}^{3+}$ show close atomic radius (125 and $124 \mathrm{pm}$, respectively), the second factor dominates in determining the formation energy of $\mathrm{ZnCo}_{2-\mathrm{x}} \mathrm{Ni}_{\mathrm{x}} \mathrm{O}_{4}$. The formation energy of $\mathrm{ZnCo}_{2-\mathrm{x}} \mathrm{Ni}_{\mathrm{x}} \mathrm{O}_{4}(\mathrm{x}=0-2)$ relative to that of $\mathrm{ZnCo}_{2} \mathrm{O}_{4}$ has been calculated based on the following equation: 
$\mathrm{E}_{f o r m}=E_{Z n C o 2-x N i x O 4}+n_{i} \mu_{C o}-E_{Z n C o 2 O 4}-n_{i} \mu_{N i}$

where $\mathrm{E}_{\text {form }}$ denotes the formation energy of compound $\mathrm{ZnCo}_{2-\mathrm{x}} \mathrm{Ni}_{\mathrm{x}} \mathrm{O}_{4}(\mathrm{x}=0-2)$;

$E_{Z n C o 2-x N i x O 4}$ represents the electronic energy of $\mathrm{ZnCo}_{2-\mathrm{x}} \mathrm{Ni}_{\mathrm{x}} \mathrm{O}_{4}(\mathrm{x}=0-2)$;

$n_{i}$ indicates the number of $\mathrm{Ni}$ which takes the place of $\mathrm{Co}$;

$\mu_{C o}$ and $\mu_{N i}$ represent the chemical potential of individual Co and Ni referenced to bulk Co and $\mathrm{Ni}$, respectively.

Material synthesis: $\mathrm{ZnCo}_{2-\mathrm{x}} \mathrm{Ni}_{\mathrm{x}} \mathrm{O}_{4}$ powders were synthesized by a thermal decomposition method. The $\mathrm{ZnCo}_{2} \mathrm{O}_{4}$ precursors were produced by dissolving $5 \mathrm{mmol} \mathrm{Zn}(\mathrm{OAc})_{2} \cdot 2 \mathrm{H}_{2} \mathrm{O}$ and $10 \mathrm{mmol} \mathrm{Co}\left(\mathrm{NO}_{3}\right)_{2} \cdot 6 \mathrm{H}_{2} \mathrm{O}$ in $30 \mathrm{~mL}$ de-ionized (DI) water and $3 \mathrm{~mL}$ nitric acid. As for $\mathrm{ZnCo}_{2-}$ ${ }_{x} \mathrm{Ni}_{\mathrm{x}} \mathrm{O}_{4}, \mathrm{Ni}\left(\mathrm{NO}_{3}\right)_{2} \cdot 6 \mathrm{H}_{2} \mathrm{O}$ and $\mathrm{Co}(\mathrm{OAc})_{2} \cdot 6 \mathrm{H}_{2} \mathrm{O}$ were added stoichiometrically for $\mathrm{Ni}$ to take the place of Co. The solutions were then heated and stirred with a magnetic stirrer to obtain a colorless solution. Then the solution was dried at $170{ }^{\circ} \mathrm{C}$ for $12 \mathrm{~h}$ to remove the remaining water followed by calcination at $300{ }^{\circ} \mathrm{C}$ for 6 hours' crystallization. The value of $\mathrm{x}$ varied from $0,0.2,0.4,0.6$ to 0.8 . When same molar number of $\mathrm{Ni}\left(\mathrm{NO}_{3}\right)_{2} \cdot 6 \mathrm{H}_{2} \mathrm{O}$ and $\mathrm{Co}(\mathrm{OAc})_{2} \cdot 6 \mathrm{H}_{2} \mathrm{O}(\mathrm{x}=1)$ were added, a structure with a mixture of spinel phases, $\mathrm{NiO}$ and $\mathrm{ZnO}$ phases began to form. When $\mathrm{Ni}\left(\mathrm{NO}_{3}\right)_{2} \cdot 6 \mathrm{H}_{2} \mathrm{O}$ totally took the place of $\mathrm{Co}(\mathrm{OAc})_{2} \cdot 6 \mathrm{H}_{2} \mathrm{O}$, a mixture of $\mathrm{NiO}$ and $\mathrm{ZnO}$ was formed instead of $\mathrm{ZnNi}_{2} \mathrm{O}_{4}$, which was in accordance with the reports that $\mathrm{ZnNi}_{2} \mathrm{O}_{4}$ has yet to be synthesized. [5]

\section{Material Characterizations:}

The crystal structure was obtained by Bruker D8 Advance with $\mathrm{Cu}-\mathrm{K}_{\alpha}$ radiation $(\lambda=1.5418$ $\AA$ ). The (Brunauer-Emitter-Teller) BET specific surface areas of the materials were obtained 
using an ASAP Tristar II 3020. XANES and extended EXAFS characterizations were carried out at the XAFCA beamline of the Singapore Synchrotron Light Source (SSLS) to obtain structural information [15]. Data reduction, data analysis, and EXAFS fitting were performed with the Athena and Artemis software packages [16]. High-resolution transmission electron microscopy (HRTEM) and electron energy loss spectroscopy (EELS) were conducted in the Institute of Physics, Chinese Academy of Sciences by a JEOL 2100F transition electron microscope at the operating voltage of $200 \mathrm{kV}$ to investigate morphology and composition after OER cycling compared with that of the as-synthesized materials. Both the raw material and cycled material were prepared by suspending them in ethanol by ultrasonication. The suspensions were then dropped onto carbon film coated $\mathrm{Cu}$ TEM grids and dried at room temperature. XPS measurements were performed using a PHI-5400 with Al Ka beam source $(250 \mathrm{~W})$ and position-sensitive detector (PSD). The binding energy resolution is $0.8 \mathrm{eV}$, angle resolution is $45^{\circ}$ and the detection limit is $80 \mathrm{~K} \mathrm{CPS}$. Base pressure of the measurement chamber is $3.0 \times 10^{-7} \mathrm{~Pa}$. The Ar ion (voltage $12 \mathrm{kV}$, current $4.2 \mathrm{~mA}$ ) sputtering speed is 0.28 $\mathrm{nm} / \mathrm{s}$ over an area of $300 \times 300 \mathrm{um}^{2}$. Data from the measurements were calibrated using the adventitious carbon peak of the $\mathrm{C} 1 \mathrm{~s}$ spectra $(\mathrm{EB}=284.8 \mathrm{eV})$. [18] Soft XAS and XMCD: Pairs of soft X-ray absorption spectra $\left(\mu_{+} / \mu_{-}\right)$are measured with circularly polarized $\mathrm{X}$-rays with $\pm 1 \mathrm{~T}$ magnetic fields applying to the samples. The XMCD spectra arise from the

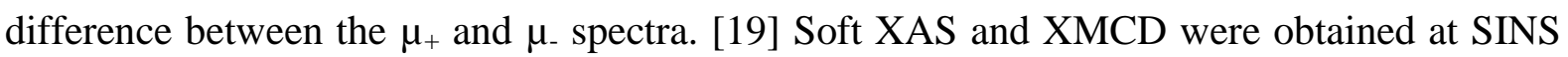
beamline of SSLS [20].

Electrochemical Tests: The electrochemical tests were carried out by the three-electrode method in a plastic cell with $\mathrm{ZnCo}_{2-\mathrm{x}} \mathrm{Ni}_{\mathrm{x}} \mathrm{O}_{4}$ as working electrode, and mercury-mercury oxide electrode $(\mathrm{Hg} / \mathrm{HgO})$ and $\mathrm{Pt}$ plate serving as reference and counter electrodes, respectively. $10 \mathrm{mg}$ perovskite material and $2 \mathrm{mg}$ carbon black were dispersed in a mixed solution of 0.4 $\mathrm{mL}$ isopropyl alcohol (IPA), $1.59 \mathrm{~mL}$ DI water and $10 \mu \mathrm{L}$ Nafion perfluorinated resin to prepare the catalyst ink. The mixture was sonicated for 10 mins to achieve homogenized dispersion of spinel and carbon. The spinel material was dispersed in a diluted IPA containing 5\% Nafion. The mass ratio of spinel material: carbon black was maintained at $4: 1$. The volume ratios of DI water: IPA: Nafion were maintained at $4: 1: 0.05 .10 \mu \mathrm{L}$ of the ink was dropped onto a newly 
polished glassy carbon electrode $\left(0.196 \mathrm{~cm}^{2}\right)$. All electrochemical potentials here were against the reversible hydrogen electrode (RHE) under the condition with 1.0 M KOH. The conversion between potentials vs. $\mathrm{Hg} / \mathrm{HgO}$ and vs. RHE was performed by the equation below. The Ohmic drop has been determined by electrochemical impedance spectroscopy as shown in Figure S12.E (vs. RHE) / V = E (vs. Hg/HgO) / V + $\mathrm{E}_{\mathrm{Hg} / \mathrm{HgO}}($ vs. SHE) $/ \mathrm{V}+0.059 \times \mathrm{pH} / \mathrm{V}$

$\left(\mathrm{E}_{\mathrm{Hg} / \mathrm{HgO}}(\mathrm{vs} . \mathrm{SHE}) / \mathrm{V}=0.098 / \mathrm{V}\right.$ vs. SHE at $\left.25^{\circ} \mathrm{C}\right)$

The oxygen evolution reaction was evaluated by cyclic voltammetry (CV) between 0.904 and $1.624 \mathrm{~V}$ (vs. RHE) at a scan rate of $10 \mathrm{mV} \mathrm{s}^{-1}$ ). The samples prepared for TEM, XAS, XMCD and XPS measurements were cycled using this program for 1000 cycles with the scan rate of $10 \mathrm{mVs}^{-1}$.

$\mathrm{pH}$ dependent experiments were conducted on pristine and cycled $\mathrm{ZnCo}_{2-\mathrm{x}} \mathrm{Ni}_{\mathrm{x}} \mathrm{O}_{4}$ to study the reaction mechanism. The second cycle for each $\mathrm{CV}$ scan was extracted to analyze the $\mathrm{pH}$ dependence of pristine $\mathrm{ZnCo}_{2-\mathrm{x}} \mathrm{Ni}_{\mathrm{x}} \mathrm{O}_{4}$ and the $1000^{\text {th }}$ cycle of $\mathrm{CV}$ has been extracted to study the $\mathrm{pH}$ dependence of cycled $\mathrm{ZnCo}_{2-\mathrm{x}} \mathrm{Ni}_{\mathrm{x}} \mathrm{O}_{4} . \mathrm{CV}$ measurements for each sample were carried out in $0.1 \mathrm{M} \mathrm{KOH}(\mathrm{pH}=13.12), 0.3162 \mathrm{M}(\mathrm{pH}=13.54)$ and $1 \mathrm{M}(\mathrm{pH}=13.98)$ with a scan rate of $10 \mathrm{mVs}^{-1}$ using three working electrodes from 1.1 to $1.7 \mathrm{~V}$ (vs. RHE). $0.1 \mathrm{M}, 0.316 \mathrm{M}$ and $1 \mathrm{M}$ $\mathrm{KOH}$ solutions were prepared and the $\mathrm{pH}$ of these solutions were determined by $\mathrm{pH}$ meter. OER experiments were conducted to the same RHE scale to ensure that the OER overpotential with respect to the equilibrium $\mathrm{O}_{2} / \mathrm{H}_{2} \mathrm{O}$ redox potential remained identical across different values of $\mathrm{pH}[21]$. Nernstian/non-Nernstian potential shift was obtained by $\mathrm{CV}$ measurements carried out in various $\mathrm{pH}$ at a scan rate of $200 \mathrm{mVs}^{-1}$ to observe the shift to lower potential for the redox peak. 

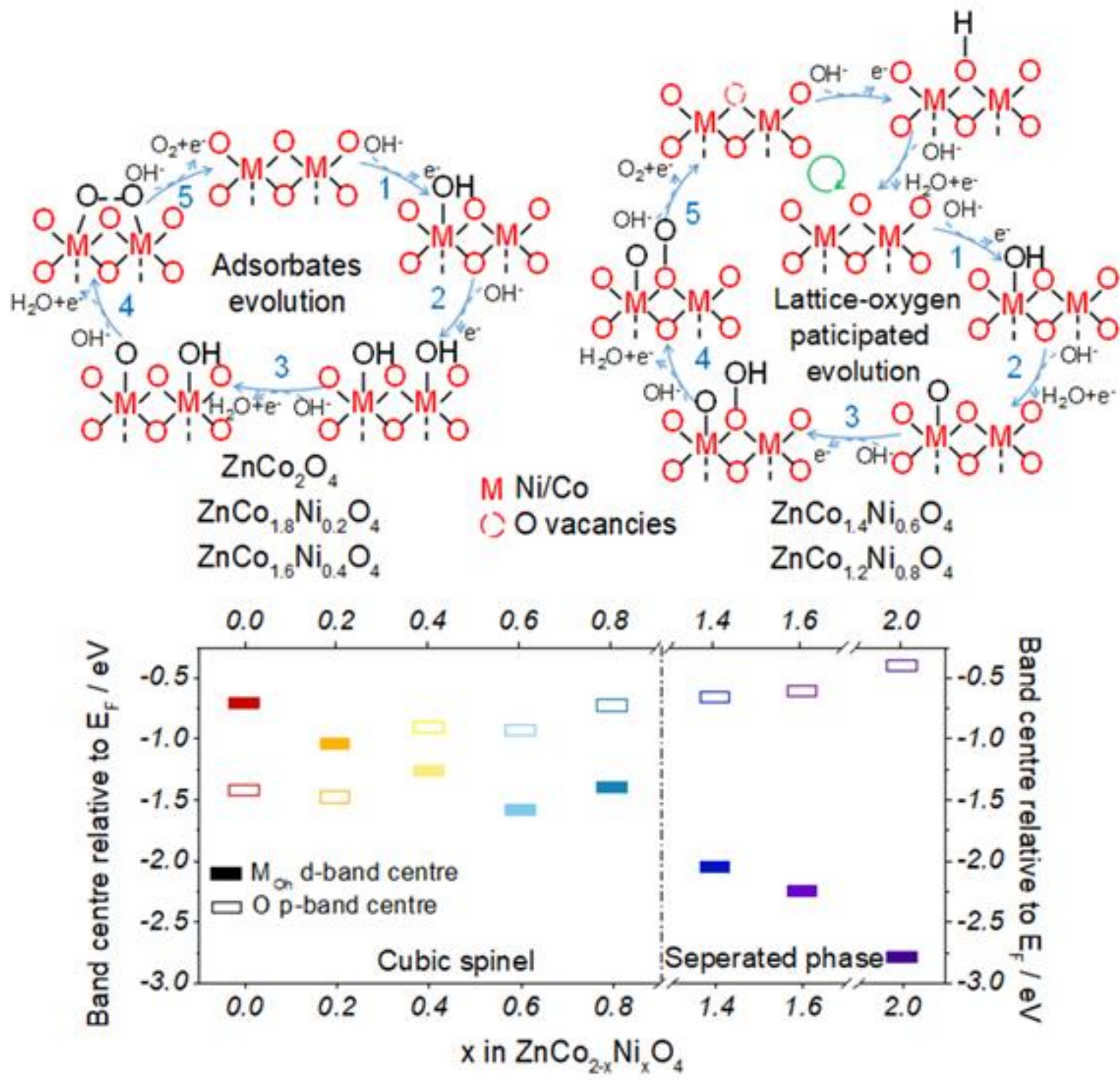

Figure S1 | The schematics in the bottom middle show the adsorbates evolution mechanism (AEM) for $\mathrm{ZnCo}_{2-\mathrm{x}} \mathrm{Ni}_{\mathrm{x}} \mathrm{O}_{4}(\mathrm{x}=0,0.2$ and 0.4$)$ and the lattice-oxygen participated evolution mechanism (LOM) for $\mathrm{ZnCo}_{2-\mathrm{x}} \mathrm{Ni}_{\mathrm{x}} \mathrm{O}_{4}(\mathrm{x}=0.6$ and 0.8$)$. Red and black atoms are from the lattice and the solvent, respectively. Bottom: Calculated $\mathrm{M}_{\mathrm{Oh}} d$-band centre (relative to $\mathrm{E}_{\mathrm{F}}$ ) 
and $\mathrm{O} p$-band centre (relative to $\left.\mathrm{E}_{\mathrm{F}}\right)$ of $\mathrm{ZnCo}_{2-\mathrm{x}} \mathrm{Ni}_{\mathrm{x}} \mathrm{O}_{4}(\mathrm{x}=0,0.2,0.4,0.6,0.8,1.4,1.6,2.0)$, denoted by solid rectangle and hollow rectangle, respectively.

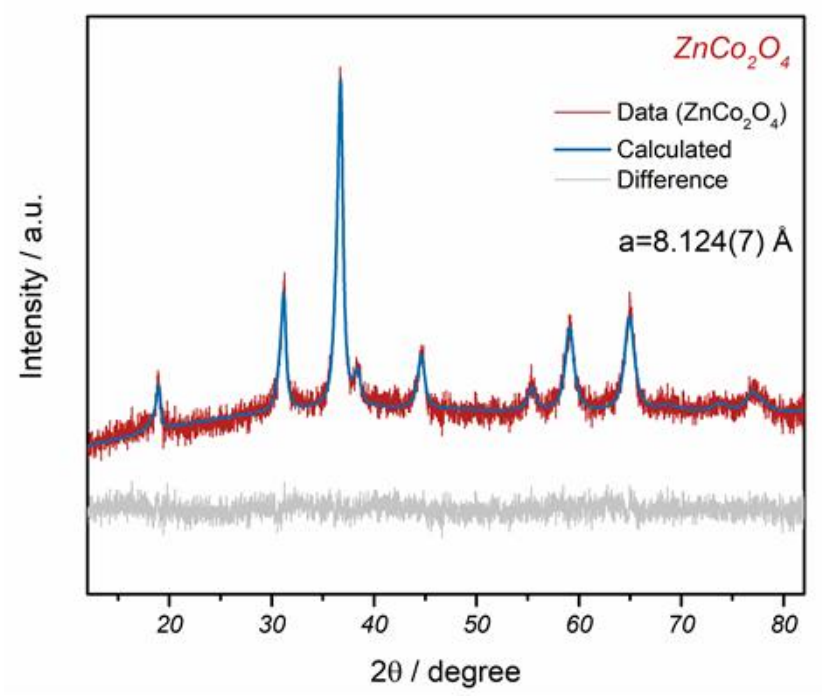

Figure S2 $\mid \mathrm{XRD}$ refinement on $\mathrm{ZnCo}_{2} \mathrm{O}_{4}$ pattern obtained by D8 ADVANCE with Pawley refinement method on TOPAS software.

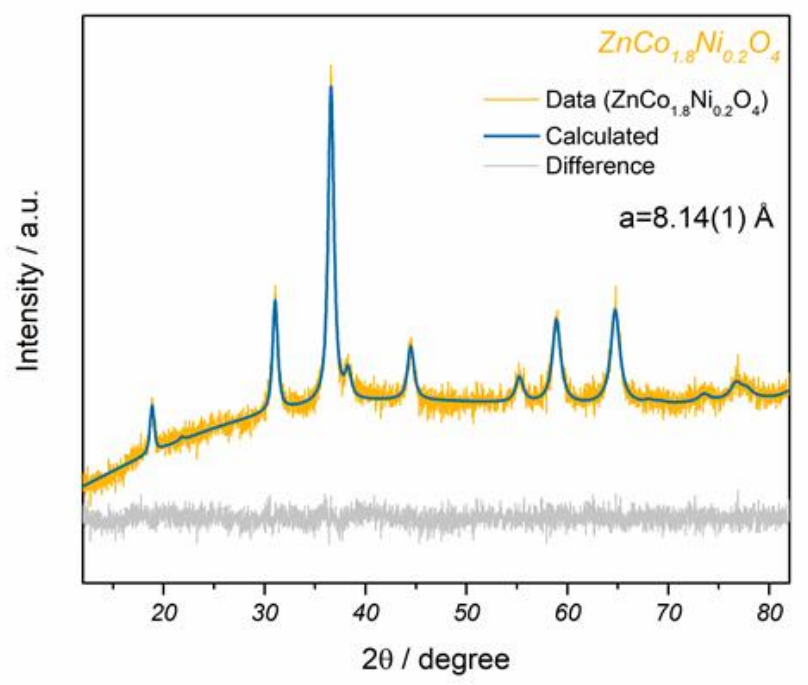


Figure S3 | XRD refinement on $\mathrm{ZnCo}_{1.8} \mathrm{Ni}_{0.2} \mathrm{O}_{4}$ pattern obtained by D8 ADVANCE with Pawley refinement method on TOPAS software.

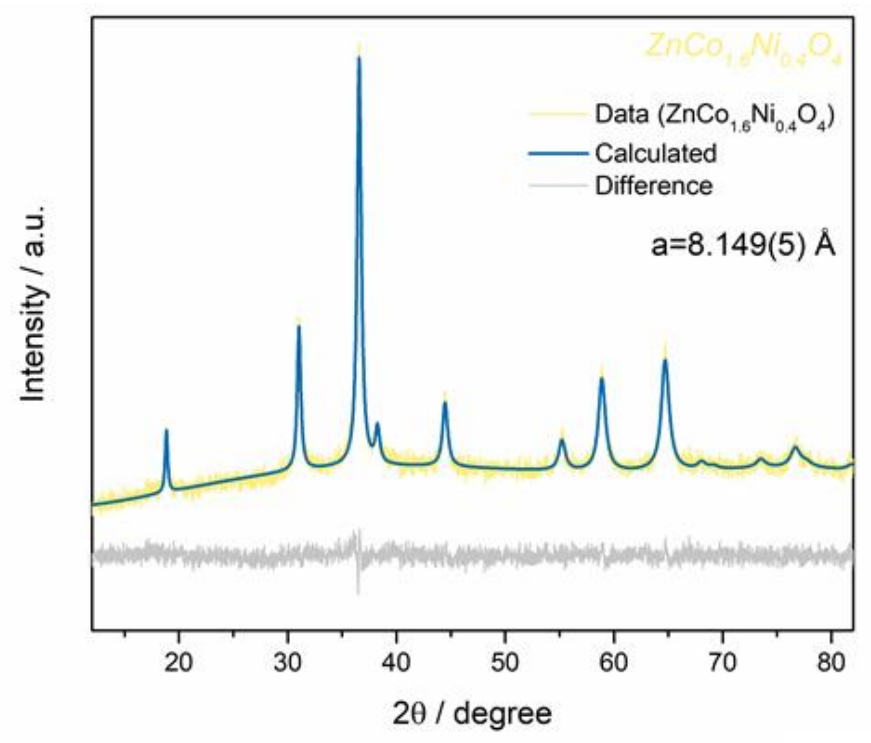

Figure S4 $\mid$ XRD refinement on $\mathrm{ZnCo}_{1.6} \mathrm{Ni}_{0.4} \mathrm{O}_{4}$ pattern obtained by D8 ADVANCE with Pawley refinement method on TOPAS software.

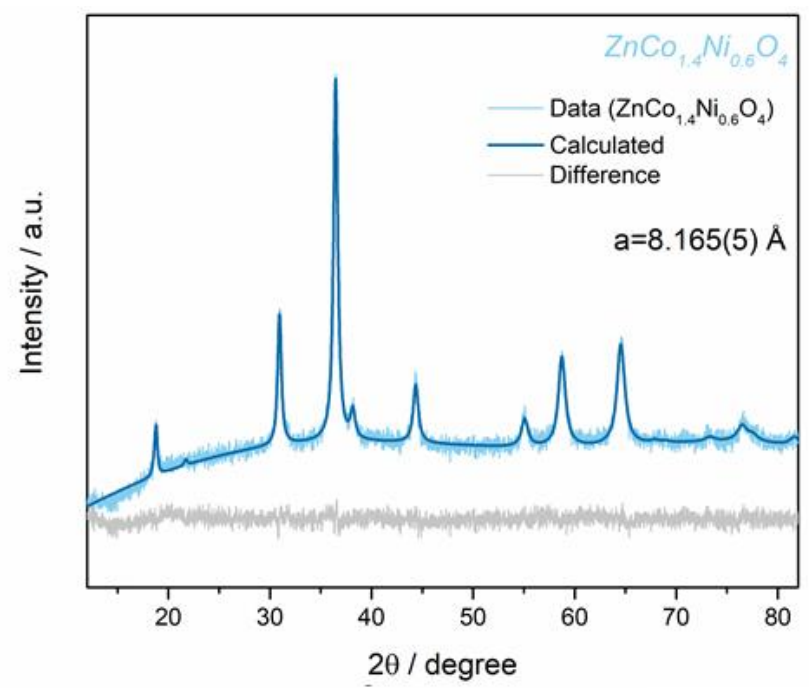

Figure S5 | XRD refinement on $\mathrm{ZnCo}_{1.4} \mathrm{Ni}_{0.6} \mathrm{O}_{4}$ pattern obtained by D8 ADVANCE with Pawley refinement method on TOPAS software. 


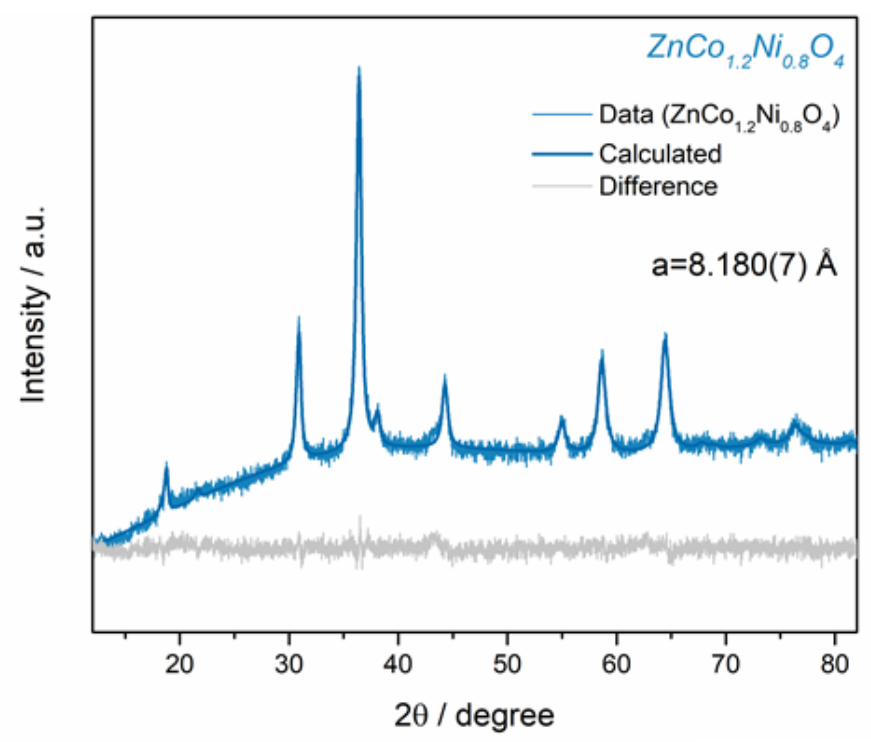

Figure S6 $\mid \mathrm{XRD}$ refinement on $\mathrm{ZnCo}_{1.2} \mathrm{Ni}_{0.8} \mathrm{O}_{4}$ pattern obtained by D8 ADVANCE with Pawley refinement method on TOPAS software.

Table S1 | Summary of lattice parameter of $\mathrm{ZnCo}_{2-\mathrm{x}} \mathrm{Ni}_{\mathrm{x}} \mathrm{O}_{4}(\mathrm{x}=0,0.2,0.4,0.6,0.8)$.

\begin{tabular}{|l|l|l|l|l|}
\hline Sample & Rwp & Lattice parameter a $(\AA)$ & Zero point error & Sample displacement \\
\hline $\mathrm{ZnCo}_{2} \mathrm{O}_{4}$ & $1.01 \%$ & $8.124(7)$ & 0.096 & -0.03 \\
\hline $\mathrm{ZnCo}_{1.8} \mathrm{Ni}_{0.2} \mathrm{O}_{4}$ & $1.02 \%$ & $8.14(1)$ & 0.00014 & 0.01 \\
\hline $\mathrm{ZnCo}_{1.6} \mathrm{Ni}_{0.4} \mathrm{O}_{4}$ & $1.004 \%$ & $8.149(5)$ & 0.068 & -0.02 \\
\hline $\mathrm{ZnCo}_{1.4} \mathrm{Ni}_{0.6} \mathrm{O}_{4}$ & $1.1 \%$ & $8.165(5)$ & 0.0029 & -0.006 \\
\hline $\mathrm{ZnCo}_{1.2} \mathrm{Ni}_{0.8} \mathrm{O}_{4}$ & $1.2 \%$ & $8.180(7)$ & 0.0075 & -0.01 \\
\hline
\end{tabular}



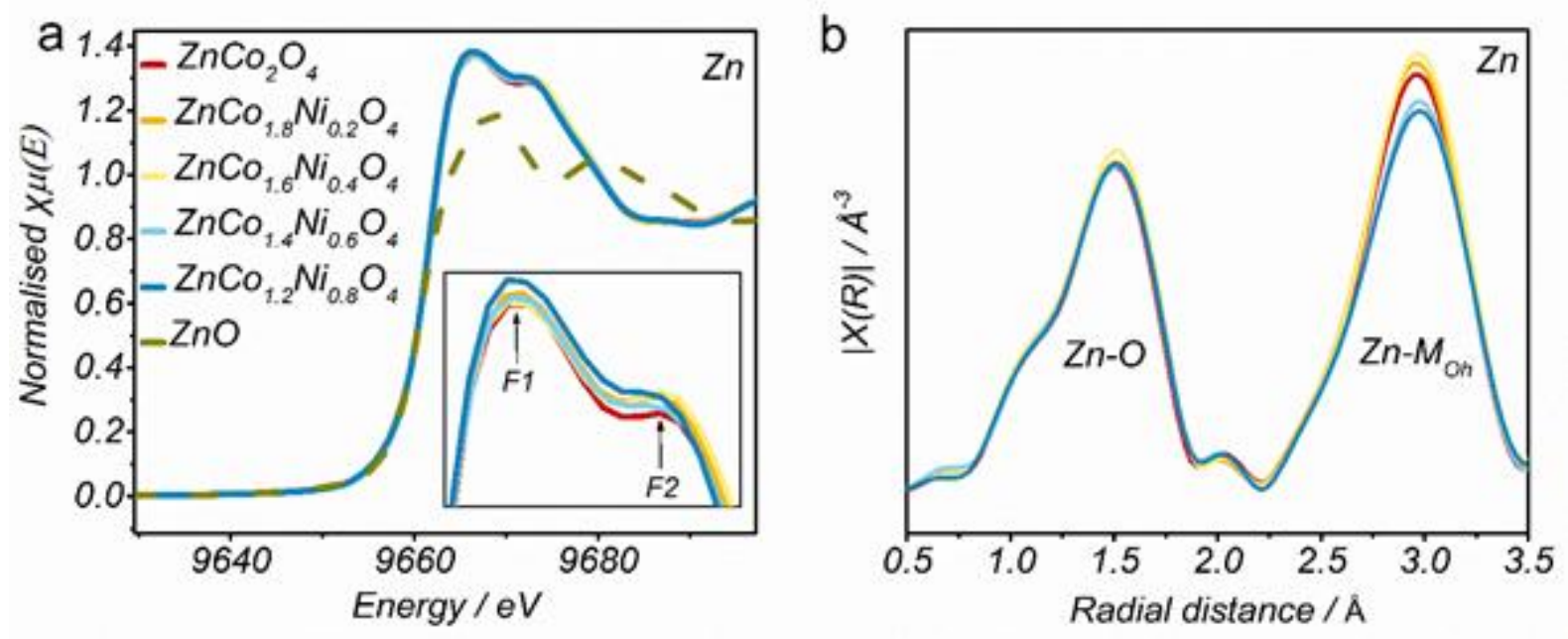

Figure S7 | (a) Normalized Zn K-edge XANES spectra of $\mathrm{ZnCo}_{2-\mathrm{x}} \mathrm{Ni}_{\mathrm{x}} \mathrm{O}_{4}(\mathrm{x}=0.0,0.2,0.4,0.6$, $0.8,1.2,1.6,2.0)$. The inset shows the white lines of $\mathrm{ZnCo}_{2-\mathrm{x}} \mathrm{Ni}_{\mathrm{x}} \mathrm{O}_{4}(\mathrm{x}=0.0,0.2,0.4,0.6,0.8)$ oxides. An increase in the intensity of F1 and decrease in F2 indicates the decreased degree of disorder in spinel structure. (b) FT-EXAFS $\mathrm{k}^{3} \chi(\mathrm{R})$ spectra of $\mathrm{ZnCo}_{2-\mathrm{x}} \mathrm{Ni}_{\mathrm{x}} \mathrm{O}_{4}(\mathrm{x}=0,0.2,0.4$, $0.6,0.8)$ at $\mathrm{Zn} \mathrm{K}$ edge. 
Table S2 Summary of the EXAFs fitting results for $\mathrm{Ni} \mathrm{K}$ edge for $\mathrm{ZnCo}_{2-\mathrm{x}} \mathrm{Ni}_{\mathrm{x}} \mathrm{O}_{4}(\mathrm{x}=0,0.2$, $0.4,0.6,0.8)$. Bond length $\left(\mathrm{Ni}-\mathrm{O}_{6}\right.$ and $\left.\mathrm{Ni}-\mathrm{O}_{4}\right)$ and Coordination number $(\mathrm{N})$ obtained by fitting the experimental EXAFS spectra.

\begin{tabular}{|l|l|l|l|l|}
\hline Sample & Bond & $\mathrm{N}$ & $\mathrm{R}(\AA)$ & $\sigma^{2}\left(\AA^{2}\right)$ \\
\hline $\mathrm{ZnCo}_{1.8} \mathrm{Ni}_{0.2} \mathrm{O}_{4}$ & $\mathrm{Ni}-\mathrm{O}_{6}$ & $6.0( \pm 0.1)$ & $1.960( \pm 0.001)$ & $0.003( \pm 0.002)$ \\
\hline $\mathrm{ZnCo}_{1.6} \mathrm{Ni}_{0.4} \mathrm{O}_{4}$ & $\mathrm{Ni}-\mathrm{O}_{6}$ & $6.0( \pm 0.1)$ & $1.962( \pm 0.001)$ & $0.005( \pm 0.001)$ \\
\hline $\mathrm{ZnCo}_{1.4} \mathrm{Ni}_{0.6} \mathrm{O}_{4}$ & $\mathrm{Ni}-\mathrm{O}_{6}$ & $6.0( \pm 0.1)$ & $1.964( \pm 0.002)$ & $0.006( \pm 0.001)$ \\
\hline $\mathrm{ZnCo}_{1.2} \mathrm{Ni}_{0.8} \mathrm{O}_{4}$ & $\mathrm{Ni} \mathrm{O}_{6}$ & $6.0( \pm 0.1)$ & $1.966( \pm 0.002)$ & $0.006( \pm 0.002)$ \\
\hline
\end{tabular}

Table S3 $\mid$ Summary of the EXAFs fitting results for Co edge of $\mathrm{ZnCo}_{2-\mathrm{x}} \mathrm{Ni}_{\mathrm{x}} \mathrm{O}_{4}(\mathrm{x}=0,0.2,0.4$, 0.6, 0.8). Bond length $\left(\mathrm{Co}-\mathrm{O}_{6}\right.$ and $\left.\mathrm{Co}-\mathrm{O}_{4}\right)$ and Coordination number $(\mathrm{N})$ obtained by fitting the experimental EXAFS spectra.

\begin{tabular}{|l|l|l|l|l|}
\hline Sample & Bond & $\mathrm{N}$ & $\mathrm{R}(\AA)$ & $\sigma^{2}\left(\AA^{2}\right)$ \\
\hline $\mathrm{ZnCo}_{2} \mathrm{O}_{4}$ & $\mathrm{Co}-\mathrm{O}_{6}$ & $6.0( \pm 0.1)$ & $1.911( \pm 0.001)$ & $0.004( \pm 0.0009)$ \\
\hline $\mathrm{ZnCo}_{1.8} \mathrm{Ni}_{0.2} \mathrm{O}_{4}$ & $\mathrm{Co}-\mathrm{O}_{6}$ & $6.0( \pm 0.1)$ & $1.912( \pm 0.001)$ & $0.003( \pm 0.0009)$ \\
\hline $\mathrm{ZnCo}_{1.6} \mathrm{Ni}_{0.4} \mathrm{O}_{4}$ & $\mathrm{Co}-\mathrm{O}_{6}$ & $6.0( \pm 0.1)$ & $1.914( \pm 0.001)$ & $0.003( \pm 0.0009)$ \\
\hline $\mathrm{ZnCo}_{1.4} \mathrm{Ni}_{0.6} \mathrm{O}_{4}$ & $\mathrm{Co}-\mathrm{O}_{6}$ & $6.0( \pm 0.1)$ & $1.914( \pm 0.001)$ & $0.003( \pm 0.0008)$ \\
\hline $\mathrm{ZnCo}_{1.2} \mathrm{Ni}_{0.8} \mathrm{O}_{4}$ & $\mathrm{Co}-\mathrm{O}_{6}$ & $6.0( \pm 0.1)$ & $1.915( \pm 0.001)$ & $0.003( \pm 0.0009)$ \\
\hline
\end{tabular}


Table S4 | EXAFS fitting results of $\mathrm{M}-\mathrm{M}$ interaction for $\mathrm{ZnCo}_{2-\mathrm{x}} \mathrm{Ni}_{\mathrm{x}} \mathrm{O}_{4}(\mathrm{x}=0,0.2,0.4,0.6$, $0.8)$.

$\mathrm{x}=0$

\begin{tabular}{|c|c|c|c|c|c|}
\hline \multicolumn{3}{|c|}{ Ni K edge } & \multicolumn{3}{|c|}{ Co K edge } \\
\hline Path & $\mathrm{R}(\AA)$ & $\sigma^{2}\left(\AA^{2}\right)$ & Path & $\mathrm{R}(\AA)$ & $\sigma^{2}\left(\AA^{2}\right)$ \\
\hline \multicolumn{3}{|c|}{ Octahedral site } & \multicolumn{3}{|c|}{ Octahedral site } \\
\hline $\mathrm{Ni}_{\mathrm{Oh}}-\mathrm{M}_{\mathrm{Oh}}$ & - & - & $\mathrm{Co}_{\mathrm{Oh}}-\mathrm{M}_{\mathrm{Oh}}$ & 2.866 & 0.005 \\
\hline $\mathrm{Ni}_{\mathrm{Oh}}-\mathrm{M}_{\mathrm{Td}}$ & - & - & $\mathrm{Co}_{\mathrm{Oh}}-\mathrm{M}_{\mathrm{Td}}$ & 3.360 & 0.005 \\
\hline \multicolumn{3}{|c|}{ Tetrahedral site } & \multicolumn{3}{|c|}{ Tetrahedral site } \\
\hline $\mathrm{Ni}_{\mathrm{Td}}-\mathrm{M}_{\mathrm{Oh}}$ & - & - & $\mathrm{Co}_{\mathrm{Td}}-\mathrm{M}_{\mathrm{Oh}}$ & 3.360 & 0.005 \\
\hline $\mathrm{Ni}_{\mathrm{Td}}-\mathrm{M}_{\mathrm{Td}}$ & - & - & $\mathrm{Co}_{\mathrm{Td}}-\mathrm{M}_{\mathrm{Td}}$ & 3.509 & 0.005 \\
\hline
\end{tabular}

$\mathrm{x}=0.2$

\begin{tabular}{|l|c|c|c|c|c|}
\hline \multicolumn{3}{|c|}{ Ni K edge } & \multicolumn{3}{c|}{ Co K edge } \\
\hline Path & $\mathrm{R}(\AA)$ & $\sigma^{2}\left(\AA^{2}\right)$ & Path & $\mathrm{R}(\AA)$ & $\sigma^{2}\left(\AA^{2}\right)$ \\
\hline \multicolumn{3}{|c|}{ Octahedral site } & \multicolumn{3}{c|}{ Octahedral site } \\
\hline $\mathrm{Ni}_{\mathrm{Oh}}-\mathrm{M}_{\mathrm{Oh}}$ & 2.873 & 0.006 & $\mathrm{Co}_{\mathrm{Oh}}-\mathrm{M}_{\mathrm{Oh}}$ & 2.870 & 0.005 \\
\hline $\mathrm{Ni}_{\mathrm{Oh}}-\mathrm{M}_{\mathrm{Td}}$ & 3.361 & 0.006 & $\mathrm{Co}_{\mathrm{Oh}}-\mathrm{M}_{\mathrm{Td}}$ & 3.381 & 0.005 \\
\hline \multicolumn{3}{|c|}{ Tetrahedral site } & & Tetrahedral site \\
\hline $\mathrm{Ni}_{\mathrm{Td}}-\mathrm{M}_{\mathrm{Oh}}$ & 3.361 & 0.006 & $\mathrm{Co}_{\mathrm{Td}}-\mathrm{M}_{\mathrm{Oh}}$ & 3.381 & 0.005 \\
\hline $\mathrm{Ni}_{\mathrm{Td}}-\mathrm{M}_{\mathrm{Td}}$ & 3.510 & 0.006 & $\mathrm{Co}_{\mathrm{Td}}-\mathrm{M}_{\mathrm{Td}}$ & 3.530 & 0.005 \\
\hline
\end{tabular}

$\mathrm{x}=0.4$

\begin{tabular}{|l|c|c|c|c|c|}
\hline \multicolumn{3}{|c|}{ Ni K edge } & \multicolumn{3}{c|}{ Co K edge } \\
\hline Path & $\mathrm{R}(\AA)$ & $\sigma^{2}\left(\AA^{2}\right)$ & Path & $\mathrm{R}(\AA)$ & $\sigma^{2}\left(\AA^{2}\right)$ \\
\hline \multicolumn{3}{|c|}{ Octahedral site } & \multicolumn{3}{c|}{ Octahedral site } \\
\hline $\mathrm{Ni}_{\mathrm{Oh}}-\mathrm{M}_{\mathrm{Oh}}$ & 2.875 & 0.006 & $\mathrm{Co}_{\mathrm{Oh}}-\mathrm{M}_{\mathrm{Oh}}$ & 2.871 & 0.005 \\
\hline $\mathrm{Ni}_{\mathrm{Oh}}-\mathrm{M}_{\mathrm{Td}}$ & 3.366 & 0.006 & $\mathrm{Co}_{\mathrm{Oh}}-\mathrm{M}_{\mathrm{Td}}$ & 3.384 & 0.005 \\
\hline \multicolumn{3}{|c|}{ Tetrahedral site } & & Tetrahedral site \\
\hline $\mathrm{Ni}_{\mathrm{Td}}-\mathrm{M}_{\mathrm{Oh}}$ & 3.366 & 0.006 & $\mathrm{Co}_{\mathrm{Td}}-\mathrm{M}_{\mathrm{Oh}}$ & 3.384 & 0.005 \\
\hline $\mathrm{Ni}_{\mathrm{Td}}-\mathrm{M}_{\mathrm{Td}}$ & 3.516 & 0.006 & $\mathrm{Co}_{\mathrm{Td}}-\mathrm{M}_{\mathrm{Td}}$ & 3.533 & 0.005 \\
\hline
\end{tabular}

$\mathrm{x}=0.6$

\begin{tabular}{|l|c|c|c|c|c|}
\hline \multicolumn{3}{|c|}{ Ni K edge } & \multicolumn{3}{c|}{ Co K edge } \\
\hline Path & $\mathrm{R}(\AA)$ & $\sigma^{2}\left(\AA^{2}\right)$ & Path & $\mathrm{R}(\AA)$ & $\sigma^{2}\left(\AA^{2}\right)$ \\
\hline \multicolumn{3}{|c|}{ Octahedral site } & \multicolumn{3}{c|}{ Octahedral site } \\
\hline $\mathrm{Ni}_{\mathrm{Oh}}-\mathrm{M}_{\mathrm{Oh}}$ & 2.888 & 0.006 & $\mathrm{Co}_{\mathrm{Oh}}-\mathrm{M}_{\mathrm{Oh}}$ & 2.874 & 0.008 \\
\hline $\mathrm{Ni}_{\mathrm{Oh}}-\mathrm{M}_{\mathrm{Td}}$ & 3.381 & 0.006 & $\mathrm{Co}_{\mathrm{Oh}}-\mathrm{M}_{\mathrm{Td}}$ & 3.386 & 0.026 \\
\hline \multicolumn{3}{|c|}{ Tetrahedral site } & & Tetrahedral site \\
\hline $\mathrm{Ni}_{\mathrm{Td}}-\mathrm{M}_{\mathrm{Oh}}$ & 3.381 & 0.006 & $\mathrm{Co}_{\mathrm{Td}}-\mathrm{M}_{\mathrm{Oh}}$ & 3.386 & 0.026 \\
\hline $\mathrm{Ni}_{\mathrm{Td}}-\mathrm{M}_{\mathrm{Td}}$ & 3.531 & 0.006 & $\mathrm{Co}_{\mathrm{Td}}-\mathrm{M}_{\mathrm{Td}}$ & 3.535 & 0.026 \\
\hline
\end{tabular}


$\mathrm{x}=0.8$

\begin{tabular}{|l|c|c|c|c|c|}
\hline \multicolumn{3}{|c|}{ Ni K edge } & \multicolumn{3}{c|}{ Co K edge } \\
\hline Path & $\mathrm{R}(\AA)$ & $\sigma^{2}\left(\AA^{2}\right)$ & Path & $\mathrm{R}(\AA)$ & $\sigma^{2}\left(\AA^{2}\right)$ \\
\hline \multicolumn{3}{|c|}{ Octahedral site } & \multicolumn{3}{c|}{ Octahedral site } \\
\hline $\mathrm{Ni}_{\mathrm{Oh}}-\mathrm{M}_{\mathrm{Oh}}$ & 2.888 & 0.006 & $\mathrm{Co}_{\mathrm{Oh}}-\mathrm{M}_{\mathrm{Oh}}$ & 2.876 & 0.010 \\
\hline $\mathrm{Ni}_{\mathrm{Oh}}-\mathrm{M}_{\mathrm{Td}}$ & 3.360 & 0.006 & $\mathrm{Co}_{\mathrm{Oh}}-\mathrm{M}_{\mathrm{Td}}$ & 3.388 & 0.027 \\
\hline \multicolumn{3}{|c|}{ Tetrahedral site } & & \multicolumn{3}{c|}{ Tetrahedral site } \\
\hline $\mathrm{Ni}_{\mathrm{Td}}-\mathrm{M}_{\mathrm{Oh}}$ & 3.360 & 0.006 & $\mathrm{Co}_{\mathrm{Td}}-\mathrm{M}_{\mathrm{Oh}}$ & 3.388 & 0.027 \\
\hline $\mathrm{Ni}_{\mathrm{Td}}-\mathrm{M}_{\mathrm{Td}}$ & 3.509 & 0.006 & $\mathrm{Co}_{\mathrm{Td}}-\mathrm{M}_{\mathrm{Td}}$ & 3.537 & 0.027 \\
\hline
\end{tabular}

Table S5 $\mid$ Summary of the EXAFs fitting results for $\mathrm{Zn}$ edge for $\mathrm{ZnCo}_{2-\mathrm{x}} \mathrm{Ni}_{\mathrm{x}} \mathrm{O}_{4}(\mathrm{x}=0,0.2,0.4$, 0.6, 0.8). Bond length $(\mathrm{Zn}-\mathrm{O})$ and Coordination number $(\mathrm{N})$ obtained by fitting the experimental EXAFS spectra.

\begin{tabular}{|l|l|l|l|l|}
\hline Sample & Bond & $\mathrm{N}$ & $\mathrm{R}(\AA)$ & $\sigma^{2}\left(\AA^{2}\right)$ \\
\hline $\mathrm{ZnCo}_{2} \mathrm{O}_{4}$ & $\mathrm{Zn}_{\mathrm{Td}} \mathrm{O}$ & $4.0( \pm 0.1)$ & $1.958( \pm 0.001)$ & $0.005( \pm 0.002)$ \\
\hline $\mathrm{ZnCo}_{1.8} \mathrm{Ni}_{0.2} \mathrm{O}_{4}$ & $\mathrm{Zn}_{\mathrm{Td}} \mathrm{O}$ & $4.0( \pm 0.1)$ & $1.964( \pm 0.002)$ & $0.006( \pm 0.002)$ \\
\hline $\mathrm{ZnCo}_{1.6} \mathrm{Ni}_{0.4} \mathrm{O}_{4}$ & $\mathrm{Zn}_{\mathrm{Td}} \mathrm{O}$ & $4.0( \pm 0.1)$ & $1.966( \pm 0.002)$ & $0.006( \pm 0.001)$ \\
\hline $\mathrm{ZnCo}_{1.4} \mathrm{Ni}_{0.6} \mathrm{O}_{4}$ & $\mathrm{Zn}_{\mathrm{Td}}-\mathrm{O}$ & $6.0( \pm 0.1)$ & $1.969( \pm 0.002)$ & $0.006( \pm 0.001)$ \\
\hline $\mathrm{ZnCo}_{1.2} \mathrm{Ni}_{0.8} \mathrm{O}_{4}$ & $\mathrm{Zn}_{\mathrm{Td}}-\mathrm{O}$ & $6.0( \pm 0.1)$ & $1.971( \pm 0.002)$ & $0.006( \pm 0.002)$ \\
\hline
\end{tabular}




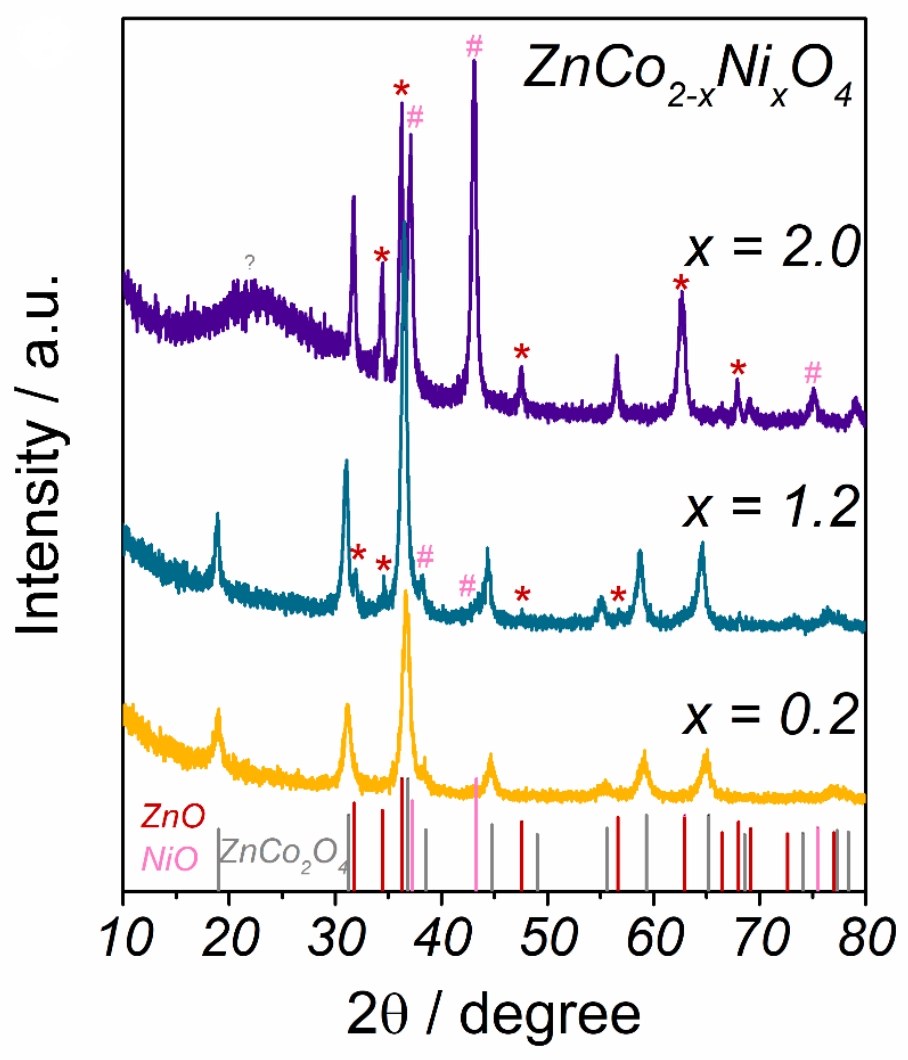

Figure S8 | XRD patterns of $\mathrm{ZnCo}_{2} \mathrm{O}_{4}, \mathrm{ZnCo}_{0.8} \mathrm{Ni}_{1.2} \mathrm{O}_{4}$ and $\mathrm{ZnNi}_{2} \mathrm{O}_{4}$. Peaks denoted by '*' correspond to $\mathrm{ZnO}$ wurtzite structure and peaks indicated with "\#, refers to $\mathrm{NiO}$ rock-salt structure. 


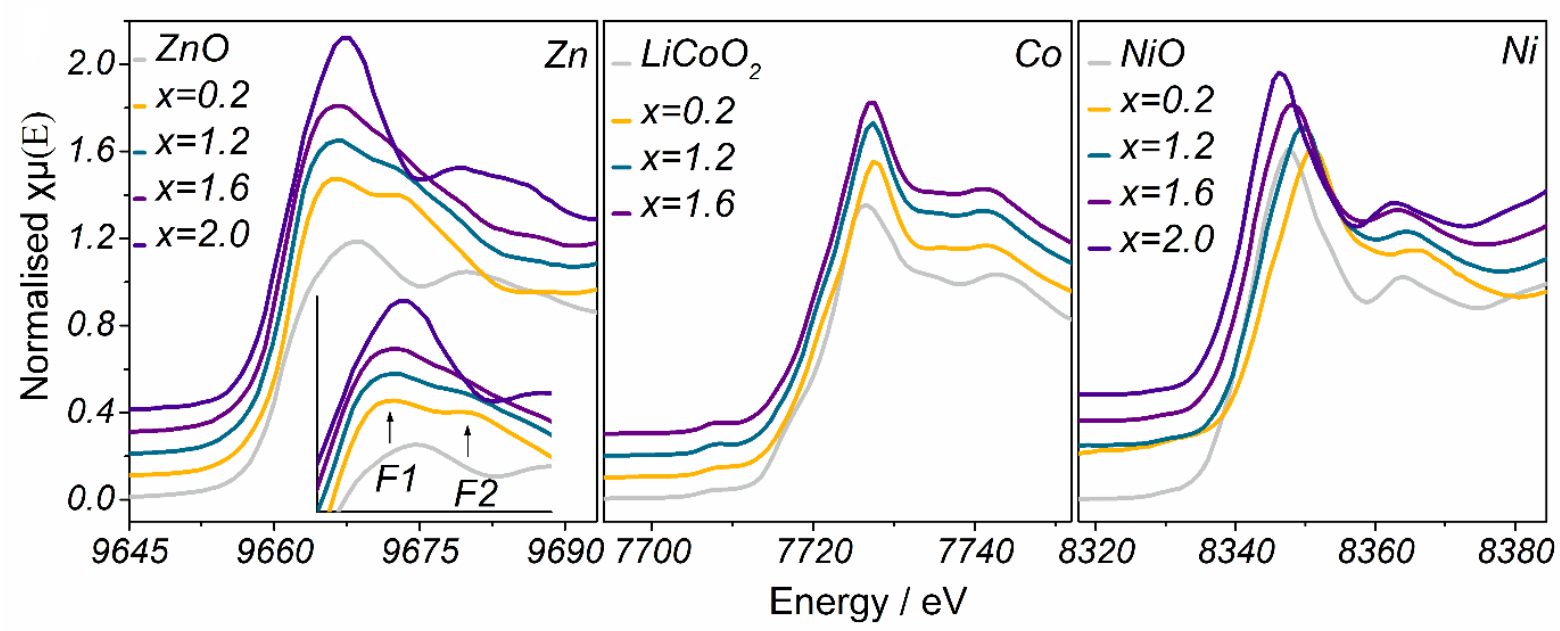

Figure S9 | Normalized Zn K-edge XANES spectra of $\mathrm{ZnCo}_{2-\mathrm{x}} \mathrm{Ni}_{\mathrm{x}} \mathrm{O}_{4}(\mathrm{x}=0.0,0.2,0.4,0.6,0.8$, $1.2,1.6,2.0)$ (left panel). The inset shows the white lines of $\mathrm{ZnCo}_{2-\mathrm{x}} \mathrm{Ni}_{\mathrm{x}} \mathrm{O}_{4}(\mathrm{x}=0.0,0.2,0.4$, $0.6,0.8)$ oxides. An increase in the intensity of F1 and decrease in F2 indicates the increased degree of disorder in spinel structure. Normalized Co K-edge XANES spectra of $\mathrm{ZnCo}_{2}$ ${ }_{x} \mathrm{Ni}_{\mathrm{x}} \mathrm{O}_{4}(\mathrm{x}=0.0,0.2,0.4,0.6,0.8,1.2,1.6)$ (middle panel). Normalized Ni K-edge XANES spectra of $\mathrm{ZnCo}_{2-\mathrm{x}} \mathrm{Ni}_{\mathrm{x}} \mathrm{O}_{4}(\mathrm{x}=0.2,0.4,0.6,0.8,1.2,1.6,2.0)$ (right panel). 


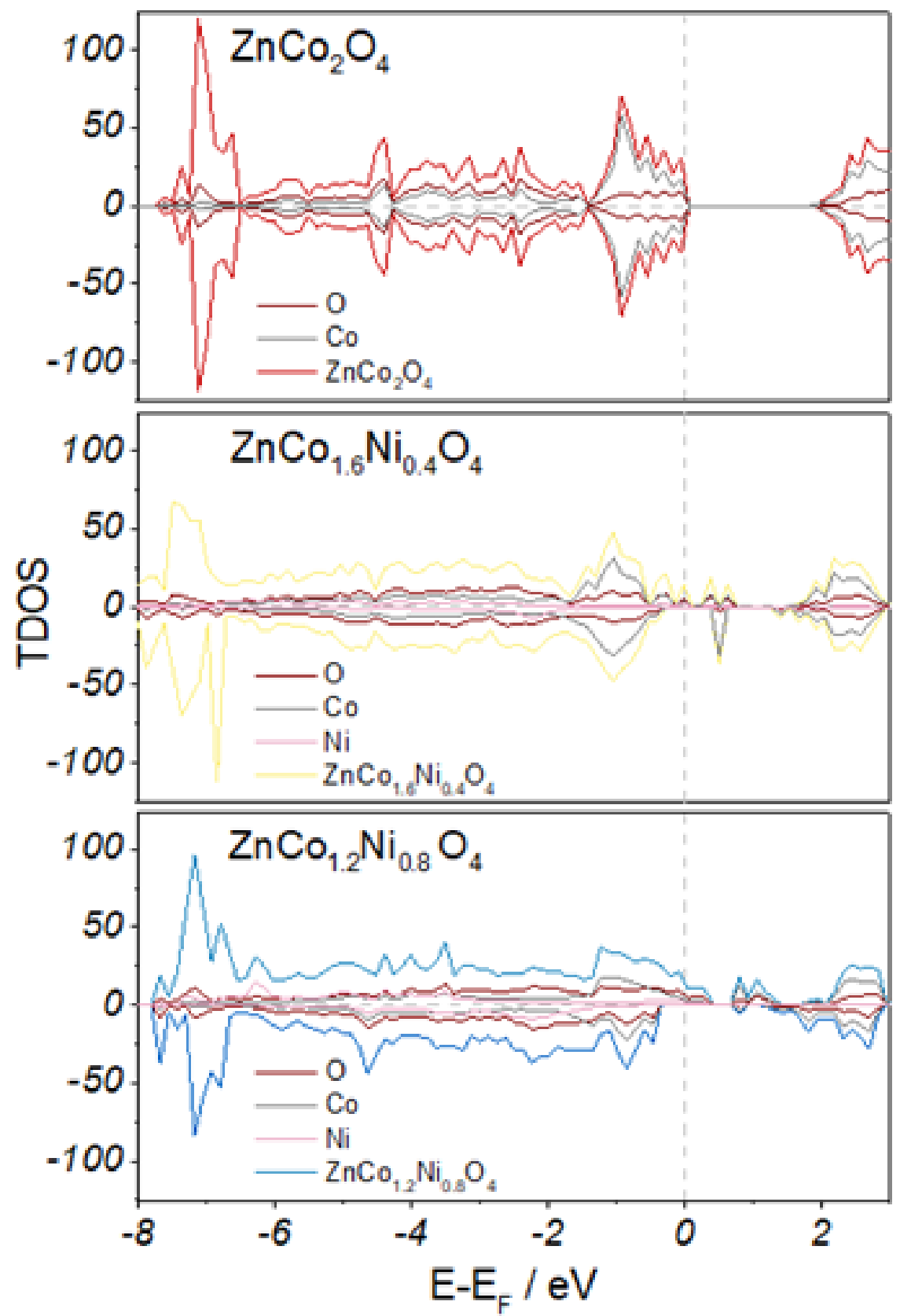

Figure S10 | Electronic density of states (DOS) of $\mathrm{ZnCo}_{2} \mathrm{O}_{4}$ (top panel), $\mathrm{ZnCo}_{1.6} \mathrm{Ni}_{0.4} \mathrm{O}_{4}$ (middle panel) and $\mathrm{ZnCo}_{1.2} \mathrm{Ni}_{0.8} \mathrm{O}_{4}$ (bottom panel). 


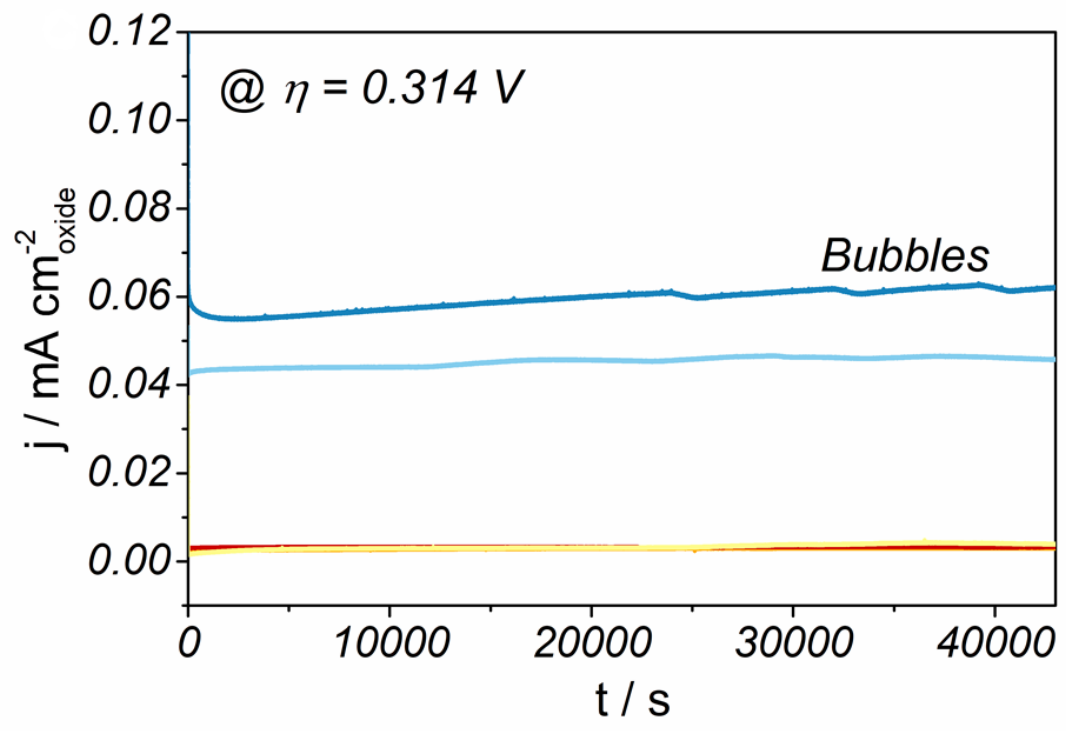

Figure S11 | Chronoamperometry of $\mathrm{ZnCo}_{2-\mathrm{x}} \mathrm{Ni}_{\mathrm{x}} \mathrm{O}_{4}(\mathrm{x}=0.0,0.2,0.4,0.6,0.8)$ after $100^{\text {th }} \mathrm{CV}$ at an overpotential of $0.314 \mathrm{~V}$ (vs. RHE). 

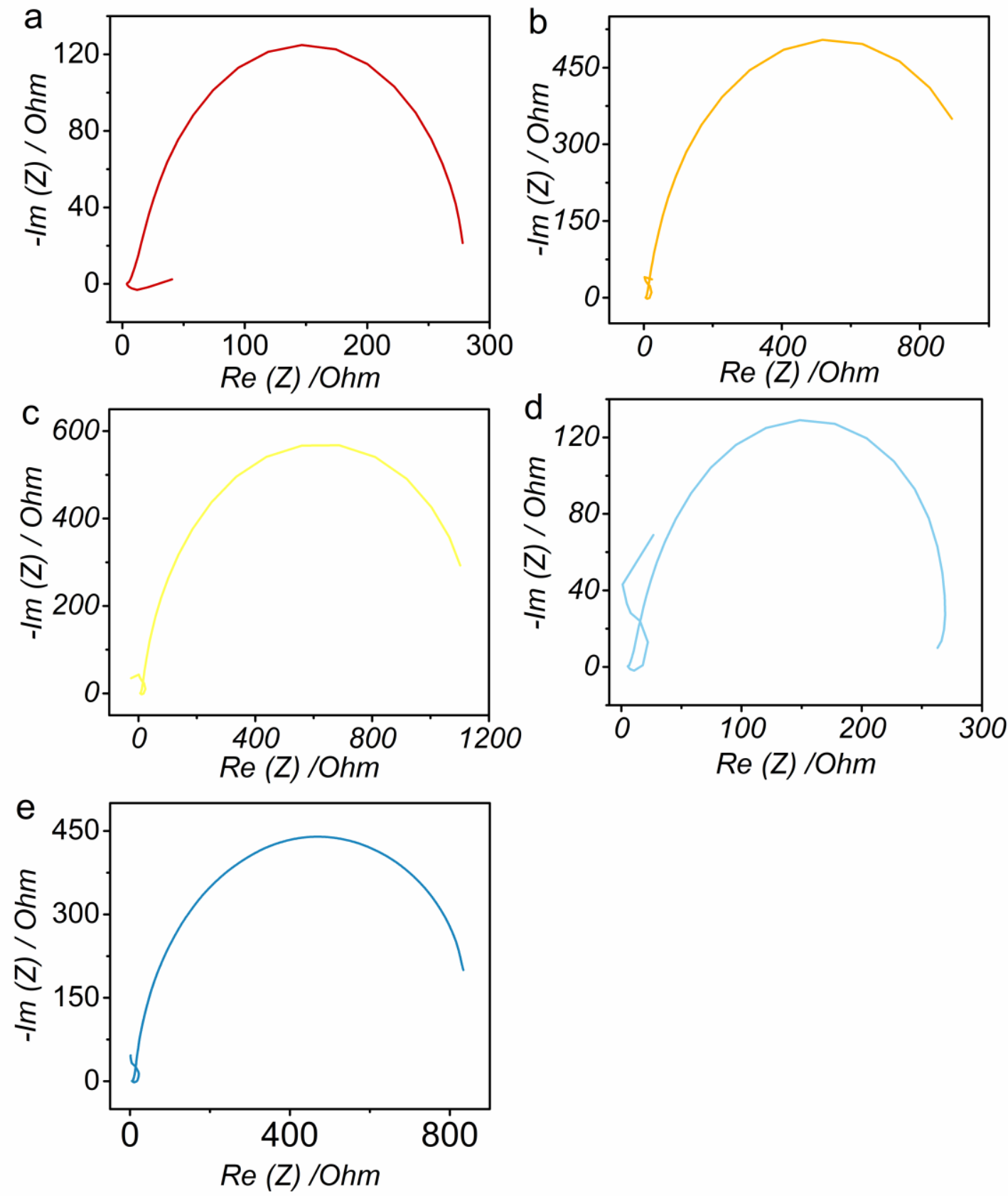

Figure S12 | Impedance curve of $\mathrm{ZnCo}_{2-\mathrm{x}} \mathrm{Ni}_{\mathrm{x}} \mathrm{O}_{4}(\mathrm{x}=0-0.8)$. 

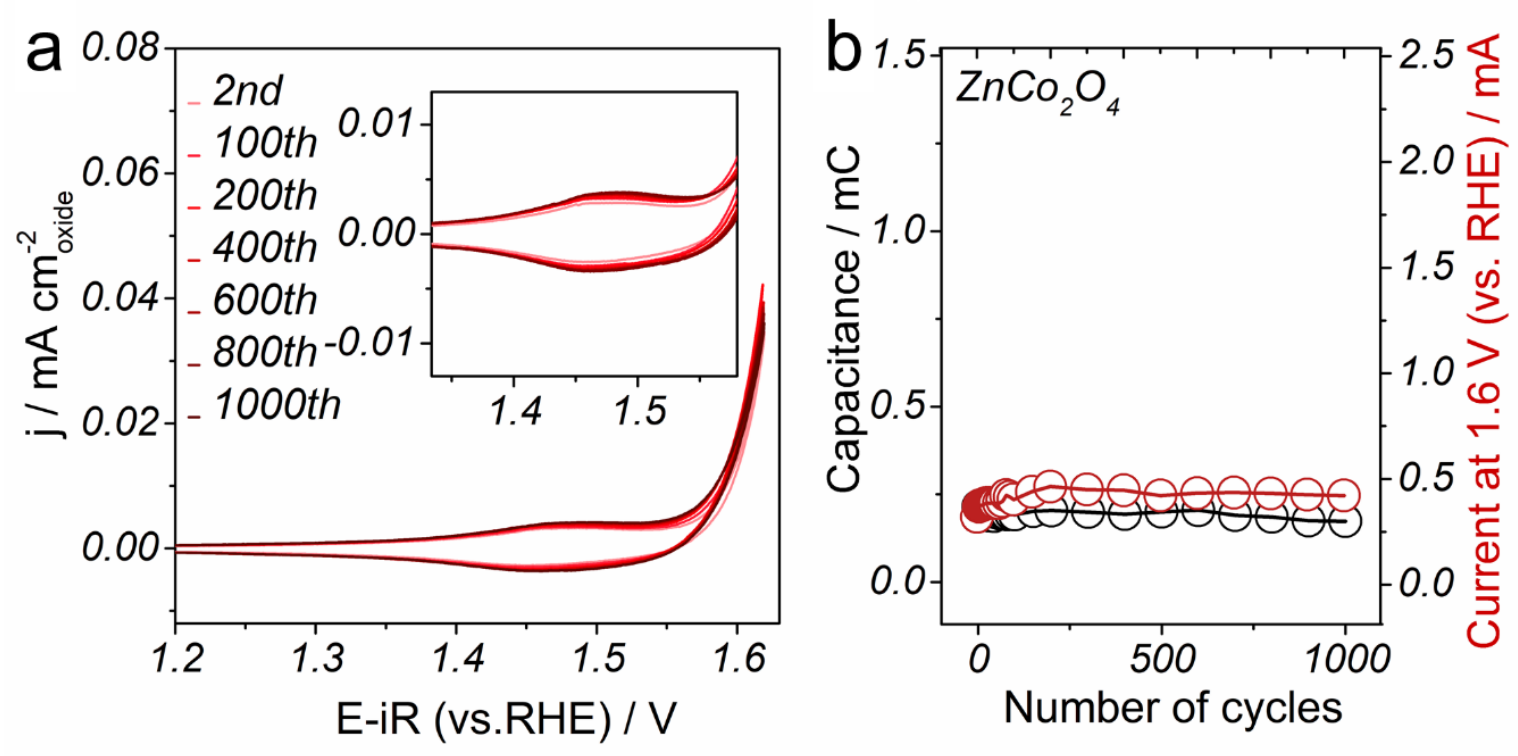

Figure S13 | a) Evolutive CV curves for representative $\mathrm{ZnCo}_{2} \mathrm{O}_{4}$ from $2^{\text {nd }}$ to $1000^{\text {th }}$ cycle in $1 \mathrm{M} \mathrm{KOH}$ at $10 \mathrm{mV} \mathrm{s}^{-1}$ in between 0.904 and $1.624 \mathrm{~V}$ (vs. RHE). The insets show the redox peaks from $1.33 \mathrm{~V}$ to $1.59 \mathrm{~V}$. b) Evolution of the pseudocapacitive charge during cycling (0.904-1.624 V versus RHE) in 1M KOH (left axis) and the OER activity at $1.6 \mathrm{~V}$ versus RHE (right axis) for $\mathrm{ZnCo}_{2} \mathrm{O}_{4}$.
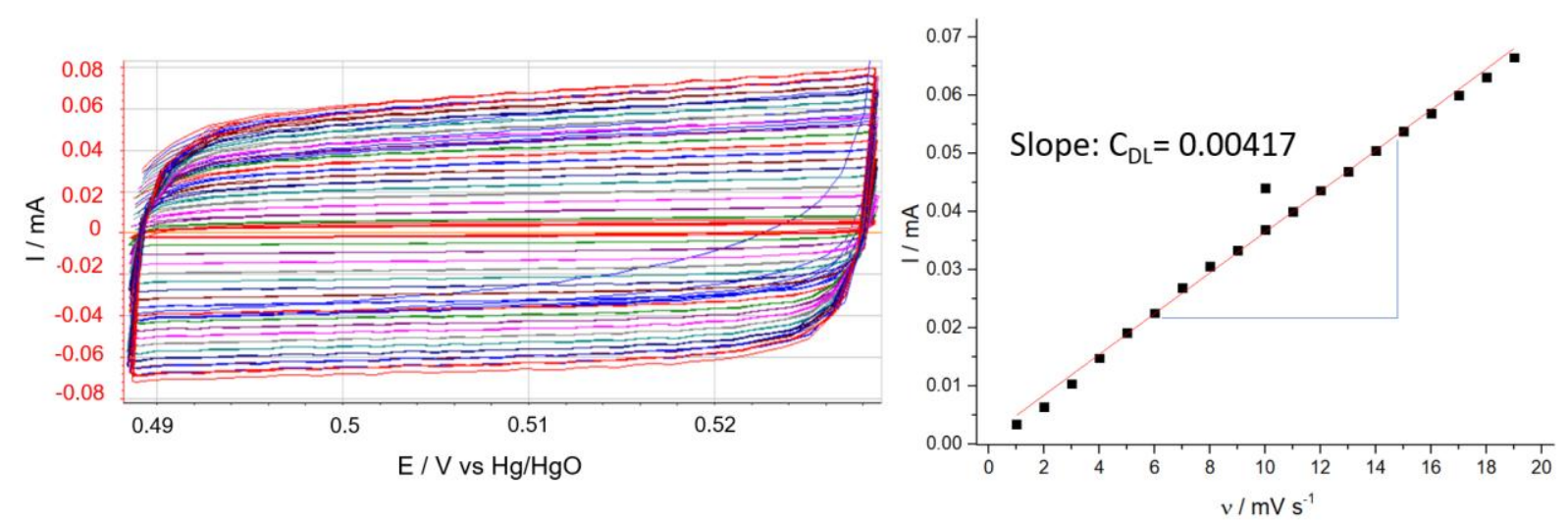

Figure S14 | a) Electrochemical double layer of $\mathrm{ZnCo}_{1.2} \mathrm{Ni}_{0.8} \mathrm{O}_{4}$ under different scan rates. b) Current versus scan rate for $\mathrm{ZnCo}_{1.2} \mathrm{Ni}_{0.8} \mathrm{O}_{4}$. 
Caculation on electrochemical surface area of $\mathrm{ZnCo}_{1.2} \mathrm{Ni}_{0.8} \mathrm{O}_{4}$ :

$\mathrm{ECSA}=\mathrm{C}_{\mathrm{DL}} / \mathrm{C}_{\mathrm{S}}$

$\mathrm{C}_{\mathrm{DL}}=\mathrm{i}_{\mathrm{DL}} / v=0.00417 \mathrm{~F}$

$\mathrm{C}_{\mathrm{S}}=60 \mu \mathrm{F} \mathrm{cm}^{-2}$

$\mathrm{ECSA}=\mathrm{C}_{\mathrm{DL}} / \mathrm{C}_{\mathrm{S}}=0.00417 /\left(60 * 10^{-6}\right)=69.5 \mathrm{~cm}^{-2}$

$\mathrm{m}=50 \mu \mathrm{g}$

$69.5 \mathrm{~cm}^{2} / 50 \mu \mathrm{g}=139 \mathrm{~m}^{2} / \mathrm{g}$
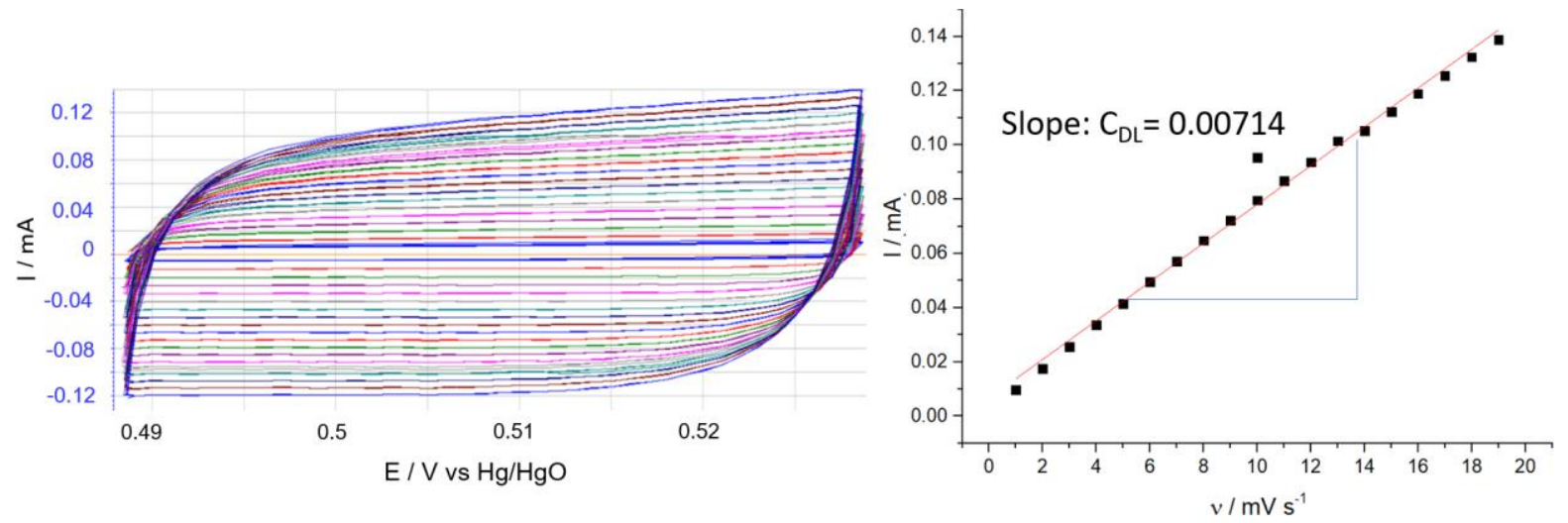

Figure S15 | a) Electrochemical double layer of cycled $\mathrm{ZnCo}_{1.2} \mathrm{Ni}_{0.8} \mathrm{O}_{4}$ under different scan rates. b) Current versus scan rate for cycled $\mathrm{ZnCo}_{1.2} \mathrm{Ni}_{0.8} \mathrm{O}_{4}$.

Caculation on electrochemical surface area of $\mathrm{ZnCo}_{1.2} \mathrm{Ni}_{0.8} \mathrm{O}_{4}$ after $1000^{\text {th }}$ cycle:

$$
\begin{aligned}
& \mathrm{ECSA}=\mathrm{C}_{\mathrm{DL}} / \mathrm{C}_{\mathrm{S}} \\
& \mathrm{C}_{\mathrm{DL}}=\mathrm{i}_{\mathrm{DL}} / v=0.00741 \mathrm{~F} \\
& \mathrm{C}_{\mathrm{S}}=60 \mu \mathrm{F} \mathrm{cm}^{-2}
\end{aligned}
$$


$\mathrm{ECSA}=\mathrm{C}_{\mathrm{DL}} / \mathrm{C}_{\mathrm{S}}=0.00741 /\left(60 * 10^{-6}\right)=123.5 \mathrm{~cm}^{-2}$

$\mathrm{m}=50 \mu \mathrm{g}$

$69.5 \mathrm{~cm}^{2} / 50 \mu \mathrm{g}=247 \mathrm{~m}^{2} / \mathrm{g}$

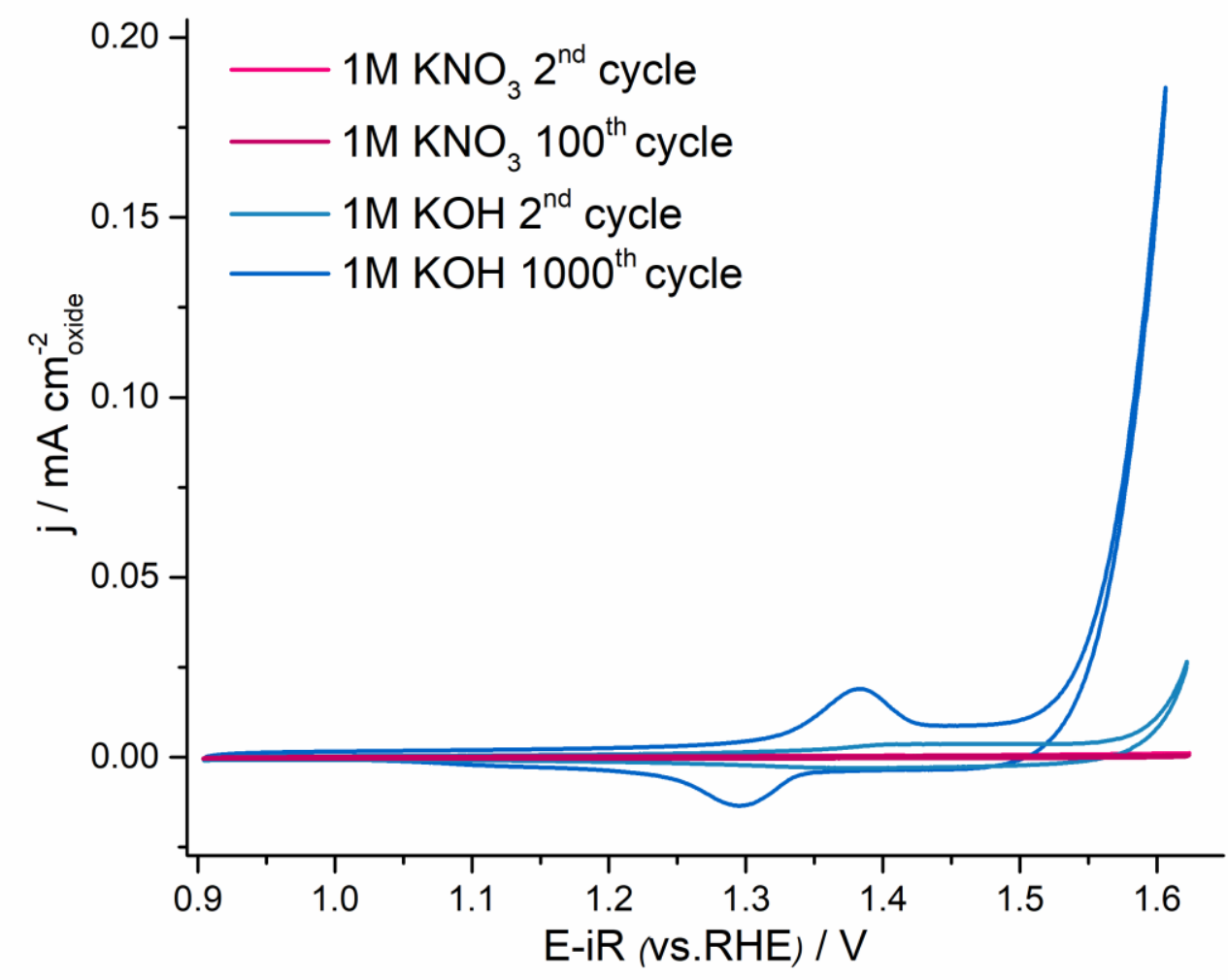

Figure S16 $\mid \mathrm{CV}$ curves of the $2^{\text {nd }}$ cycle and the $100^{\text {th }}$ cycle of $\mathrm{ZnCo}_{1.2} \mathrm{Ni}_{0.8} \mathrm{O}_{4}$ in $1 \mathrm{M} \mathrm{KNO}$ with $\mathrm{pH}=7 . \mathrm{CV}$ curves of the $2^{\text {nd }}$ cycle and the $1000^{\text {th }}$ cycle of $\mathrm{ZnCo}_{1.2} \mathrm{Ni}_{0.8} \mathrm{O}_{4}$ in $1 \mathrm{M} \mathrm{KOH}$ with $\mathrm{pH}=14$.

The activity of $\mathrm{ZnCo}_{1.2} \mathrm{Ni}_{0.8} \mathrm{O}_{4}$ is very low in neutral electrolyte and there is no improvement of activity along cycles. The other samples $\mathrm{ZnCo}_{2-\mathrm{x}} \mathrm{Ni}_{\mathrm{x}} \mathrm{O}_{4}(\mathrm{x}=0.0-0.6)$ would have low activity and no improvement along cycles as well. It shows that it is important to active our material $\mathrm{ZnCo}_{2-\mathrm{x}} \mathrm{Ni}_{\mathrm{x}} \mathrm{O}_{4}(\mathrm{x}=0.6-0.8)$ in alkaline medium, so that there is enough $\mathrm{OH}^{-}$to form active oxyhydroxide. Along cycles, there will be continuously improved OER activity. 

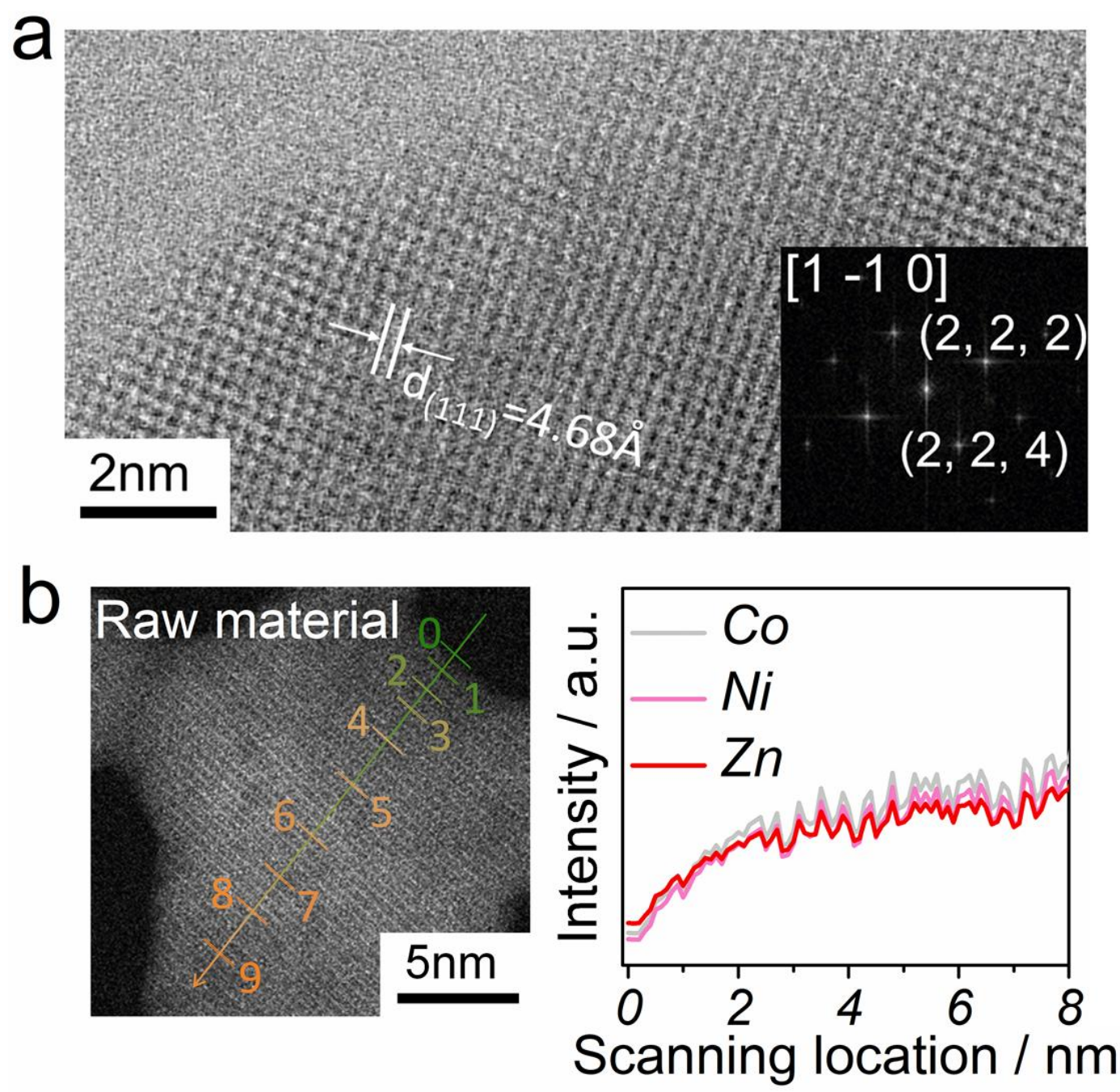

Figure S17 | (a) ABF images of $\mathrm{ZnCo}_{1.2} \mathrm{Ni}_{0.8} \mathrm{O}_{4}$ before OER. The inset at the bottom right is the FFT pattern which can be referred to $\mathrm{Fd} 3 \mathrm{~m}$ space group. For the pristine material $\mathrm{ZnCo}_{1.2} \mathrm{Ni}_{0.8} \mathrm{O}_{4}$, in the High-resolution transmission electron microscopy (HRTEM), the sample shows the characteristic spacing of $0.468 \mathrm{~nm}$ for the (111) lattice plane of spinel. The selected area electron diffraction (SAED) patterns for the pristine material (inset) can be indexed to (222) and (112) planes. (b) STEM-EDS image and analysis of pristine $\mathrm{ZnCo}_{1.2} \mathrm{Ni}_{0.8} \mathrm{O}_{4}$. 

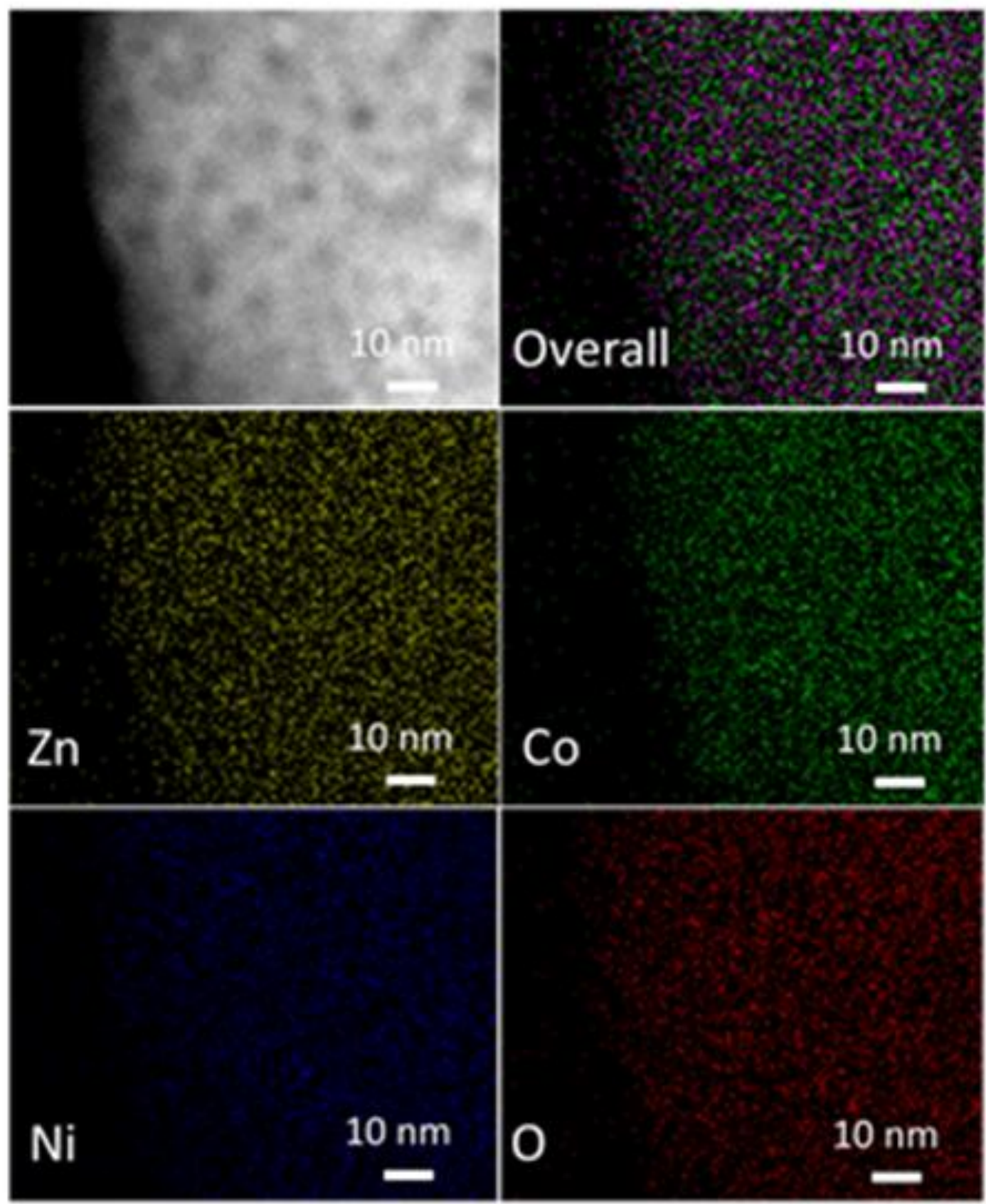

Figure S18 | Elemental mapping images of pristine $\mathrm{ZnCo}_{1.2} \mathrm{Ni}_{0.8} \mathrm{O}_{4}$. It indicates the homogenous distribution of $\mathrm{Zn}$, Co, $\mathrm{Ni}$ and $\mathrm{O}$ consistent with the formation of spinel $\mathrm{ZnCo}_{1.2} \mathrm{Ni}_{0.8} \mathrm{O}_{4}$. 

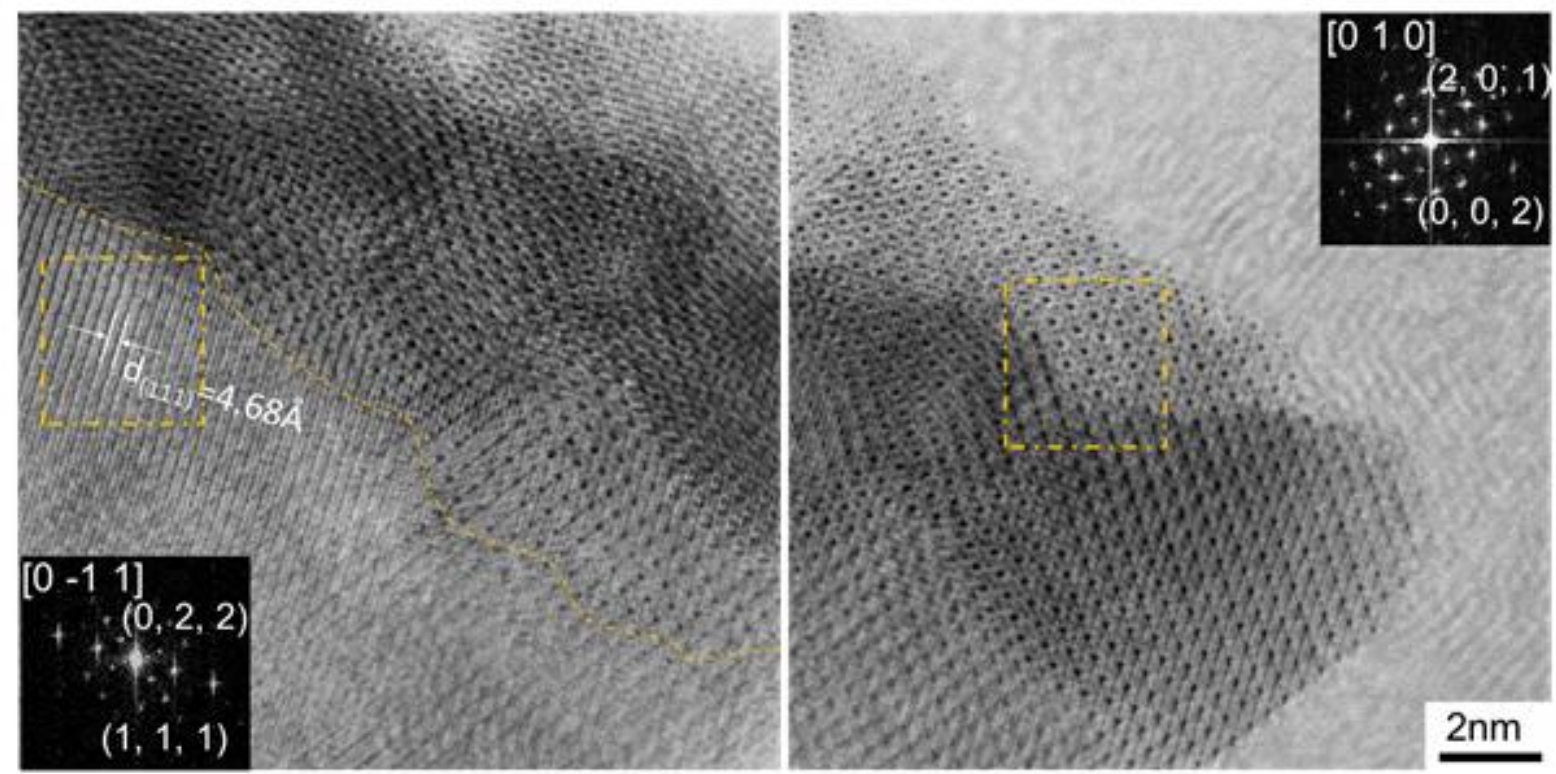

Figure S19 | HRTEM images of $\mathrm{ZnCo}_{1.2} \mathrm{Ni}_{0.8} \mathrm{O}_{4}$ after thousand cycles of OER in $1 \mathrm{M} \mathrm{KOH}$ at $10 \mathrm{mV} / \mathrm{s}$ between 0.904 and $1.624 \mathrm{~V}$ (vs. RHE). The left panel shows the bulk and surface of cycled $\mathrm{ZnCo}_{1.2} \mathrm{Ni}_{0.8} \mathrm{O}_{4}$. The inset at the bottom left is the SAED pattern for the bulk. The right panel shows the surface of cycled $\mathrm{ZnCo}_{1.2} \mathrm{Ni}_{0.8} \mathrm{O}_{4}$. The inset at the top right is the SAED pattern for the surface. After the $1000^{\text {th }}$ cycle of OER, the HRTEM image and SAED patterns (inset) collected from the bulk region imply that spinel phases are preserved for the bulk after cycling. This is supported by the nearly identical $\mathrm{Zn}$, Co and $\mathrm{Ni}$ K-edge XAS spectra of as-synthesized $\mathrm{ZnCo}_{1.2} \mathrm{Ni}_{0.8} \mathrm{O}_{4}$ and the cycled material (Figure S22). 

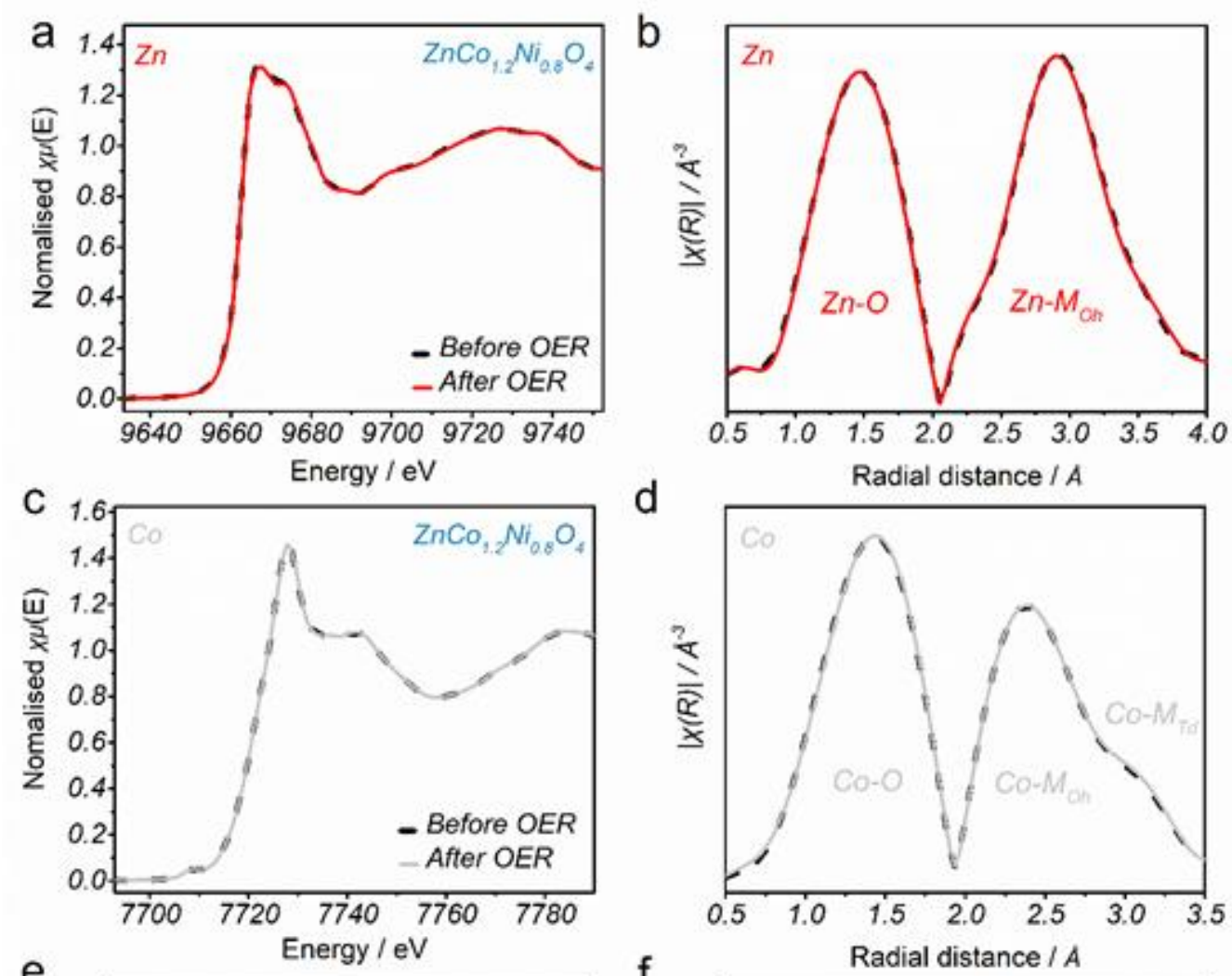

d
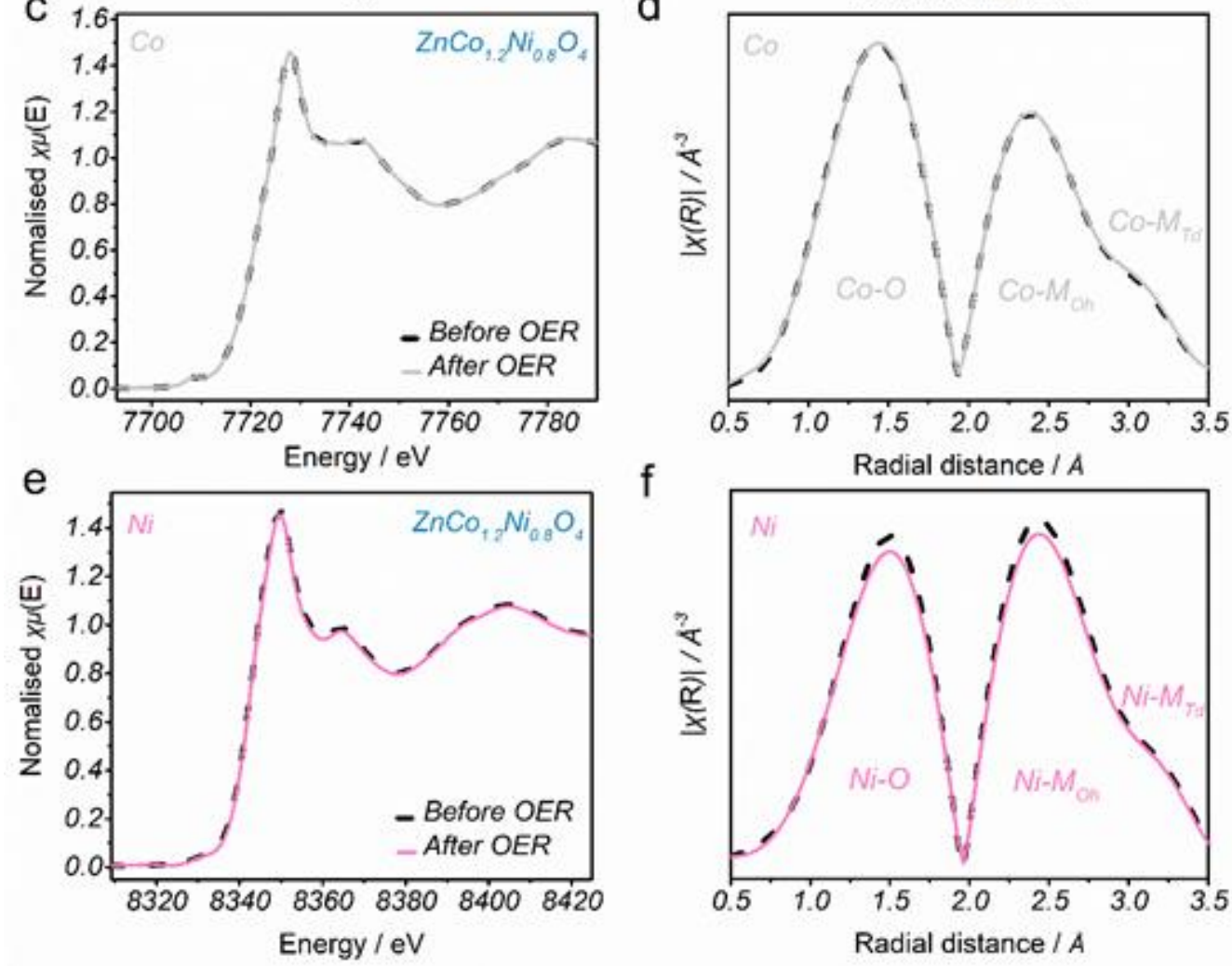

Figure S20 | X-ray absorption spectroscopy on $\mathrm{ZnCo}_{1.2} \mathrm{Ni}_{0.8} \mathrm{O}_{4}$ before and after OER. a) $\mathrm{Zn}$ $\mathrm{K}$-edge b) Co K-edge and c) $\mathrm{Ni} \mathrm{K}$-edge XANES recorded for $\mathrm{ZnCo}_{1.2} \mathrm{Ni}_{0.8} \mathrm{O}_{4}$ before cycling and after $100^{\text {th }}$ cycling. FT-EXAFS spectra on $\mathrm{ZnCo}_{1.2} \mathrm{Ni}_{0.8} \mathrm{O}_{4}$ before and after $100^{\text {th }}$ cycling at d) Zn K-edge e) Co K-edge and f) $\mathrm{Ni}$ K-edge. The black dashed lines indicate $\mathrm{ZnCo}_{1.2} \mathrm{Ni}_{0.8} \mathrm{O}_{4}$ before OER and the coloured lines (orange for $\mathrm{Zn} \mathrm{K}$-edge, blue for Co or $\mathrm{Ni}$ K-edge) indicate $\mathrm{ZnCo}_{1.2} \mathrm{Ni}_{0.8} \mathrm{O}_{4}$ after OER. 

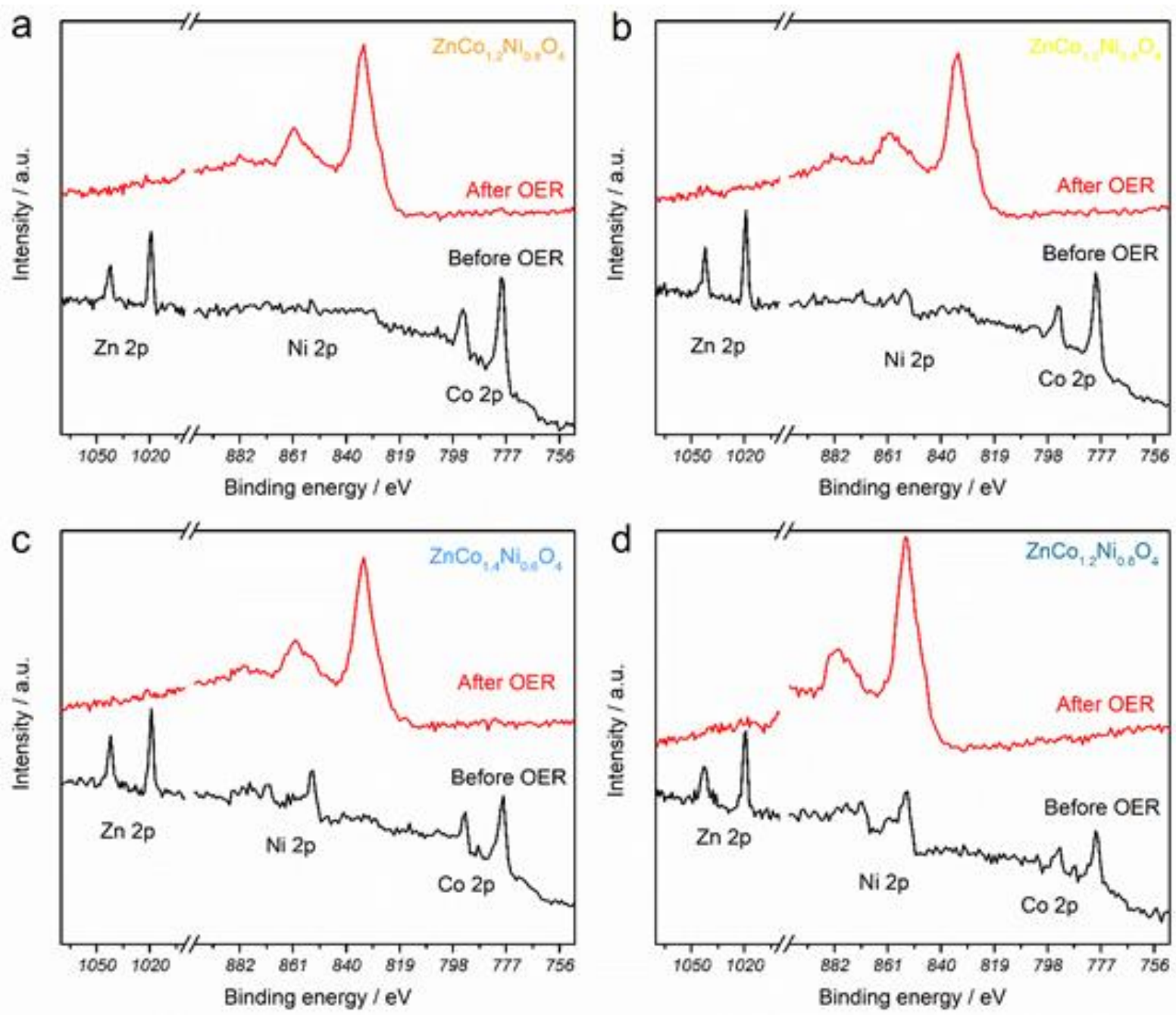

Figure S21 | X-ray photoelectron spectra (XPS) survey of Zn, Co and Ni $2 p$ regions for $\mathrm{ZnCo}_{1.8} \mathrm{Ni}_{0.2} \mathrm{O}_{4}$ (a), $\mathrm{ZnCo}_{1.6} \mathrm{Ni}_{0.4} \mathrm{O}_{4}$ (b), $\mathrm{ZnCo}_{01.4} \mathrm{Ni}_{0.6} \mathrm{O}_{4}$ (c) and $\mathrm{ZnCo}_{1.2} \mathrm{Ni}_{0.8} \mathrm{O}_{4}$ (d) surface before OER testing (black line) and after thousand cycles of OER (after OER) in 1M KOH at $10 \mathrm{mVs}^{-1}$ between 0.904 and $1.624 \mathrm{~V}$ (vs. RHE). 

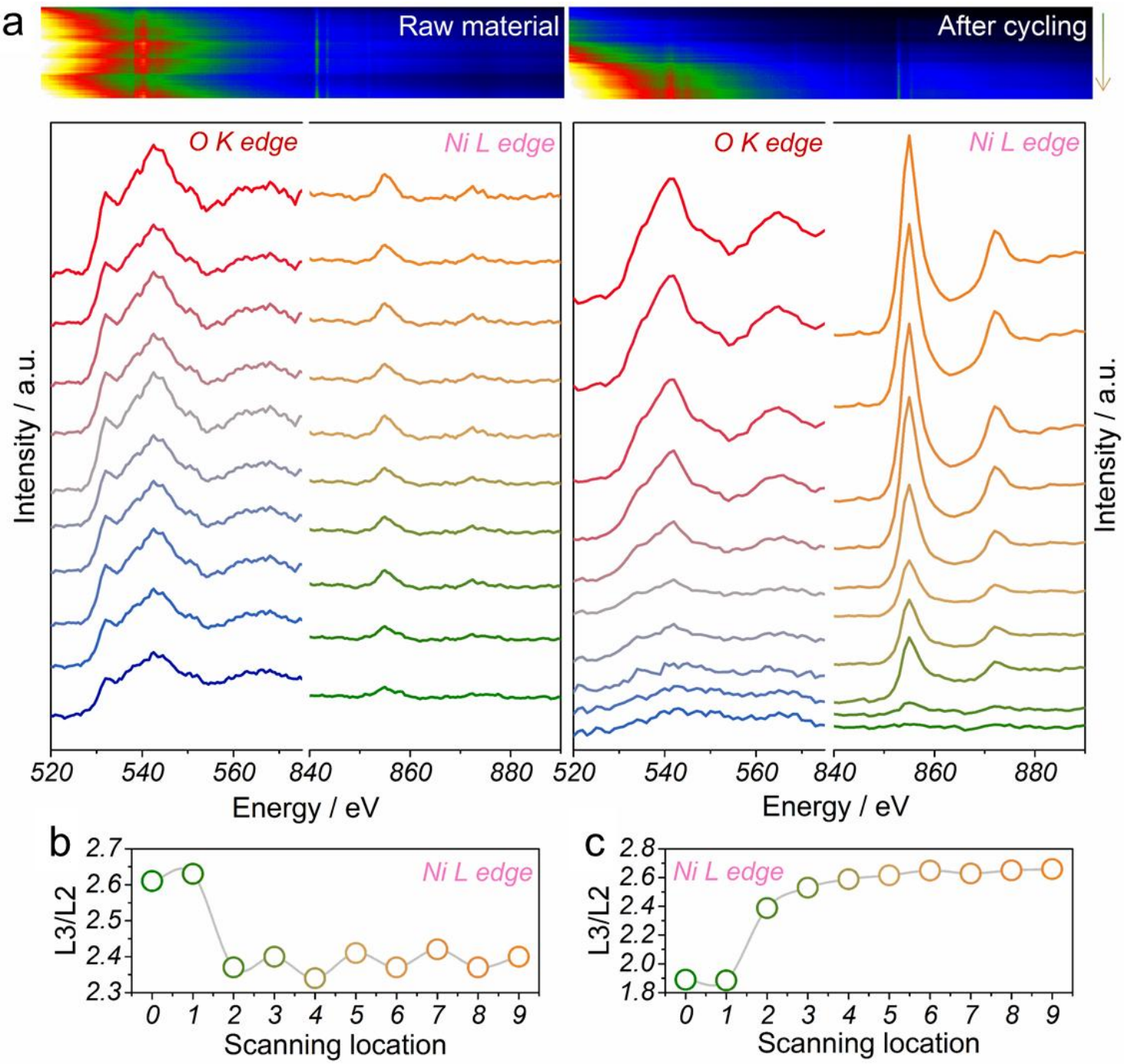

Figure S22 | (a) EELS spectra of O K-edge and Ni L-edge along the scanning pathway shown in Figure S19b and $2 \mathbf{f}$ to detect the change in $\mathrm{O}$ electronic structures and charge distributions of metal cations. L3/L2 ratios of Ni edge calculated from Ni L-edge EELS spectra for pristine $\mathrm{ZnCo}_{1.2} \mathrm{Ni}_{0.8} \mathrm{O}_{4}$ (b) and cycled $\mathrm{ZnCo}_{1.2} \mathrm{Ni}_{0.8} \mathrm{O}_{4}$ (c). The ratios of $\mathrm{L} 3 / \mathrm{L} 2$ for Ni edge before (Figure S24b) and after cycling (Figure S24c) have been determined by a Hartree-Slater cross section method [22]. Lower L3/L2 corresponds to higher chemical states of the Ni cations. This indicates that there is surface $\mathrm{Ni}^{2+}$ before OER, and these surface $\mathrm{Ni}$ cations acquire higher valence state after cycling. 

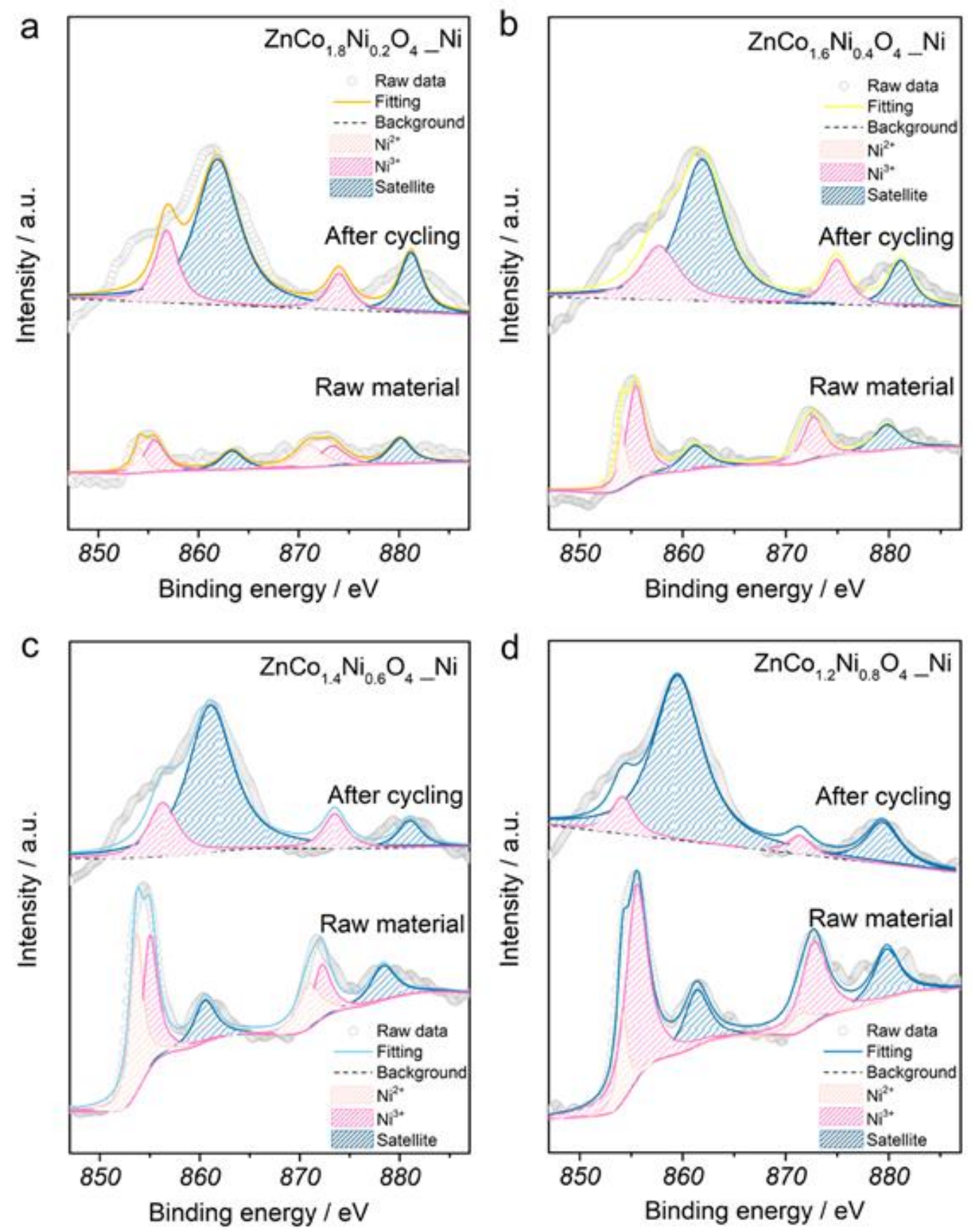

Figure S23 | X-ray photoelectron spectra (XPS) of $\mathrm{Ni} 2 p$ regions for $\mathrm{ZnCo}_{2-\mathrm{x}} \mathrm{Ni}_{\mathrm{x}} \mathrm{O}_{4}$ surface before OER testing and after thousand cycles of OER in $1 \mathrm{M} \mathrm{KOH}$ at $10 \mathrm{mVs}^{-1}$ between 0.904 and $1.624 \mathrm{~V}$ (vs. RHE). Fittings of experimental spectra obtained for $\mathrm{ZnCo}_{2-\mathrm{x}} \mathrm{Ni}_{\mathrm{x}} \mathrm{O}_{4}$ are shown in coloured curves. Fittings of satellites are shown in dark blue colour. 


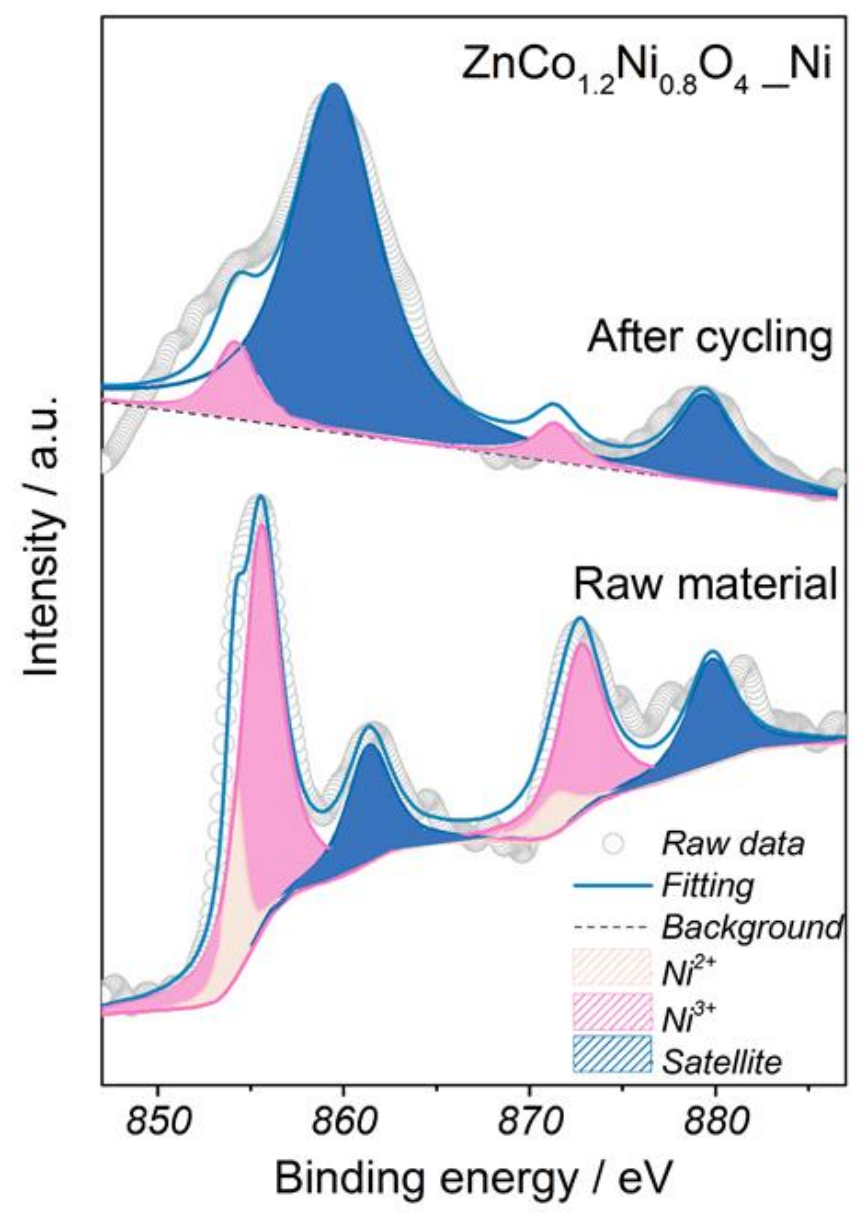

Figure S24 $\mid$ XPS of Ni $2 p$ regions for $\mathrm{ZnCo}_{1.2} \mathrm{Ni}_{0.8} \mathrm{O}_{4}$ surface before OER testing and after thousand cycles of OER in $1 \mathrm{M} \mathrm{KOH}$ at $10 \mathrm{mVs}^{-1}$ between 0.904 and $1.624 \mathrm{~V}$ (vs. RHE). Fittings of experimental spectra obtained for $\mathrm{ZnCo}_{1.2} \mathrm{Ni}_{0.8} \mathrm{O}_{4}$ are shown in coloured curves. Fittings of satellites are shown in dark blue colour. Shadowed area demonstrates the fitting of satellites. The satellite structure at $881 \mathrm{eV}$ is associated with a $2 p^{5} 3 d^{7}$ final state transformed from a $2 p^{6} 3 d^{7}$ state in the photoemission process, and the structure at $861 \mathrm{eV}$ is attributed to the $2 p^{5} 3 d^{8}$ L final state from $2 p^{6} 3 d^{8}$. [23] Thus, the relatively strong satellite structure at the lower binding strength compared to that at higher binding strength is the result of increased $\mathrm{Ni}^{3+}$ which gives rise to removal of electrons from valence levels to which charge transfer from the ligand is facilitated [24]. The broadening of main peaks for the $\mathrm{Ni}$ edge indicates the presence of delocalised electrons on $3 d-2 p$ states after OER. [24a] 


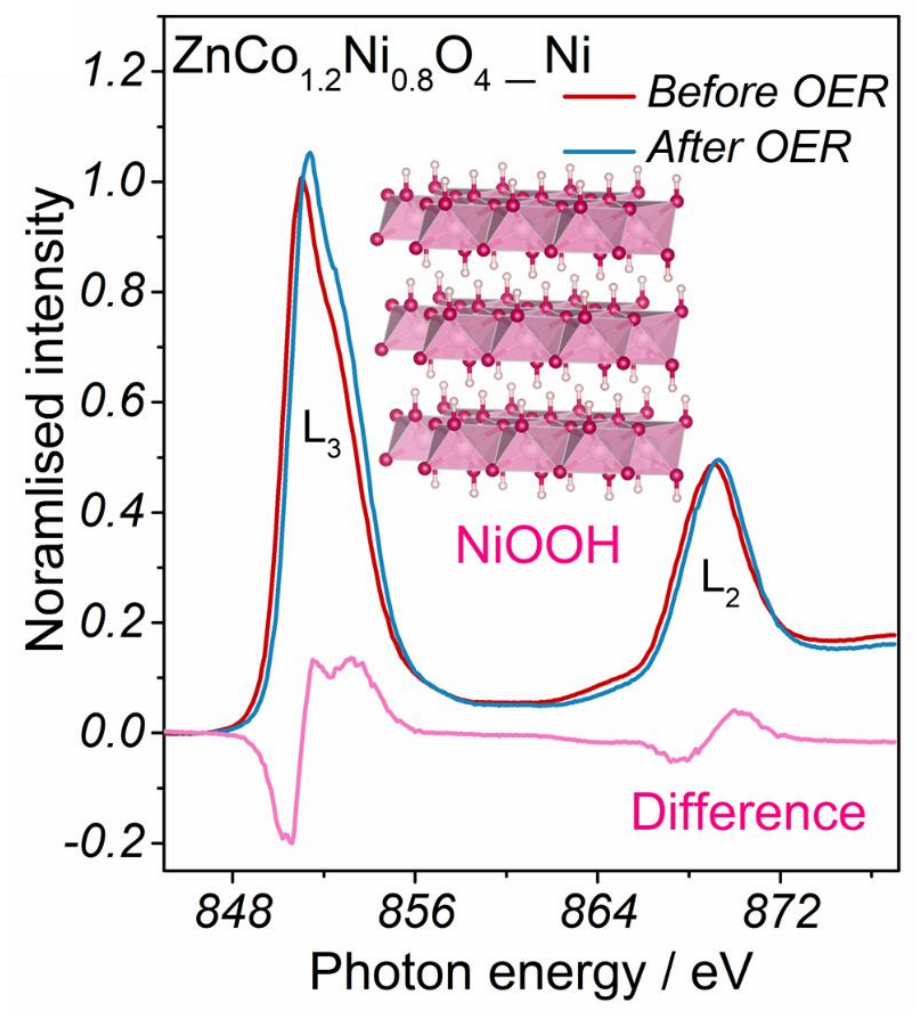

Figure S25 $\mid$ Soft XAS spectra at the $\mathrm{Ni} \mathrm{L}_{2,3}$-edge for $\mathrm{ZnCo}_{1.2} \mathrm{Ni}_{0.8} \mathrm{O}_{4}$ before (red line) and after OER cycling (blue line). 


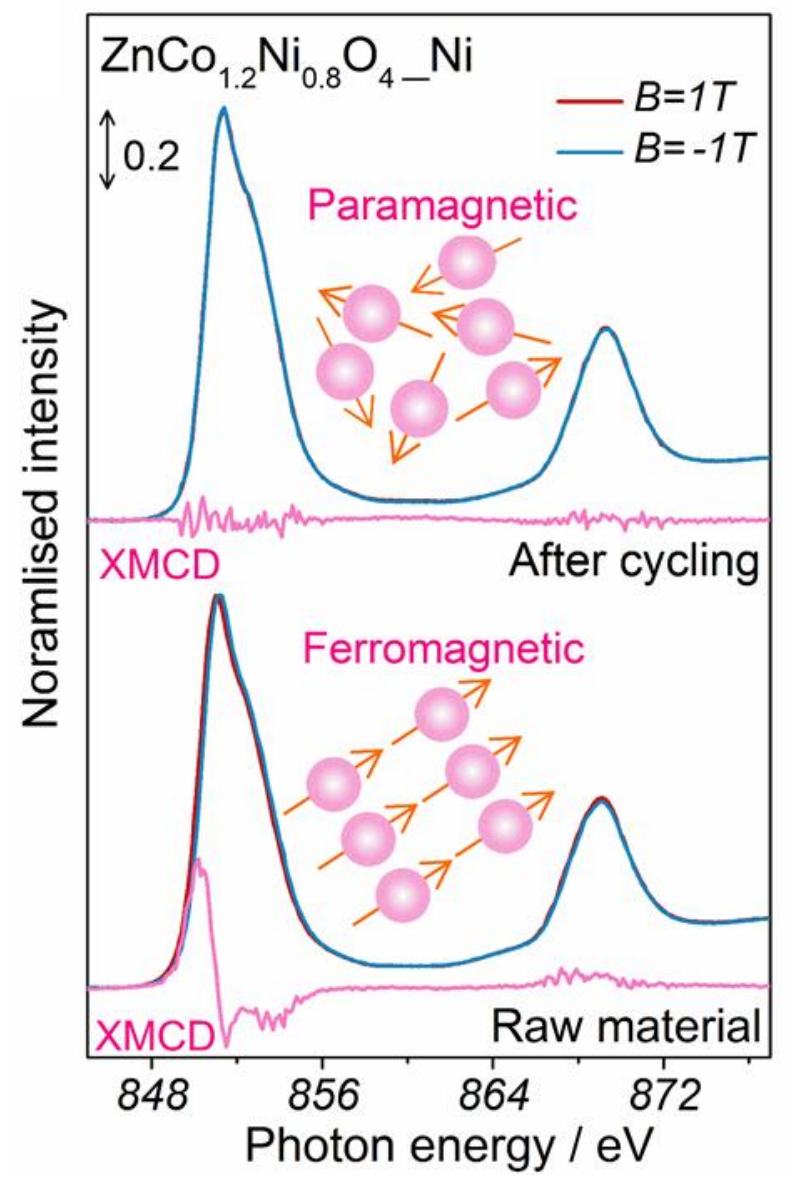

Figure S26 XMCD spectra raised from the difference between the $\mu^{+}$and $\mu^{-}$soft XAS spectra at the $\mathrm{Ni} \mathrm{L}_{2,3}$-edge for $\mathrm{ZnCo}_{1.2} \mathrm{Ni}_{0.8} \mathrm{O}_{4}$ before (bottom) and after OER cycling (top). 


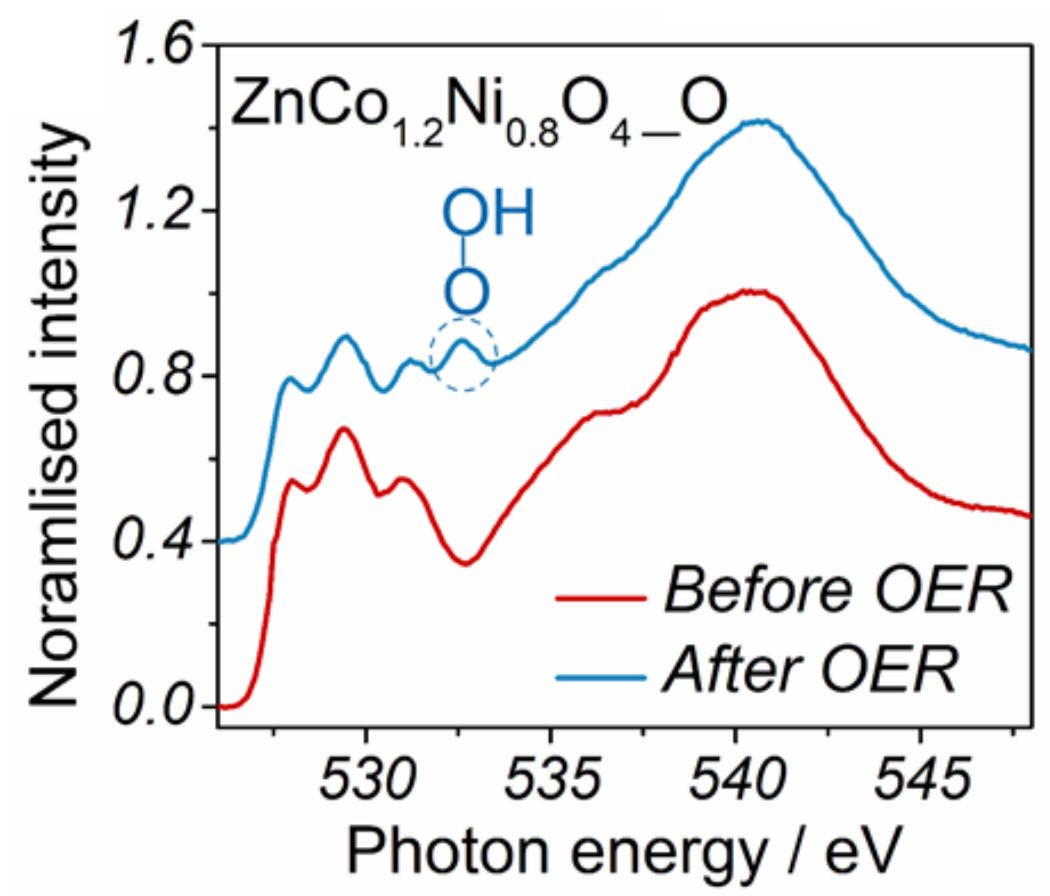

Figure S27 | Soft XAS spectra at the O K-edge for $\mathrm{ZnCo}_{1.2} \mathrm{Ni}_{0.8} \mathrm{O}_{4}$ before (red line) and after OER cycling (blue line). 


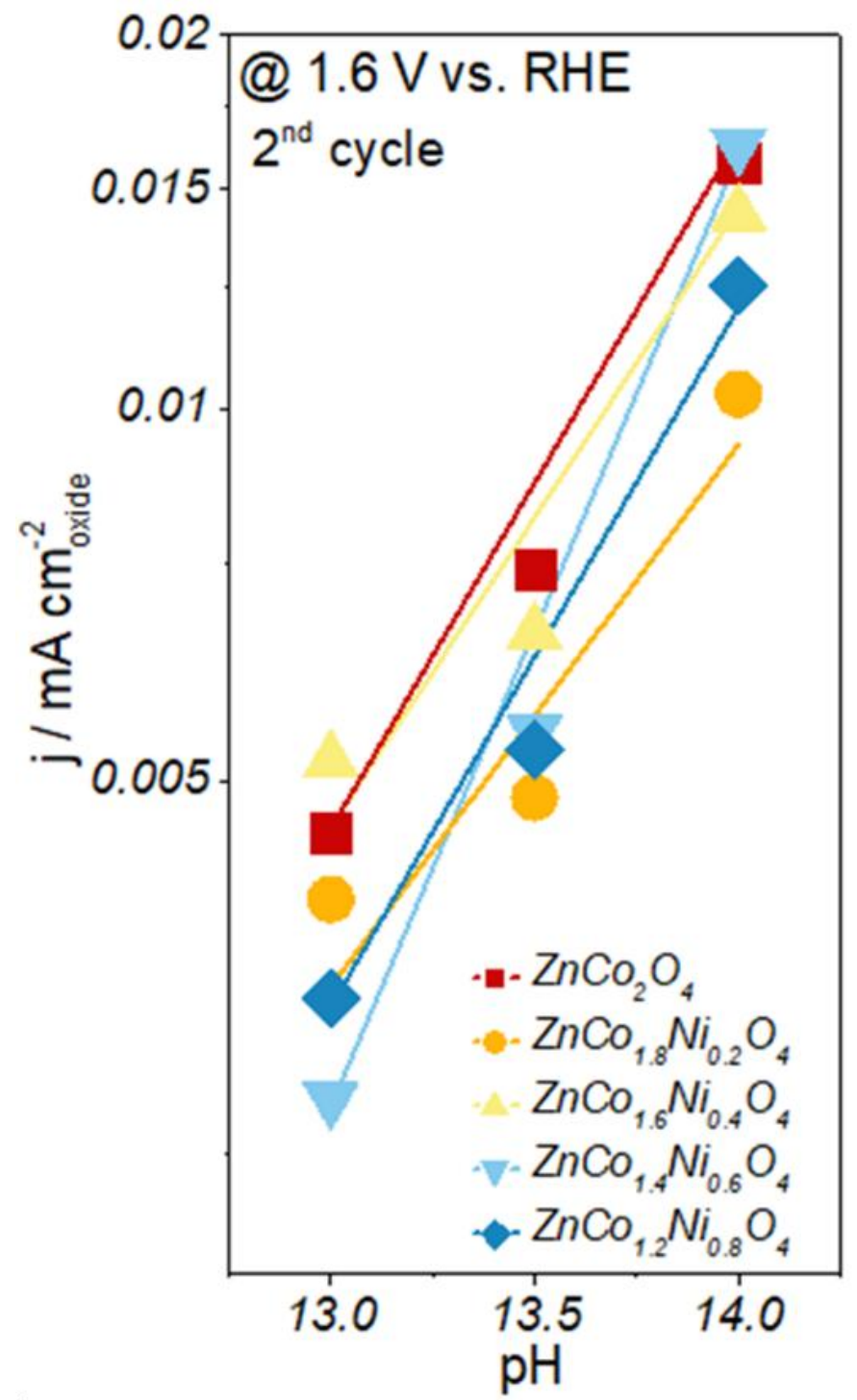

Figure S28 | OER activity (current normalized by surface area of oxide) of pristine $\mathrm{ZnCo}_{2-}$ ${ }_{x} \mathrm{Ni}_{\mathrm{x}} \mathrm{O}_{4}$ at $1.6 \mathrm{~V}$ (versus RHE) after $\mathrm{iR}$ correction as a function of $\mathrm{pH}$. 

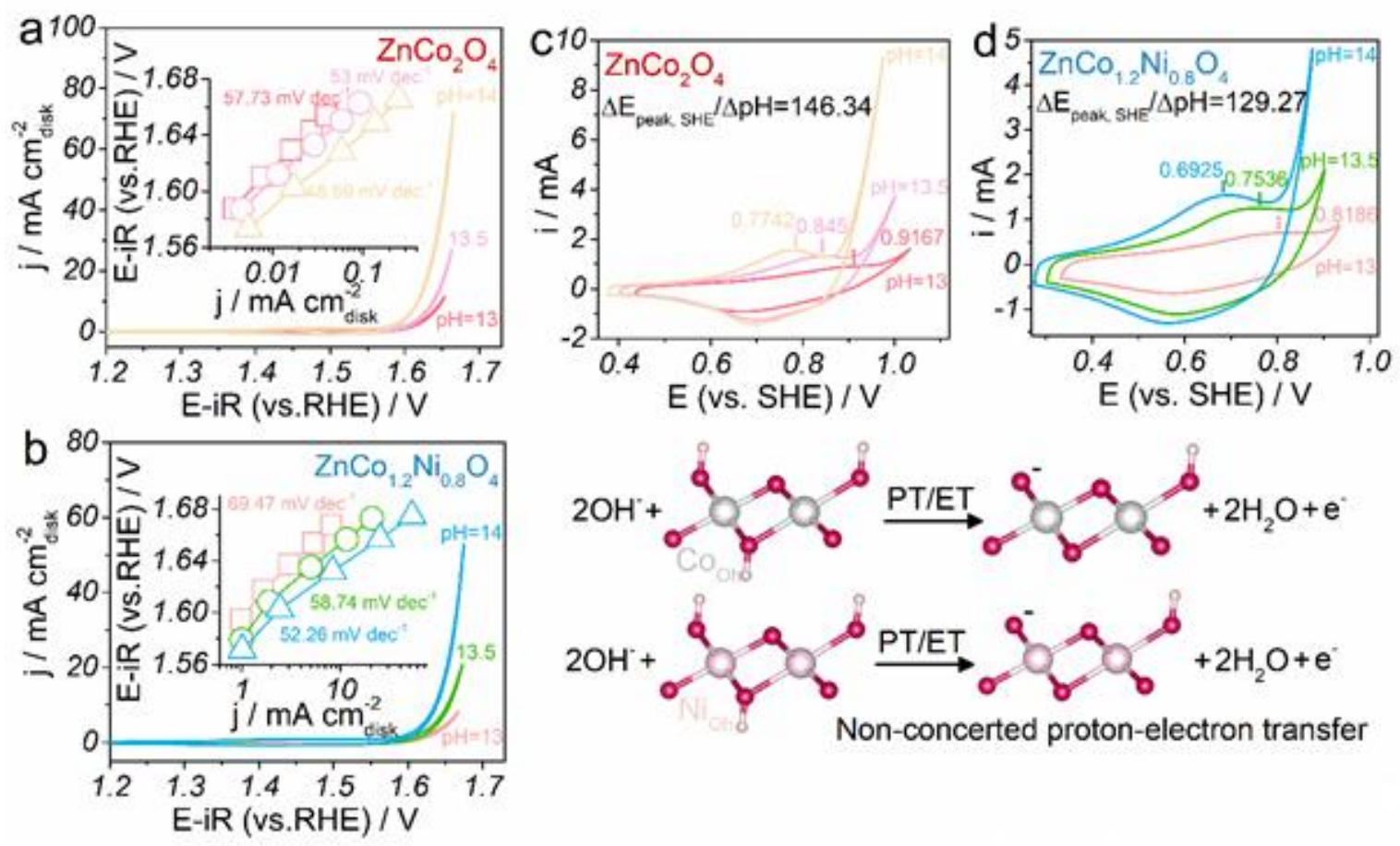

Figure S29 | pH-dependent OER activity for pristine $\mathrm{ZnCo}_{2-\mathrm{x}} \mathrm{Ni}_{\mathrm{x}} \mathrm{O}_{4}$. CV measurements for pristine $\mathrm{ZnCo}_{2} \mathrm{O}_{4}$ (a) and $\mathrm{ZnCo}_{1.2} \mathrm{Ni}_{0.8} \mathrm{O}_{4}$ (b) from $0.1 \mathrm{M} \mathrm{KOH}(\mathrm{pH} 13$ ) to $1 \mathrm{M} \mathrm{KOH}$ (pH 14) recorded at $10 \mathrm{mV} \mathrm{s}^{-1}$ on the RHE scales after $\mathrm{iR}$ correction. Insets are the Tafel plots in different $\mathrm{pH}$. Increasing the $\mathrm{pH}$ value from 13 to 14 leads to seven times greater intrinsic OER activity (OER activity normalised by the surface area of working electrode) for pristine $\mathrm{ZnCo}_{2} \mathrm{O}_{4}$. The decreased Tafel slope along with increased $\mathrm{pH}$, from $57.73 \mathrm{mV} \mathrm{dec}^{-1}$ to 48.59 $\mathrm{mV} \mathrm{dec}^{-1}$, (inset) indicates a change in reaction pathways when using $\mathrm{KOH}$ with different concentrations. [25] All other samples exhibit similar performance (Figure S30). CV measurements for pristine $\mathrm{ZnCo}_{2} \mathrm{O}_{4}$ (c) and $\mathrm{ZnCo}_{1.2} \mathrm{Ni}_{0.8} \mathrm{O}_{4}$ (d) from $0.1 \mathrm{M} \mathrm{KOH}$ (pH 13) to 1 M KOH (pH 14) recorded at $200 \mathrm{mV} \mathrm{s}^{-1}$ on the SHE scales. Bottom panel shows the schematic for non-concerted proton-electron transfer of surface deprotonation of pristine $\mathrm{ZnCo}_{2} \mathrm{O}_{4}$ and $\mathrm{ZnCo}_{1.2} \mathrm{Ni}_{0.8} \mathrm{O}_{4}$. The Pourbaix slopes obtained for these materials are quite different from $\mathrm{Ni}(\mathrm{OH})_{2}(-90 \mathrm{mV} / \mathrm{pH})$ which also reconstructs to $\mathrm{NiOOH}$ under OER conditions, meaning that this deprotonation behaviour is very dependent on the oxide which is used to form the hydroxide. 


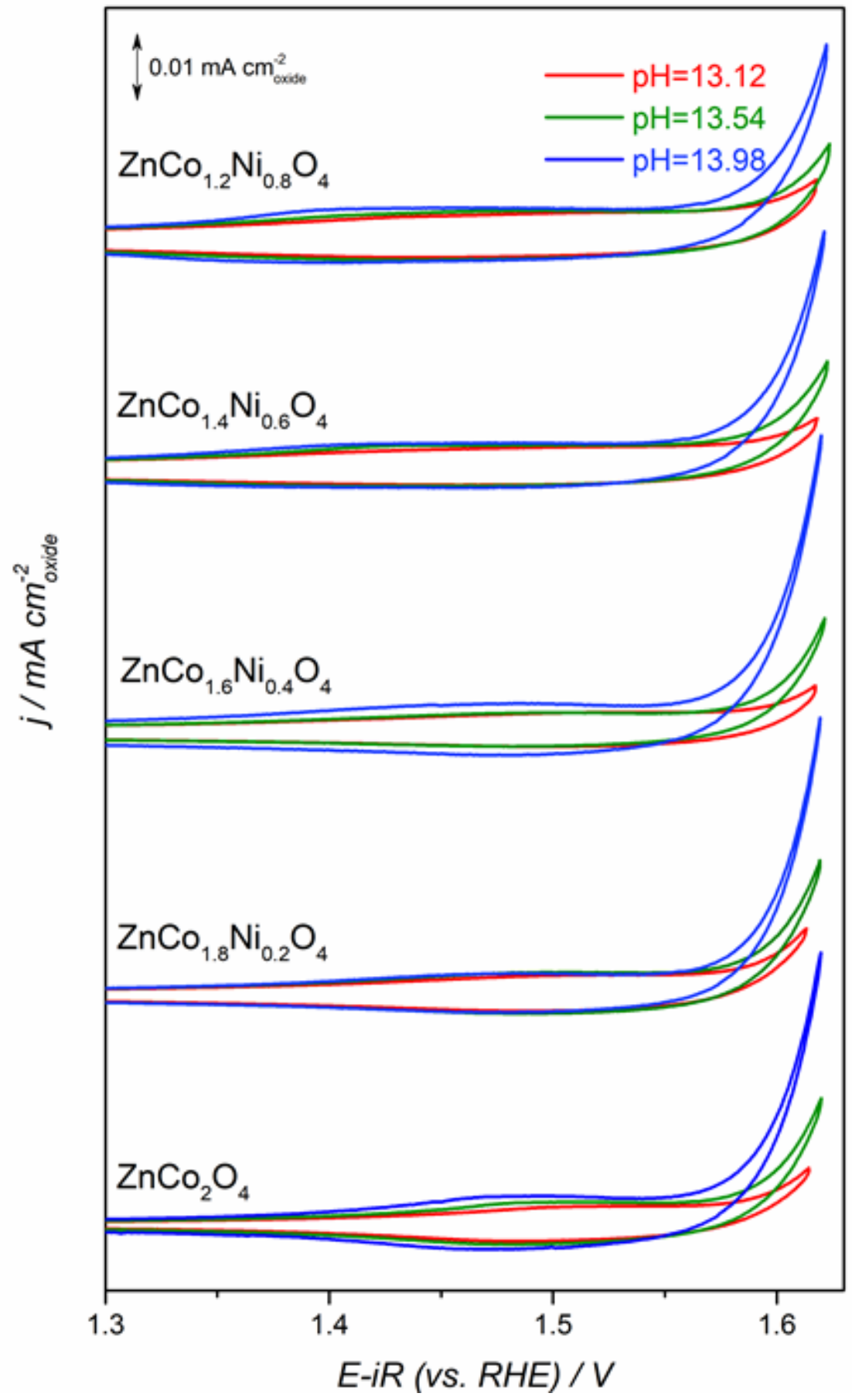

Figure S30 | OER activity swept from low $\mathrm{pH}$ to high $\mathrm{pH}$ for pristine $\mathrm{ZnCo}_{2-\mathrm{x}} \mathrm{Ni}_{\mathrm{x}} \mathrm{O}_{4}$. 

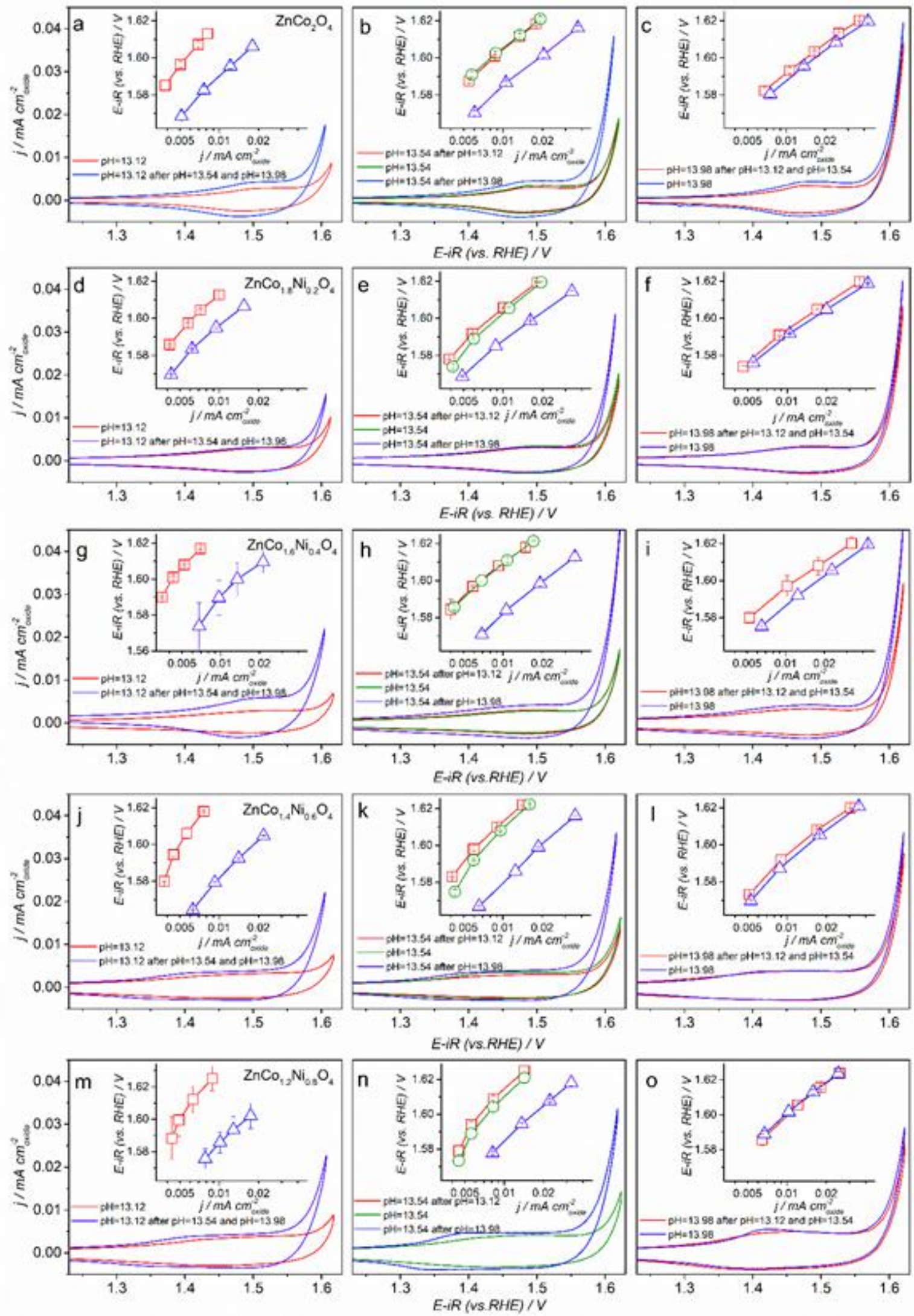

Figure S31 | OER activity swept from low $\mathrm{pH}$ to high $\mathrm{pH}$ comparing with activity swept from high $\mathrm{pH}$ to low $\mathrm{pH}$ in $\mathrm{pH}=13, \mathrm{pH}=13.5$ and $\mathrm{pH}=14$ for pristine $\mathrm{ZnCo}_{2-\mathrm{x}} \mathrm{Ni}_{\mathrm{x}} \mathrm{O}_{4}$. 


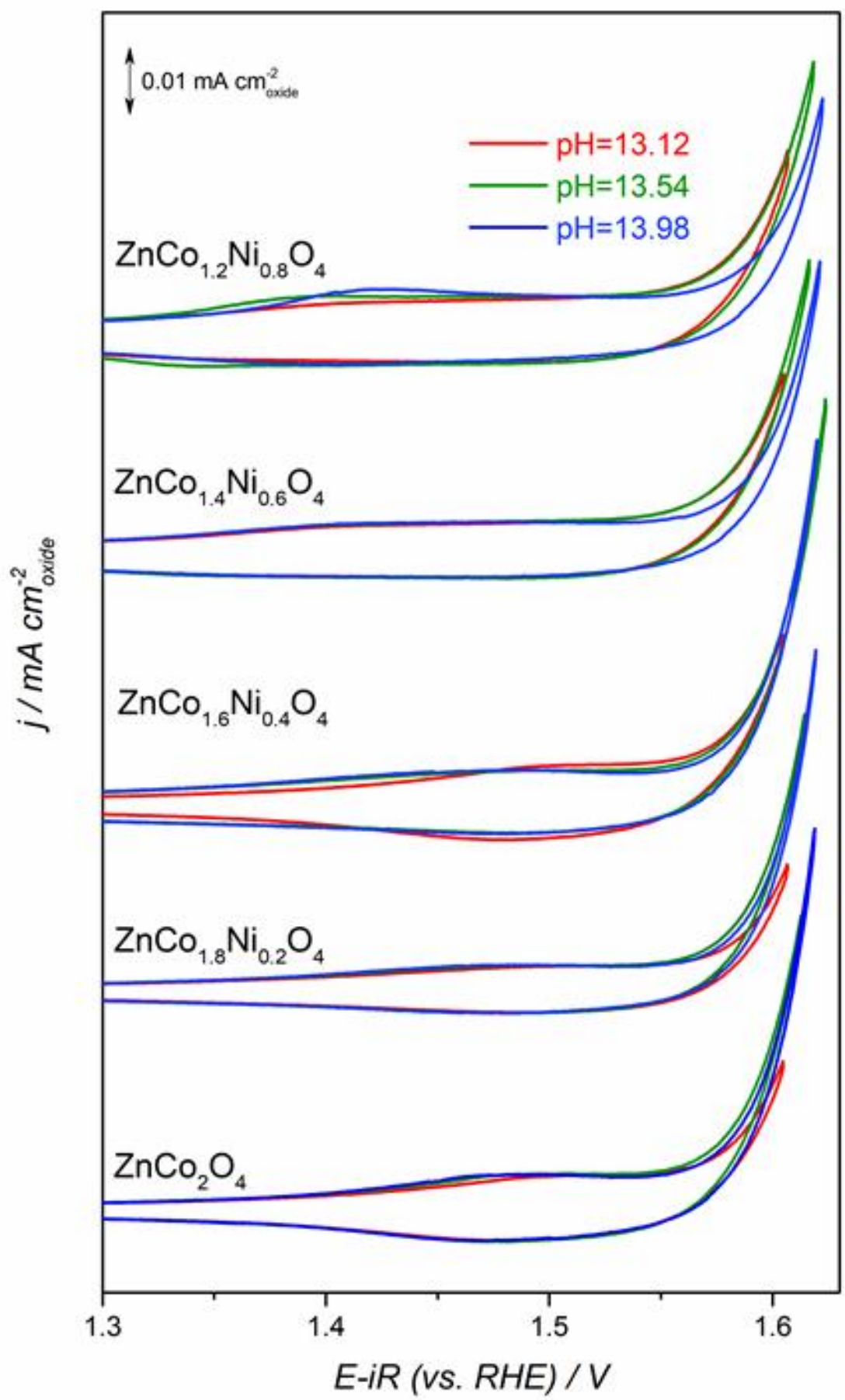

Figure S32 | OER activity swept from high $\mathrm{pH}$ to low $\mathrm{pH}$ for pristine $\mathrm{ZnCo}_{2-\mathrm{x}} \mathrm{Ni}_{\mathrm{x}} \mathrm{O}_{4}$. 

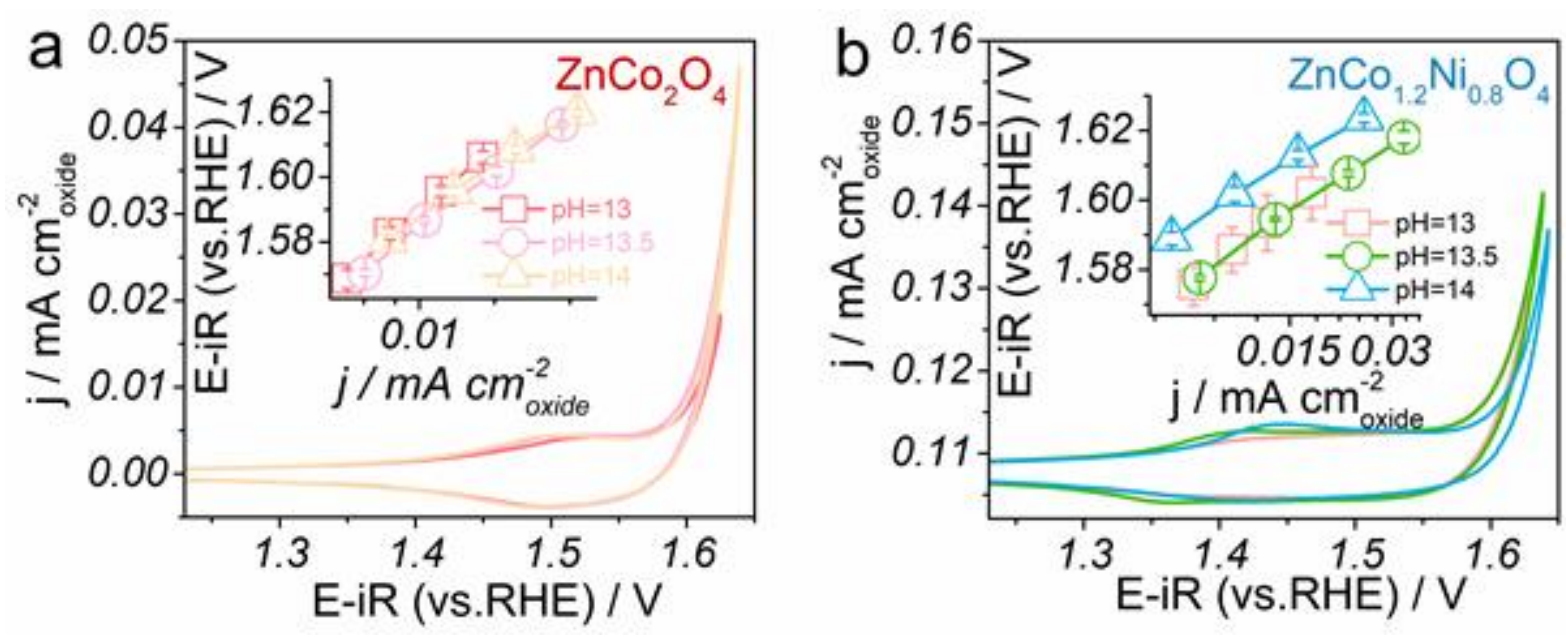

Figure S33 | OER activity swept from high $\mathrm{pH}$ to low $\mathrm{pH}$ for pristine $\mathrm{ZnCo}_{2} \mathrm{O}_{4}$ (a) and $\mathrm{ZnCo}_{1.2} \mathrm{Ni}_{0.8} \mathrm{O}_{4}$ (b). Tafel plots are shown in the insets. 

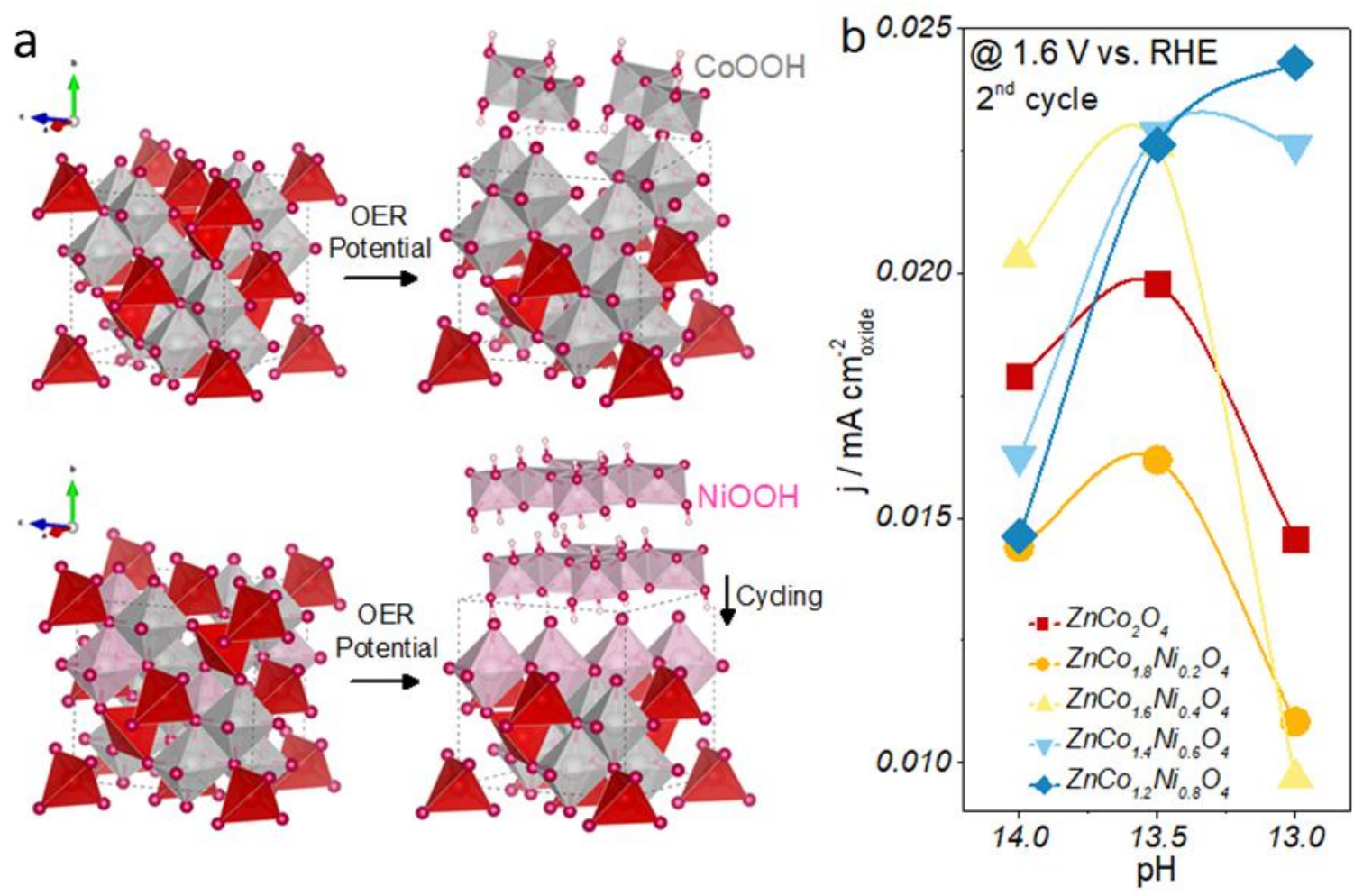

Figure S34 | a) The schematic for the transition from pristine $\mathrm{ZnCo}_{2} \mathrm{O}_{4} / \mathrm{ZnCo}_{1.2} \mathrm{Ni}_{0.8} \mathrm{O}_{4}$ to $\mathrm{CoOOH} / \mathrm{NiOOH}$. b) OER activity swept from high $\mathrm{pH}$ to low $\mathrm{pH}$ (current normalized by surface area of oxide) of pristine $\mathrm{ZnCo}_{2-\mathrm{x}} \mathrm{Ni}_{\mathrm{x}} \mathrm{O}_{4}$ at $1.6 \mathrm{~V}$ (versus $\mathrm{RHE}$ ) after $\mathrm{iR}$ correction as a function of $\mathrm{pH}$. 

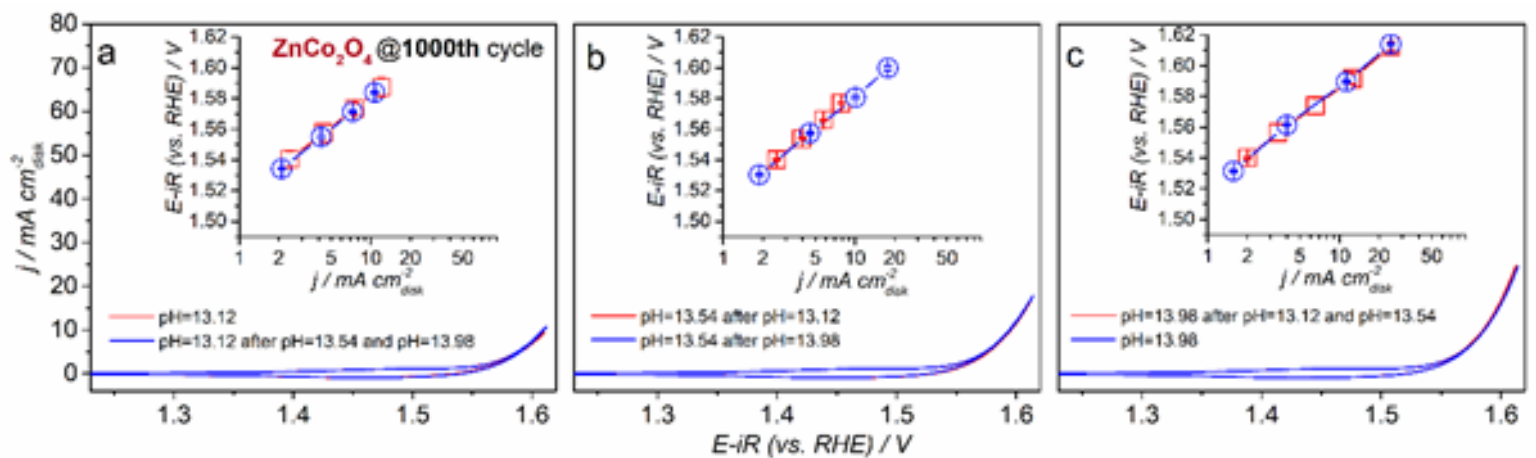

Figure S35 | OER activity swept from low $\mathrm{pH}$ to high $\mathrm{pH}$ comparing with activity swept from high $\mathrm{pH}$ to low $\mathrm{pH}$ in $\mathrm{pH}=13$ (a), $\mathrm{pH}=13.5$ (b) and $\mathrm{pH}=14$ (c) for $\mathrm{ZnCo}_{2} \mathrm{O}_{4}$ after $1000^{\text {th }}$ OER cycles. 

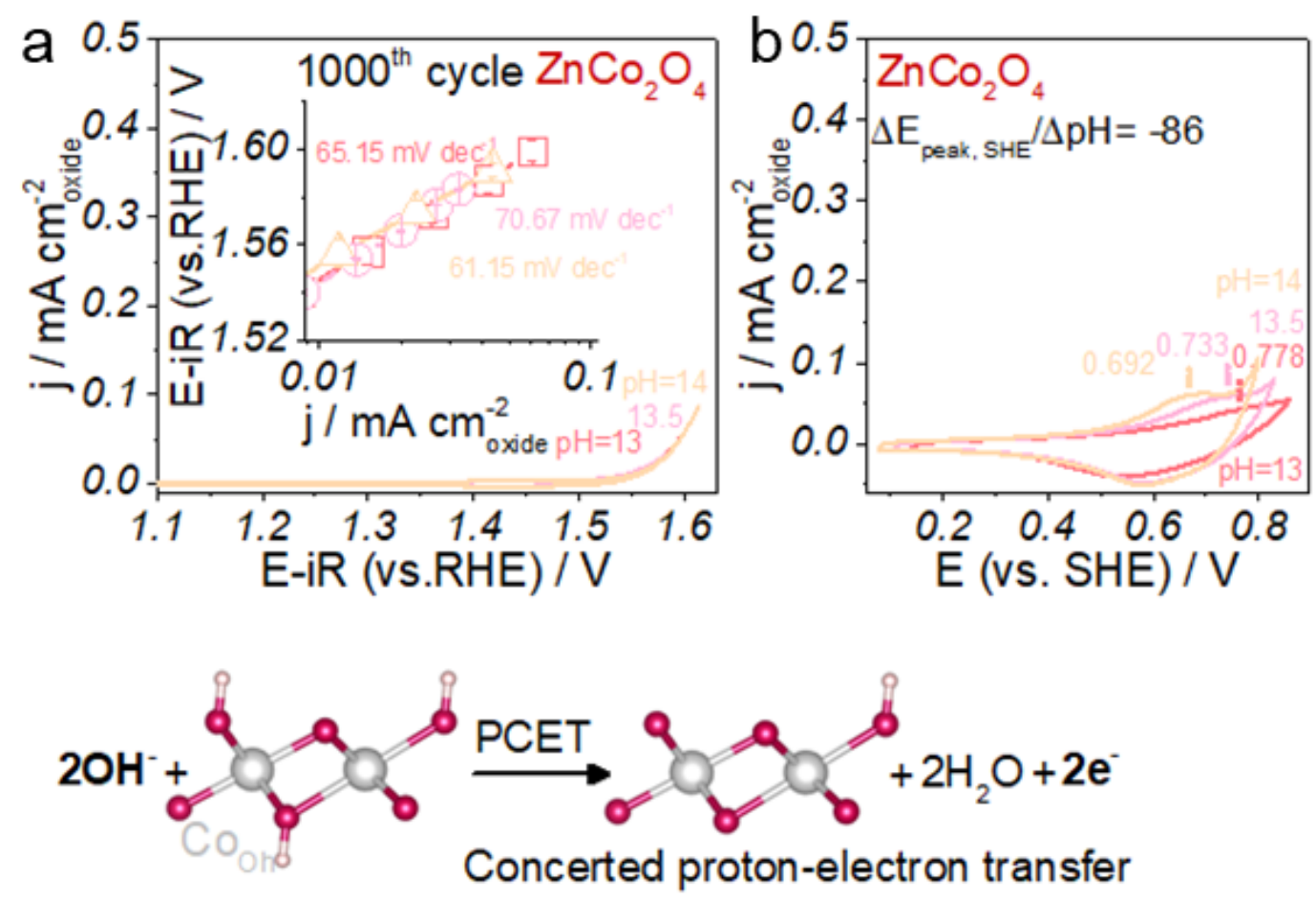

Figure S36 | (a) CV measurements for cycled $\mathrm{ZnCo}_{2} \mathrm{O}_{4}$ from $0.1 \mathrm{M} \mathrm{KOH}(\mathrm{pH} 13.12$ ) to $1 \mathrm{M}$ $\mathrm{KOH}(\mathrm{pH} 13.98)$ recorded at $10 \mathrm{mV} \mathrm{s}^{-1}$ on the RHE scales after $\mathrm{R}$ correction. Insets are the Tafel plots in different $\mathrm{pH}$. (b) $\mathrm{CV}$ measurements for cycled $\mathrm{ZnCo}_{2} \mathrm{O}_{4}$ from $0.1 \mathrm{M} \mathrm{KOH}(\mathrm{pH}$ 13.12) to $1 \mathrm{M} \mathrm{KOH} \mathrm{(pH} \mathrm{13.98)} \mathrm{recorded} \mathrm{at} 200 \mathrm{mV} \mathrm{s}^{-1}$ on the SHE scales. Bottom panels show the schematic for concerted proton-electron transfer of surface deprotonation of cycled $\mathrm{ZnCo}_{2} \mathrm{O}_{4}$. 

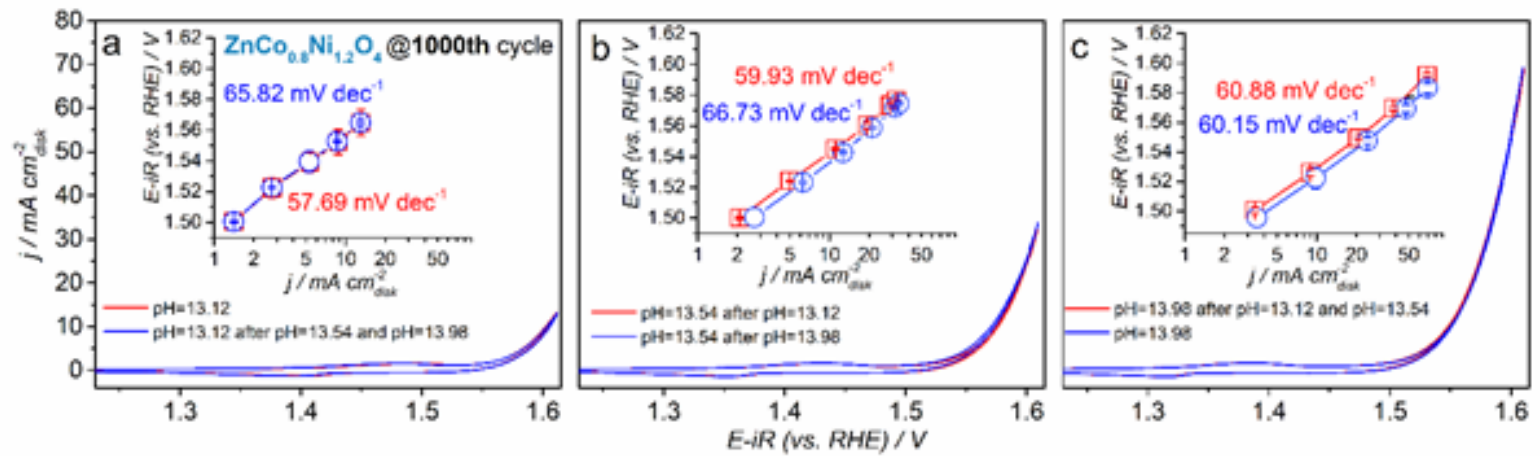

Figure S37 | OER activity swept from low $\mathrm{pH}$ to high $\mathrm{pH}$ comparing with activity swept from high $\mathrm{pH}$ to low $\mathrm{pH}$ in $\mathrm{pH}=13, \mathrm{pH}=13.5$ and $\mathrm{pH}=14$ for $\mathrm{ZnCo}_{1.2} \mathrm{Ni}_{0.8} \mathrm{O}_{4}$ after $1000^{\text {th }} \mathrm{OER}$ cycles. 


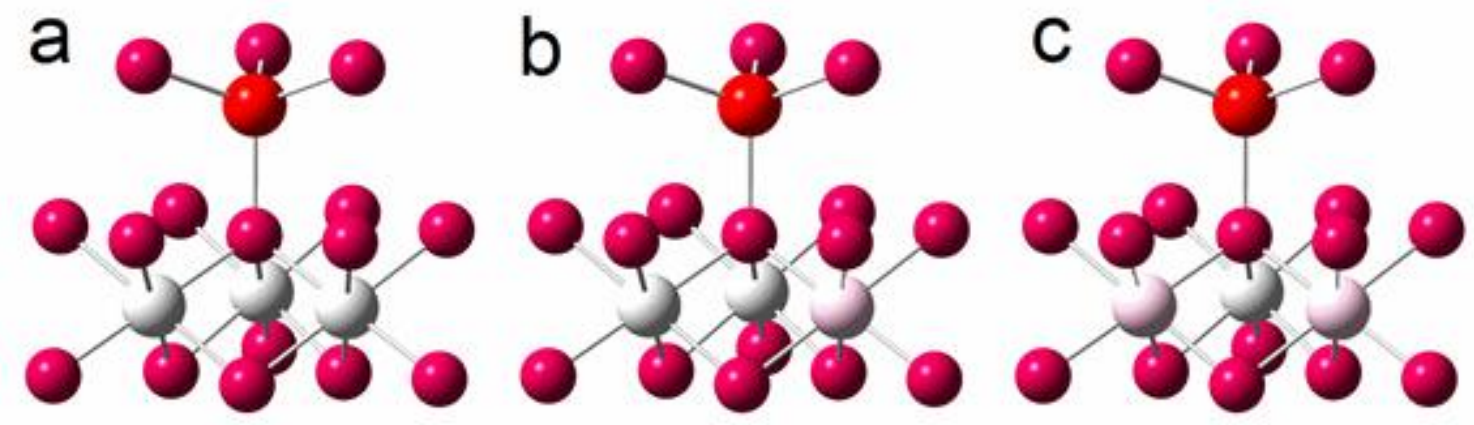

Figure S38 | (a) Model with one Zn atom in tetrahedral site, three Co atoms in octahedral site. (b) Model with one Zn atom in tetrahedral site, two Co atoms and one Ni atom in octahedral site. (c) Model with one $\mathrm{Zn}$ atom in tetrahedral site, one Co atom and two $\mathrm{Ni}$ atoms in octahedral site. 
References

[1] B. Hammer, J. K. Norskov, Nature 1995, 376, 238;

[2] V. R. Stamenkovic, B. Fowler, B. S. Mun, G. Wang, P. N. Ross, C. A. Lucas, N. M. Marković, Science 2007, 315, 493.

[3] B. Hammer, J. K. Norskov, Academic Press 2000, 45, 71.

[4] J. Suntivich, K. J. May, H. A. Gasteiger, J. B. Goodenough, Y. Shao-Horn, Science 2011, $334,1383$.

[5] P. Parida, R. Kashikar, A. Jena, B. R. K. Nanda, (2018). J. Phys. Chem. Solids. 2018, 123, 133.

[6] C. Yang, A. Grimaud, Catalysts 2017, 7, 149.

[7] J. B. Goodenough, A. L. Loeb, Phys. Rev. 1955, 98, 391.

[8] M. N. Amini, H. Dixit, R. Saniz, D. Lamoena, B. Partoensa, Phys. Chem. Chem. Phys. 2014, 16, 2588

[9] a) J. Haenen, W. Visscher, E. Barendrecht, J. Electroanal. Chem. 1986, 208, 323; b) X. Shi, S. L. Bernasek, A. Selloni, J. Phys. Chem. C. 2016, 120, 14892; c) A. Navrotsky, O. J. Kleppa, J. Inorg. Nucl. Chem. 1967, 29, 2701.

[10] G. Kresse, J. Furthmüller, Phys. Rev. B. 1996, 54, 11169.

[11] J. P. Perdew, K. Burke, M. Ernzerhof, Phys. Rev. Lett. 1996, 77, 3865.

[12] S. L. Dudarev, G. A. Botton, S. Y. Savrasov, C. J. Humphreys, A. P. Sutton, Phys. Rev. B. 1998, 57, 1505 .

[13] H. J. Monkhorst, J. D. Pack, Phys. Rev. B. 1976, 13, 5188. 
[14] a) F. Calle-Vallejo, O. A. Díaz-Morales, M. J. Kolb, M. T. Koper, ACS Catal. 2015, 5, 869; b) C. D. Gelatt Jr, A. R. Williams, V. L. Moruzzi, Phys. Rev. B. 1983, 27, 2005; c) J. I. Martinez, H. A. Hansen, J. Rossmeisl, J. K. Nørskov, Phys. Rev. B. 2009, 79, 045120.

[15] Y. Du, Y. Zhu, S. Xi, P. Yang, H. O. Moser, M. B. Breese, A. Borgna, J. Synchrotron. Radiat. 2015, 22, 839.

[16] B. Ravel, M. Newville, J. Synchrotron. Radiat. 2005, 12, 537.

[17] a) Z. L. Wang, J. S. Yin, Y. D. Jiang, Micron. 2000, 31, 571; b) H. Tan, J. Verbeeck, A. Abakumov, G. Van Tendeloo, Ultramicroscopy. 2012, 116, 24; c) J. Graetz, C. C. Ahn, H. Ouyang, P. Rez, B. Fultz, Phys. Rev. B. 2004, 69, 235103.

[18] T. L. Barr, S. J. Seal, Vac. Sci. Technol. 1995, 13, 1239.

[19] M. N. Sanz-Ortiz, F. Rodríguez, J. Rodríguez, G. Demazeau, J. Phys. Condens. Matter. 2011, 23, 415501 .

[20] X. Yu, O. Wilhelmi, H. O. Moser, S. V. Vidyaraj, X. Gao, A. T. Wee, T. Nyunt, H. Qian, H. Zheng, J. Electron. Spectrosc. Relat. Phenom. 2005, 144, 1031.

[21] L. Giordano, B. Han, M. Risch, W. T. Hong, R. R. Rao, K. A. Stoerzinger, Y. ShaoHorn, Catal. Today. 2016, 262, 2.

[22] a) Z. L. Wang, J. S. Yin, Y. D. Jiang, Micron. 2000, 31, 571; b) H. Tan, J. Verbeeck, A. Abakumov, G. Van Tendeloo, Ultramicroscopy. 2012, 116, 24; c) J. Graetz, C. C. Ahn, H. Ouyang, P. Rez, B. Fultz, Phys. Rev. B. 2004, 69, 235103; d) X. F. Lu, L. F. Gu, J. W. Wang, J. X. Wu, P. Q. Liao, G. R. Li, Adv. Mater. 2017, 29, 1604437.

[23] a) Z. X. Shen, C. K. Shih, O. Jepsen, W. E. Spicer, I. Lindau and J. W. Allen, Phys. Rev. Lett. 1990, 64, 2442; b) A. Fujimori, F. Minami, Phys. Rev. B. 1984, 30, 957; c) J. X. Feng, H. Xu, Y. T. Dong, S. H. Ye, Y. X. Tong, G. R. Li, Angew. Chem-ger. Edit., 2016, 128, 3758. 
[24] a) B. W. Veal and A. P. Paulikas, Phys. Rev. B. 1985, 31, 5399; b) J. Ghijsen, L. H. Tjeng, J. van Elp, H. Eskes, J. Westerink, G. A. Sawatzky, M. T. Czyzyk, Phys. Rev. B. 1988, 38, 11322; c) C. A. F. Vaz, D. Prabhakaran, E. I. Altman, V. E. Henrich, Phys. Rev. B. 2009, $80,155457$.

[25] W. T. Hong, K. A. Stoerzinger, Y. L. Lee, L. Giordano, A. Grimaud, A. M. Johnson, J. Hwang, E. J. Crumlin, W. Yange, Y. Shao-Horn, Energy Environ. Sci. 2017, 10, 2190. 